University of Nebraska - Lincoln

DigitalCommons@University of Nebraska - Lincoln

2009

\title{
College Students and Service: A Mixed Methods Exploration of Motivations, Choices, and Learning Outcomes
}

\author{
Ronald Chesbrough \\ University of Nebraska at Lincoln, rchesbrough@hastings.edu
}

Follow this and additional works at: https://digitalcommons.unl.edu/cehsedaddiss

Part of the Educational Administration and Supervision Commons, and the Student Counseling and Personnel Services Commons

Chesbrough, Ronald, "College Students and Service: A Mixed Methods Exploration of Motivations, Choices, and Learning Outcomes" (2009). Educational Administration: Theses, Dissertations, and Student Research. 8.

https://digitalcommons.unl.edu/cehsedaddiss/8

This Article is brought to you for free and open access by the Educational Administration, Department of at DigitalCommons@University of Nebraska - Lincoln. It has been accepted for inclusion in Educational Administration: Theses, Dissertations, and Student Research by an authorized administrator of DigitalCommons@University of Nebraska - Lincoln. 


\title{
COLLEGE STUDENTS AND SERVICE: A MIXED METHODS EXPLORATION OF MOTIVATIONS, CHOICES, AND LEARNING OUTCOMES
}

\author{
Ronald D. Chesbrough
}

\section{A DISSERTATION}

\author{
Presented to the Faculty of \\ The Graduate College at the University of Nebraska \\ In Partial Fulfillment of Requirements \\ For the Degree of Doctor of Philosophy \\ Major: Educational Studies \\ (Educational Leadership \& Higher Education)
}

Under the Supervision of Professor James V. Griesen

Lincoln, Nebraska

November, 2009 


\title{
COLLEGE STUDENTS AND SERVICE: A MIXED METHODS EXPLORATION OF MOTIVATIONS, CHOICES, AND LEARNING OUTCOMES
}

\author{
Ronald D. Chesbrough, Ph.D. \\ University of Nebraska, 2009
}

Advisor: James V. Griesen

The purpose of this two-phase exploratory mixed methods research was to add to an understanding of the motivations toward service among college students, to get a clearer sense of how students choose their particular service involvements, and to better understand the learning outcomes from service involvement during college. Underlying philosophical assumptions of the study were that service involvement during college contributes in several positive ways to student development, and that student descriptions of their motivations, choices, and learning from service will vary based on gender, year in college, and amount of service performed.

Findings indicated that students spoke in rich and varied terms about their service involvements, choices, and learning outcomes. Differences did exist in their description of aspects of their service experiences based on gender, hours of service, and to some extent year in school. The study found statistically significant differences in how students responded to questions about motivations toward service, choice of service, and learning outcomes from service based on gender, hours of service, and year in school. The research hypotheses were accepted that differences did exist in how students described motivation toward service, choice of service, and learning from service based on gender and hours of service. 
Implications of research findings include recommendations for marketing of service opportunities to students in a manner that recognizes gender difference in motivation to serve, involving students in service early in their college careers, offering a variety of types of service involvement, ensuring that students involved in service have an opportunity to discuss and process their learning, and expanding and centralizing service as a core mission of the college or university. Recommendations for further study include replication of the study across several college or university sites and conducting research that would allow for greater discernment of differences in student learning and development between students involved in service and those not involved. 


\section{ACKNOWLEDGMENTS}

As for most, the completion of this dissertation has been a consuming passion, in my case for the past eighteen months. I have come to understand in that time the purposes of the dissertation - to learn the art and discipline of independent scholarship, to contribute original and useful research findings to the chosen field of study, and to seek and find a moment of expertise in an area of study sufficient to the wearing of the mantle of 'expert' or 'scholar' in that field conferred by the degree of Doctor of Philosophy. For me this has been an exciting and gratifying journey made possible by the support and efforts of many.

My wife Annie has provided the steady and unfailing support without which the journey would not have been possible. Through endless conversations about topic and the literature to excited narration of findings, Annie has been an interested and engaged partner in this project. Through nearly two years of nights and weekend mornings at the office she has cheerfully acted as single parent to our two young children, Emma and Mia, who have come to know this project as 'dad's book,' one that looks far too long and boring to be worth all of this time. My deepest gratitude upon completion of this journey goes to Annie, with love and admiration. And my thanks to my older daughters for their interest and support.

In the workplace, the steady support of President Phillip Dudley over four years in the Ph.D. program has been invaluable. Dr. Dudley's support extended beyond words of encouragement to institutional and moral support for my studies and this research. I am indebted to Dr. Dudley in many ways, this not least among them. One gets to work for and with special people only occasionally in life; I am grateful to have had the opportunity to work with this very special man and grateful for his support for and interest in my completion of this program.

For their scholarly interest, colleagueship, and friendship I am indebted to Drs. Jim Wiest, Dan Deffenbaugh, Jean Heriot, and Bob Kettlitz. Dr. Wiest was my statistics lifeline for more than a year, always cheerfully interested in my research and patiently accommodating of my slow progress toward facility with the language and logic of statistical analysis and reporting. Dr. Deffenbaugh read every word that was written, offering comment and critique in endless scholarly discussion of the topic. If the dissertation was a birth, Dan would be my birth partner. I could not have found more capable or kind colleagues than these two scholars. Dr. Heriot stands as embodiment of the work that this dissertation seeks to explicate and encourage. Dr. Kettlitz' endless appetite for academic discourse added the final perfect spice to the recipe of scholarship for this project.

Tim Gaskill of the NEAR Center provided invaluable assistance in the testing of the survey instrument and interpretation of results of the quantitative portion of the study and Jeff Ritchins of Qualtrics was always there for questions and advice about the survey itself. Kim Burdett emerged as a steady colleague and companion throughout my graduate work. Our mutual check-ins and consultations with one another throughout the 
program were I hope as helpful to her as they have been to me. Cindy DeRyke spent hours ensuring that the final product was worthy of acceptance and publication; her help was invaluable.

Dr. Jim Griesen, chair of my supervisory committee, deserves thanks for his patience with my impatience. I am probably a difficult student, given my typically frenetic pace and 'let's get it done yesterday' approach to all things. Dr. Griesen and committee members Drs. Cejda, and Franco, and Hoover have my gratitude and appreciation for their willingness to work with me on this project and for their scholarly critique and probing questions into my work. I chose this committee in order to be pushed and challenged. I was not disappointed. A special thank you is owed to Dr. Cejda, whose capable guidance meant the difference to me on more than a few occasions.

Several scholars cited in this work offered personal support and feedback throughout my research and writing. Dr. Arthur Chickering of Goddard College, Dr. Susan R. Jones of the University of Maryland, Dr. Marcia Baxter Magolda at Miami University, and Dr. Linda Sax of UCLA all offered support and the insights of their own scholarship at points during my research. I am fortunate to have had access to such scholars and giants in their respective fields. Dr. Robert Nash of the University of Vermont, my mentor of 25 years and the man to whom I refer as 'the person who taught me that I could think,' offered his unfailing support and considerable optimism and love for my completion of the Ph.D. these many years after our work together. Every scholarly life needs a mentor; I am grateful to have had mine in Robert Nash.

Finally, to the participants in my research, I offer thanks for the time, wisdom, and thoughtfulness of these young adults in response to my questions, queries, and curiosities. As can be seen in the responses described in this work, these young people offer a measure of hope and promise, wisdom and maturity that many of us can only aspire toward. My many hours of interviews with these students can be said to have done for me what one participant observed that service had done for her. "I learned what love is,” she told me about her service experience. I can say the same in regard to my work with these young people. I am fortunate to have worked with each and every one of them.

It is with gratitude to each of the individuals named here that I proudly submit this dissertation in partial completion of requirements for the degree of Doctor of Philosophy and as a contribution to the fields of study this research encompasses. 


\section{Table of Contents}

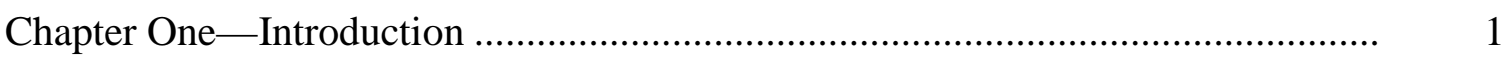

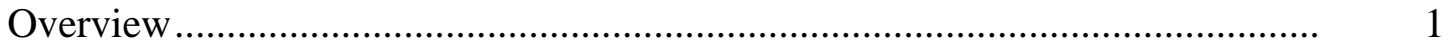

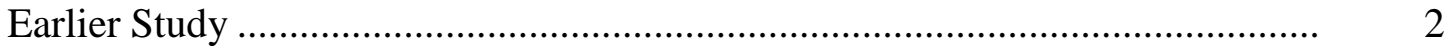

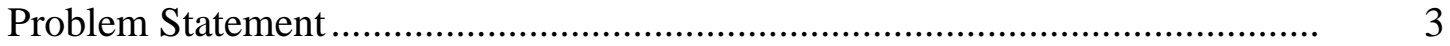

Significance of Study .........................................................................

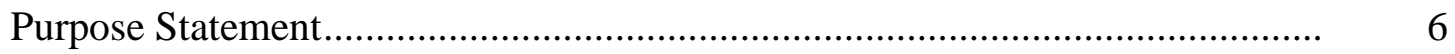

Research Questions .............................................................................. 7

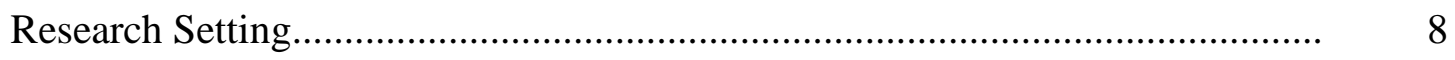

Definition of Service ......................................................................... 9

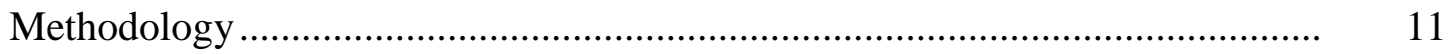

Limitations/Delimitations ......................................................................... 13

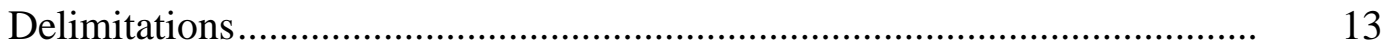

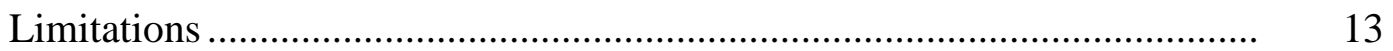

Overview of Chapters ........................................................................ 14

Chapter Two - Review of the Literature .......................................................... 16

Restatement of the Problem ..................................................................... 16

Overview of Related Literature ................................................................. 17

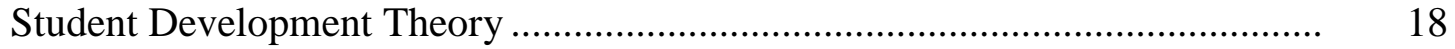

Psychosocial Theories........................................................................... 19

Cognitive-Structural Theories.................................................................. 23

Typological Theories ....................................................................... 28

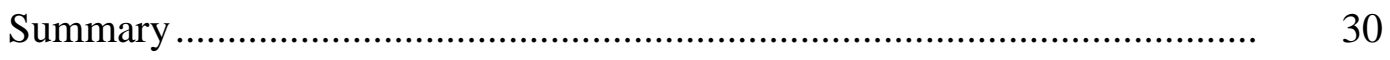

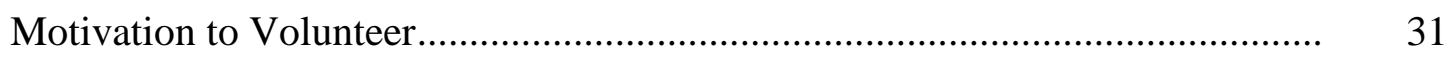

Service and Student Development .............................................................. $\quad 36$ 
Gender Difference in College .................................................................. $\quad 40$

Symbolic Interactionism ...................................................................... 43

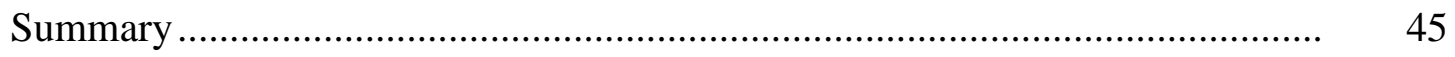

Chapter Three - Methodology .................................................................... 46

Restatement of the Problem ...................................................................... 46

Purpose of the Study/Research Questions ........................................................ 46

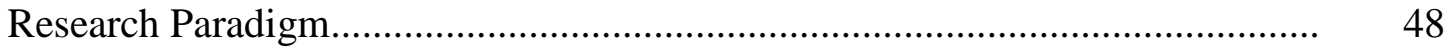

Tradition of Inquiry/Rationale .................................................................... $\quad 50$

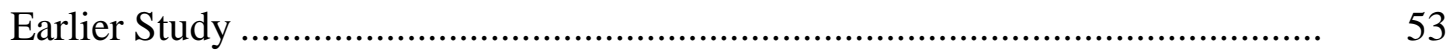

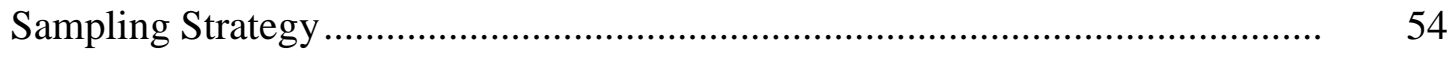

Qualitative Phase ......................................................................... 54

Quantitative Phase .......................................................................... 55

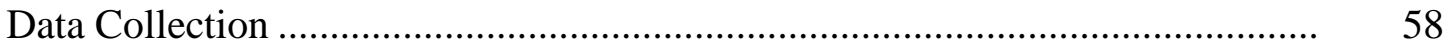

Qualitative Phase ............................................................................. 58

Quantitative Phase ............................................................................... 63

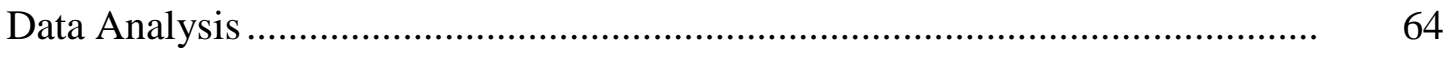

Qualitative Phase ............................................................................ 65

Quantitative Phase .......................................................................... 66

Verification Procedures ....................................................................... 68

Qualitative Validity ..................................................................... $\quad 70$

Quantitative Validity..................................................................... $\quad 71$

Ethical Considerations .......................................................................... $\quad 71$

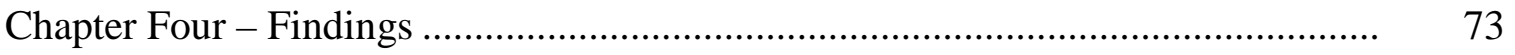

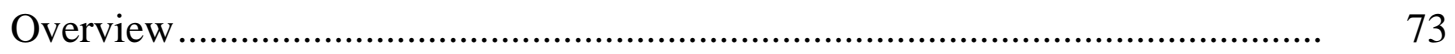

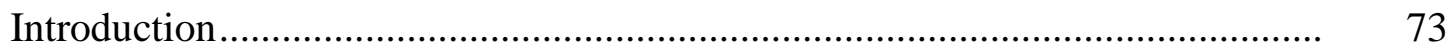




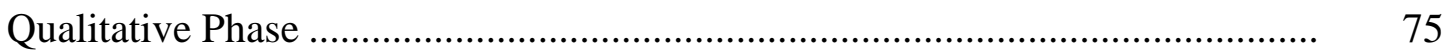

The Participants ............................................................................... $\quad 75$

Analysis of Focus Group Interview Responses ..................................... $\quad 76$

Single Gender Focus Group Findings......................................................

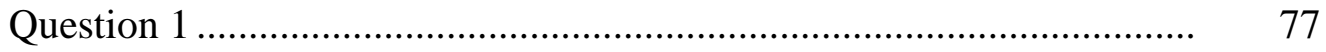

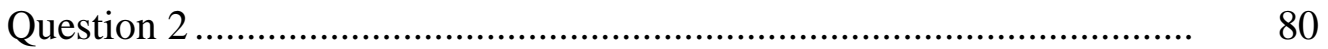

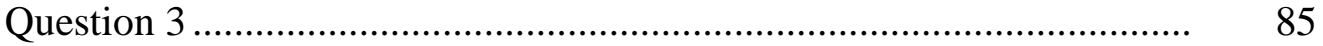

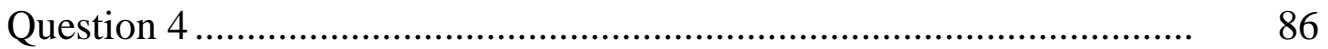

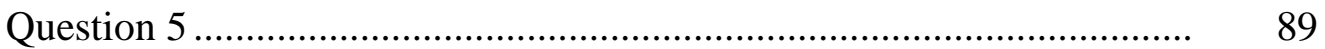

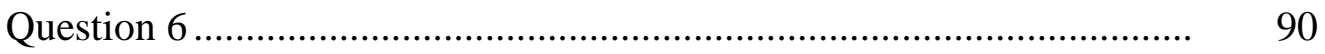

Mixed Gender Focus Group Findings.................................................... 92

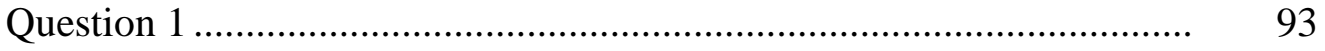

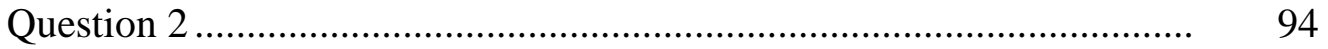

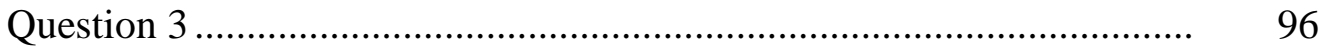

Question 4 ................................................................................... 96

Individual Interviews ................................................................... 97

Analysis of Individual Interview Responses........................................... 98

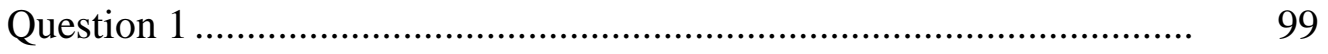

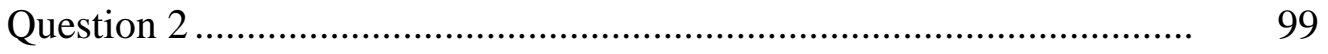

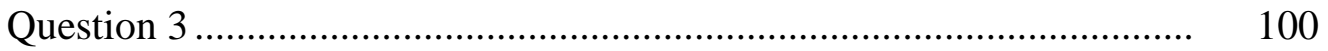

Question 4 ............................................................................. 100

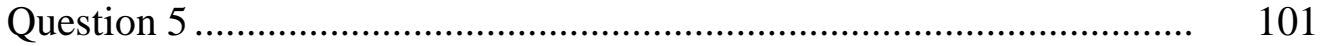

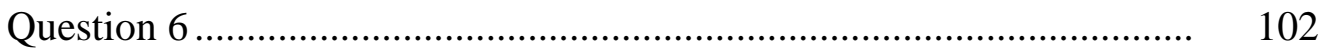

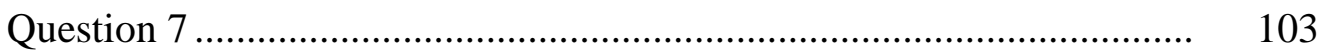

Summary of Qualitative Findings .......................................................... 104 
Quantitative Phase ..................................................................................... 104

The Participants ...................................................................................... 104

Survey Construction and Testing ......................................................... 107

Descriptive Analysis ...................................................................... 108

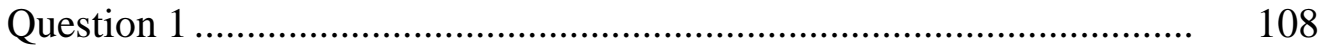

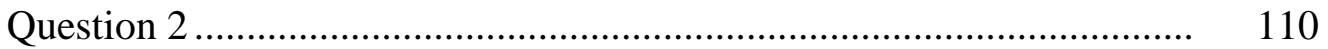

Question 3 ........................................................................................... 111

Summary of Quantitative Findings ........................................................... 115

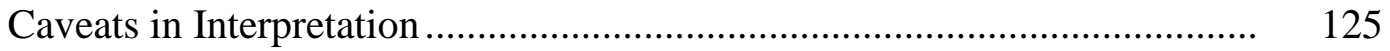

The Null Hypotheses...................................................................... 127

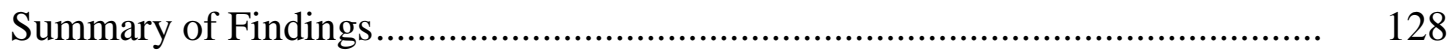

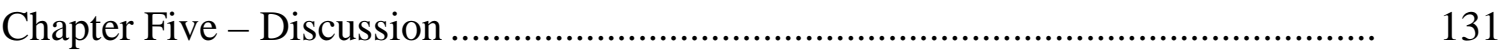

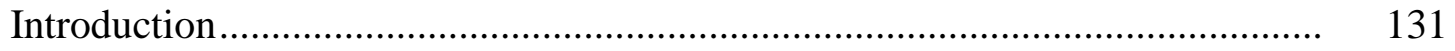

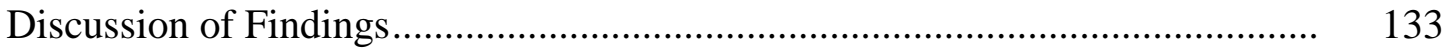

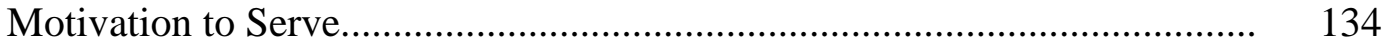

Choosing Service ............................................................................... 142

Description of Service...................................................................... 147

Learning from Service .................................................................. 150

Significance of Findings ................................................................... 157

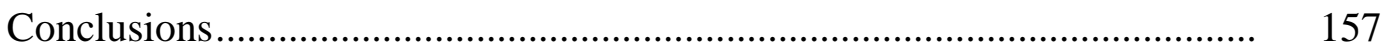

Implications.............................................................................. 159

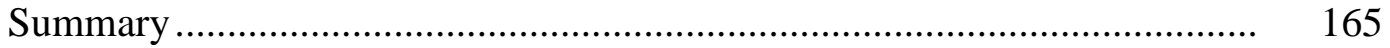

Recommendations for Further Study ........................................................ 167

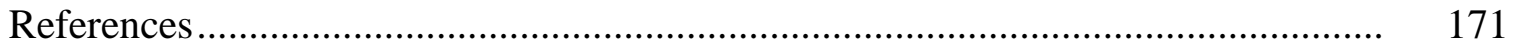

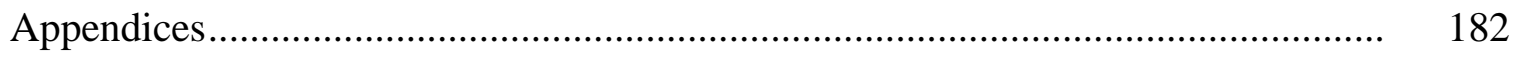




\section{List of Tables}

Table 1 Summary of Erickson's Stages of Development ...................................... 20

Table 2 Kegan's Orders of Consciousness …………………………………...... 25

Table $3 \quad$ Kohlberg's Stages of Development ......................................................... 26

Table 4 Gilligan’s Stages of Development .......................................................... 27

Table 5 Comparison of Four Important Paradigms Used in the Social

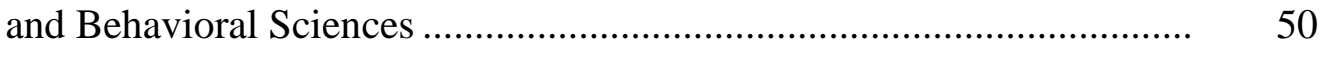

Table 6 Participant Demographics—Focus Groups and Individual Interviews....................................................................................... 56

Table $7 \quad$ Participant Demographic by Gender.......................................................... 57

Table 8 Participant Demographic by Year in School ............................................ 57

Table $9 \quad$ Participant Demographic by Hours of Service ......................................... 58

Table 10 Potential Threats to the Validity of Sequential Designs in Mixed Methods Research ...................................................................... 69

Table 11 Coding Definition of Service ................................................................... 77

Table 12 Coding Motivation to Serve.................................................................. 81

Table 13 Coding Choice of Service Involvement ................................................... 84

Table 14 Coding Learning from Service................................................................ 86

Table 15 Focus Group Coding Summary .............................................................. 105

Table 16 Chronbach’s Alpha Scores for Ordinal Data Questions ........................... 107

Table 17 Factors Contributing to Involvement ........................................................ 109

Table 18 Factors in Choice of Service Project(s) .................................................. 111

Table 19 Learning from Service ……………………......................................... 112

Table 20 Impact of Service on Development.......................................................... 113

Table 21 Summary of Statistically Significant Findings ........................................ 116

Table 22 Mean Comparisons Q.5. Factors Contributing to Involvement in Service 
Table 23 Motivation to Serve by Gender.......................................................... 137

Table 24 Motivation to Serve by Hours of Service .......................................... 139

Table 25 Motivation to Serve by Year in School............................................... 140

Table 26 Choice of Service by Gender ............................................................... 143

Table 27 Choice of Service by Year in School ................................................... 143

Table 28 Choice of Service by Hours of Service.................................................. 144

Table 29 Gender Differences in Leisure Time among First-Year Students, Fall 2006.............................................................................. 146

Table 30 Description of Service by Gender..................................................... 148

Table 31 Learning from Service by Hours of Service ...................................... 154

Table 32 Impact of Service by Hours of Service ............................................... 155

Table 33 Summary of Focus Group Properties................................................ 166 


\section{List of Figures}

Figure 1 Chickering and Reisser's Seven Vectors of

Development............................................................................ 22

Figure 2 Mean Comparisons Q.5. Factors Contributing to Involvement

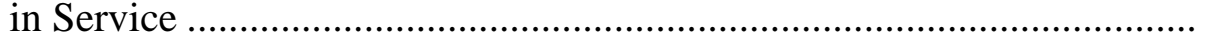




\section{List of Appendices}

Appendix A Invitation to Participate and Informed Consent .............................. 182

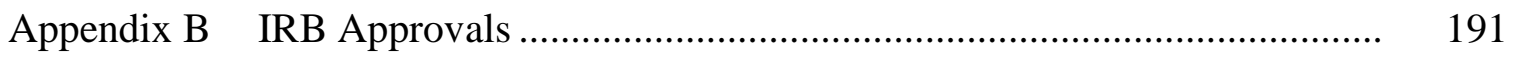

Appendix C Interview Methodology and Scripts............................................ 200

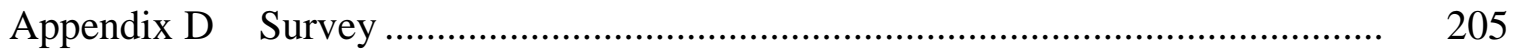

Appendix E $\quad$ External Audit............................................................................ 215

Appendix F $\quad$ Response Coding Summary ........................................................ 218

Appendix G Chi-square/Spearman Scores ......................................................... 222

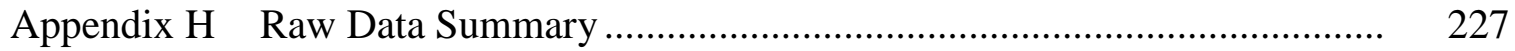




\section{Chapter One}

\section{Introduction}

"The idea of what is true merit should also be presented to youth, explain'd and impress'd upon their minds, as consisting in an Inclination join'd with an Ability to serve Mankind, one's Country, Friends and Family... which ability should be the great Aim and End of all Learning."

Benjamin Franklin, 1749 in Best, 1962, pp.150-151

\section{Overview}

In April of 2009, two hundred and sixty years after Benjamin Franklin’s assertion of the importance of service to others, President Barack Obama signed the Edward M. Kennedy Serve America Act, dramatically expanding the AmeriCorps national service program over the next ten years. This thread of the importance of service to others and of service as a vital aspect of a democratic education is unbroken in this country's history.

John Dewey (1938) described the importance of service and service learning as an “intimate and necessary relation between the processes of actual experiences and education” (p. 20). Nel Noddings (1992), in her discussion of the critical priorities for schools, suggested that "education might best be organized around centers of care: care for self, for intimate others, for associates and acquaintances, for distant others, for nonhuman animals, for plants and the physical environment, for the human-made worlds of objects and instruments, and for ideas” (p. xiii). More recently, Alexander Astin (1997), in a review of college and university mission statements, described the central roles found in these statements to be those of "preparing students for responsible citizenship, developing character, developing future leaders, and preparing students to serve society” (pp. 210-211). 
Given this historical devotion to the importance of service particularly in higher education, this study sought to explore the ways in which college students in one setting became involved in service during college, how and why they chose to become involved in service, and how they described their learning from service. The aim was to provide an understanding of motivations toward service during college, of how student chose particular service involvements, and of their learning outcomes from service.

This introductory chapter provides an overview of how the research was designed, planned, and conducted. A brief outline of earlier study findings leading to this research is presented below. The problem statement is then presented, followed by a statement of purpose of the study. Research questions are then presented, followed by a brief statement of the significance of the study and description of the research setting.

A definition of terms is then presented, followed by a brief discussion of methodology, to be detailed in Chapter Three. The limitations and delimitations of the study are presented and finally, the organization of the dissertation is outlined.

\section{Earlier Study}

In a study conducted as part of a class project in the spring of 2008 regarding students' motivations toward and learning from service, interesting disparities were noted in how participants described their experiences. Nathan, a junior at the pilot site, the site of this current research, when asked how he selected his service involvement while in college, gave a detailed account of the social issues motivating him toward the particular type of service he chose, described how his particular skills and interests could be maximized at this site, and discussed specific strategies for applying these skills at this 
service site and in this type of service. Megan, a junior at the same college, when asked the same question, responded "I followed my heart."

Nathan, when asked how his service had impacted him and what he had learned, described a number of positive impacts on his ability to manage, delegate, communicate, and supervise. Megan, asked what she had learned, replied "I learned what love is.” The disparity in these responses caught the researcher's attention. Might it be the case that students become involved in service during college for substantially different reasons? Might it also be the case that learning outcomes come in vastly different forms and sizes for students who are involved in service? And if either or both of these is true, and if we acknowledge the benefits generally of service as described in the introduction and below, might it help us to better understand the differing motivations toward service and learning outcomes from service as a means to maximize student involvement in and learning from service? These questions led to this research study.

\section{Problem Statement}

A good deal of research has documented the positive effects of students’ involvement in service during their college years. Pascarella and Terenzini, in their extensive compilation of the affects of college on students, devoted attention to the particular impacts of community service and service learning on students (2005, pp. 307309). Researchers have found service involvement during college to contribute to students’ academic development, life skills development, sense of civic responsibility, and overall physical and emotional well being (Thoits \& Hewitt, 2001; Astin \& Sax, 1998; Eyler, et. al., 1997, Rhoads, 1997). Other research has found service to impact personal efficacy, self esteem, relationships, and confidence in political and social skills 
(Eyler \& Giles, 1999; Kendrick, 1996; Rhoads, 1997; Youniss \& Yates, 1997). More recent research has begun to explore the patterns of college student involvement in service and the impact of their involvements (Jones \& Abes, 2004; Jones \& Hill, 2003). A body of primarily sociological research exists that seeks to discern volunteer motivation (Wilson \& Musick, 1997; Wilson, 2000; Clary \& Snyder, 2004). Still, the researcher found very few studies describing the motivations specifically of college students toward service in the words of students (Winniford, Carpenter, \& Grider, 1997; Serow, 1991) - e.g., why some students engage in service and others do not. Similarly, very little has been written about students' self-reported learning outcomes from service involvement. Further, recent comprehensive national studies of service involvement at all levels and in all types of higher education institutions revealed that women engage in service at consistently higher levels than men at all ages, but most particularly during their college years (Corporation for National \& Community Service, 2007, 2008). One recent survey of over 8 million college freshmen showed male participation in service in college to drop off even among those men who had engaged in service during high school (Sax, 2008).

The overall theoretical framework for this current study was designed to facilitate an understanding of these phenomena from several perspectives. The study utilized student development theory, particularly the work of Chickering and Reisser (1993), Kegan (1994), and Baxter Magolda (2000) in order to understand and interpret the developmental effects of service on study participants. Research on gender difference in college (Astin \& Sax, 1998; Sax, 2008) provided a theoretical framework within which to discuss gender-related difference in the findings of the study. This discussion was aided 
by introduction of the field of research on the moral development of women (Gilligan, 1977; Noddings, 1984). Finally, the field of sociological inquiry known as symbolic interactionism (Berger \& Luckman, 1967) was employed in discussion of participants’ making of meaning from the social interactions of their service experiences.

\section{Significance of Study}

We know from previous research that service during the college years generally contributes positively to student development and general well-being. We also know that different student populations tend to participate in service during college at sometimes dramatically different rates. These facts lead to a logical interest in understanding the self-reported motivations of students toward service and how they choose their specific service involvements. These same facts compel educators to more fully understand the learning outcomes from service as these are reported by student participants in service.

This research focused specifically on these three phenomena - motivations toward service, selection of service involvements, and learning outcomes from service - with the purpose of providing a better understanding of all three phenomena. This understanding should better enable practitioners in student affairs and service learning to involve students in service and to maximize the learning outcomes of service involvement for various student groups.

At the same time, the current reinvigorated national attention being paid to the importance of service under the current administration and among higher education institutions and accrediting bodies made this research timely for potential contributions to what we know about motivations to serve and the outcomes of service involvement during college. In December of 2006, the Carnegie Foundation for the Advancement of 
Teaching announced an inaugural selection of seventy-six higher education institutions as “institutions of community engagement” under the new elective Community Engagement classification. In January of 2008, two hundred and seventeen institutions initially began application procedures for this new classification, of which one hundred and twenty institutions attained the classification (Sandmann, Thornton, \& Jaeger, 2009). This growing interest in service should provide an audience for this research among policy-makers in state and federal government and among higher education leaders.

\section{Purpose Statement}

This mixed methods study explored college student involvement in service - their motivations, choices of service involvement, and reported learning outcomes. The purpose of this two-phase exploratory mixed methods research was to add to our understanding of the motivations toward service among college students, to get a clearer sense of how students choose their particular service involvements, and to better understand the learning outcomes from service involvement during college. Underlying philosophical assumptions of the study were that service involvement during college contributes in several positive ways to student development, and that student descriptions of their motivations, choices, and learning from service will vary based on gender, year in college, and amount of service performed.

The first phase of the research was a qualitative exploration of these questions via focus group and individual interviews with 24 college students in a small, Midwestern liberal arts college. In the second phase of the research, emergent themes from these interviews were utilized to develop a survey instrument to test a series of hypotheses that relate to possible differences in how students describe their motivations toward service, 
choices of service involvement, and learning from service based on gender, year in college, and amount of service performed. The explicit aim of this exploratory study was not to develop and test a survey instrument, but rather to determine if, in this study sample, differences exist in how students describe their service motivations, choices, and learning outcomes based on the variables of gender, year in college, and amount of service performed. One thousand students at the same small liberal arts college were surveyed in the quantitative phase.

\section{Research Questions}

The central research question for this study was: how do students describe their motivation toward service involvement during college and the learning outcomes of their service involvement?

Three specific qualitative research questions flowed from this central question:

1. What factors motivated students to become involved in service during college?

2. How did students in the study choose their particular service involvements?

3. How did students describe the learning outcomes from their service involvements?

Three additional emergent questions were explored in the quantitative phase of the research following completion of the phase one qualitative inquiry:

1. Is there a difference in how students describe motivation to serve, selection of service, and learning outcomes from service based on gender?

2. Is there a difference in how students describe motivation to serve, selection of service, and learning outcomes based on year in college? 
3. Is there a difference in how students describe motivation to serve, selection of service, and learning outcomes based on amount of service performed?

The specific research hypotheses corresponding to these questions were:

1. There is a difference in how students describe motivation to serve, selection of service, and learning outcomes from service based on gender.

2. There is a difference in how students describe motivation to serve, selection of service, and learning outcomes based on year in college.

3. There is a difference in how students describe motivation to serve, selection of service, and learning outcomes based on amount of service performed.

\section{Research Setting}

The setting for this study was a small private liberal arts college in the Midwest. The college has a largely residential undergraduate enrollment of approximately 1,100 students. The college offers a single masters level degree, the Master of Arts in Teaching and provides some 50 undergraduate academic majors in the arts, sciences, education, business, and communications built around a core liberal arts foundational program. The college stresses the active involvement of students in and out of the classroom and offers several hallmark programs to encourage student involvement in community service via the curriculum and co-curricular programs. The college has been recognized regionally and nationally for its outstanding student service programs.

While the college affords many opportunities for the active involvement and leadership of students through service, it is also somewhat typical of most liberal arts college settings in this regard. This provided the researcher both a rich service-oriented environment in which to conduct the research and an environment fairly representative of 
a traditional liberal arts learning environment, with a traditional focus on service and learning outside of the classroom. The researcher was careful in analyzing data and reporting outcomes of the research not to generalize conclusions beyond the particular research site.

\section{Definition of Service}

The phenomenon of service to others is described variously in the literature as service, service learning, community service, volunteerism, and community outreach, to name just a few terms (Corporation for National \& Community Service, 2008; Stanton, 1990). And while there are distinctions of note between these various terms, for the purposes of this study these distinctions are largely inconsequential. This study sought to explore students' descriptions of their engagement in service broadly defined as an act of serving others on a voluntary basis and without compensation. Rhoades (1997), in his treatment of the subject, distinguished between community service and service learning by identifying a structured reflective component present in the latter. Again, for the purposes of this study, the presence or absence of such a component was treated as incidental and not definitive of the concept of "service” as used here.

Secondly, there may be concerns and even objections raised to a study or studies which seek to explore among other things gender-based differences in a service learning context. Again, definitional questions emerge about what constitutes 'service,' as men and women tend to serve at different participation rates and in somewhat different contexts (Corporation for National \& Community Service, 2007; Net Impact, 2008). Further, some point out that the study of gender difference in college allegedly has the unintended effect primarily of reinforcing gender difference, particularly as results of 
such studies are reported in a way that reaffirms the ways that men and women are inherently “different,” in this case in how they approach, talk about, and learn from service (Sax, 2008, pp. 42-44).

Gender difference in college is real - both in terms of differences at entry to college and in terms of the sometimes differential impact of college on men and women (Astin, Vogelgesang, Ikeda, \& Yee, 2000; Bryant, 2007; Sax, 2008). This study did not seek to either build on or expand research on gender difference in college. Rather the research sought to explore motivations for and learning from service as described both by men and women in a college setting. To the extent that gender difference was discerned in this study it was reported in terms of gender-related difference and not gender-specific difference, meaning that differences were not reported as exclusive by gender, but rather related to gender. The researcher was open to findings that might either reinforce or argue against differences between men and women related to their service experiences and has reported on both in Chapter Four.

Finally, there are those who would argue that gender is a purely social construct, and that the framing of questions designed to understand difference within our traditionally bifurcated conception of “male” and "female” uses an outdated and inaccurate construct of gender (Lorber, 1994; Whitehead \& Reid, 1992). In that the traditional construct of gender does exist and does remain an accepted construct within which discussions of difference such as those undertaken in this research, the researcher acknowledged this potential criticism of the research and utilized this traditional gender construct in the research and analysis of outcomes. 


\section{Methodology}

This study utilized a mixed methods exploratory design for data collection and analysis. The exploratory design is suited to studies wherein the aim is to explore a phenomenon, in this case motivations and learning from service, where measures or instruments are unavailable, and there is no guiding framework or theory (Creswell, Plano Clark, Gutmann, \& Hanson, 2003). The design is of particular use in studies such as this one to identify important variables in the early first-phase qualitative data gathering to study further in the quantitative phase and where these variables are unknown (Creswell, 1999; Creswell, Fetters, \& Ivankova, 2004). The exploratory mixed methods design is also used to test aspects of an emergent theory or to explore a phenomenon in depth qualitatively and then measure its prevalence quantitatively (Morgan, 1998; Morse, 1991).

The first, qualitative phase of the study was conducted in the phenomenological tradition of inquiry. As described by Creswell, a phenomenological study "describes the meaning for several individuals of their lived experiences of a concept of phenomenon” (2007, p. 57). The aim of phenomenological research, according to Moustakas, is to determine what an experience means to those who have had the experience, and from this to derive more generalized or universal meanings of the experience (Moustakas, 1994, p. 13). More about this research approach and the overall methodology of the study is provided in Chapter Three. Underlying philosophical assumptions about the phenomenon under study are also outlined in detail in Chapter Three.

The initial qualitative phase of the research involved five focus group interviews with 24 male and female participants at the research site. Participants were selected 
utilizing purposeful sampling methods identified in Chapter Three based on criteria related to their involvement in service in the past year. An equal number of male and female participants were selected for this phase of the study. Participants were initially sorted into groups by gender. Focus groups were conducted first with single gender groups - males then females - with identical interview scripts for each group (Appendix C, pp. 201-205). A mixed gender focus group interview was then conducted to begin to test certain emergent themes from previous interviews. The mixed gender group was comprised of half of the men and women from each of the previous groups.

Following focus group interviews, individual interviews were conducted with four male and four female participants selected from among focus group participants. The script for these interviews was more in-depth regarding participants' historical patterns of involvement in service and their general backgrounds. The aim of these interviews was to gather more specific historical and biographical information about these participants. More detailed information about the selection process for individual interviews and data collection and analysis is provided in Chapter Three.

Simultaneously with the completion of individual interviews, a survey was constructed from the focus group interviews based on emergent themes from those interviews relative to motivation toward service, selection of service, and learning from service. This survey instrument was tested with focus group participants for validity with regard to the themes identified and with faculty colleagues at the research site. Validity testing procedures are outlined thoroughly in Chapter Three. The survey was administered in an online format to all undergraduate students at the research site ( $n=1,004)$, with 447 completed surveys, for an overall response rate of $44.5 \%$. 


\section{Limitations/Delimitations}

\section{Delimitations}

This study was delimited by an ability to generalize findings only to the population studied. The study was delimited to the self-reported experiences of study participants. Attempts to replicate the study in other settings may reach other findings. In keeping with the common challenges of the qualitative tradition of inquiry, the researcher must decide in phase one of the research whether the case itself or the issue it seeks to illustrate is worthy of study, and whether to study a single case or multiple cases. A rationale must be established for the particular case or cases to be studied and for the purposeful sampling strategy adopted by the study. Further care must be given to the extraction of emergent themes from the qualitative portion of the data collection and analysis and attention given to validity testing of the survey instrument derived from these themes (Creswell, 2007). These concerns are addressed in Chapter Three.

\section{Limitations}

Several potential limitations of the study existed. Bracketing personal experiences and biases of the researcher may be difficult to achieve in phenomenological qualitative research due to the researcher's own typically strong interest in the phenomenon under study (Creswell, 2007, p. 62). In this case the researcher was careful to allow for open interpretation of the self-described experiences of participants and to allow for member checking of emergent themes from the qualitative phase of the research.

At the same time, in keeping with the phenomenological tradition, the study was grounded in some broader philosophical assumptions about students’ experiences of service during the college years regarding gender differences and difference based on 
year in college and amount of service performed - and these assumptions were identified by the researcher. In turn, these assumptions (e.g., that service experiences in college tend to have positive impact on participants, that students tend to approach and be impacted differently by some aspects of their college experiences), if openly expressed to participants might have had a leading effect on participant responses.

Another potential limitation involved the researcher's role at the college. In addition to author of this study, the researcher was the vice president for student affairs at the study site; this had the potential to skew responses of students if there was a perception that there were 'desired' and 'undesired' responses to questions. The researcher paid particular attention to discourage or prevent this dynamic from emerging in focus group and individual interviews. Assurances of anonymity were provided to all respondents to the survey in the quantitative phase of the research. The researcher was unaware of survey completion or non-completion by individual students.

\section{Overview of Chapters}

Following this introductory chapter, the review of the literature is addressed in two sections of this dissertation: Chapters Two and Five. Chapter Two provides an overview of literature related to college student development and the impacts of service with some discussion also of sociological theory relevant to this study. Recent research related to gender difference in college is also discussed. Chapter Five presents a more thorough application of this literature and research to the findings of this study.

Chapter Three details the methodology used to conduct this study. The research problem, questions, and hypotheses are restated. The null hypotheses are introduced. A rationale for a mixed methods approach to the research is provided, as well as discussion 
of instrument construction, data collection and analysis procedures, and verification procedures. Finally, ethical considerations related to the research are outlined.

Chapter Four presents the findings of the research. A restatement of the research problem, questions and hypotheses is provided. This is followed by an interpretation and analysis of both qualitative and quantitative of data relevant to the research questions.

Chapter Five presents a summary of the study and findings, a discussion of implications for practice, conclusions, limitations of the study, and suggestions for further research. 


\section{Chapter Two}

\section{Review of the Literature}

This chapter provides a restatement of the research problem, followed by an overview of the literature pertinent to the problem. This is followed by a discussion of student development theory in three general categories. An overview of research related to motivation and attitudes toward volunteerism is provided. Research related to service and student development and gender difference in college follows. The chapter concludes with a discussion of the psycho-social theory of symbolic interactionism as a template for understanding how individuals derive meaning and a sense of self from their social interactions.

\section{Restatement of the Problem}

Research has documented the positive effects of students' involvement in service during their college years. Research has found service involvement during college to contribute to students' academic development, life skills development, and sense of civic responsibility (Astin \& Sax, 1998). Other research has found service to impact personal efficacy, self esteem, relationships, and confidence in political and social skills (Eyler \& Giles, 1996; 1999; Kendrick, 1996; Waterman, 1993).

Not enough is known about particular motivations toward service specifically among college students (Rhoades, 1997; Serow, 1991; Winneford, Carpenter, \& Grider, 1997) - e.g., why some students engage in service and others do not. Further, studies have revealed that women engage in service at consistently higher levels than men at all ages, but most particularly during their college years (Corporation for National \& Community Service, 2007, 2008). 
This study explored college student involvement in service - their motivations, choices of service involvement, and reported learning outcomes. The purpose of this research was to add to our understanding of the motivations toward service among college students, to get a clearer sense of how students choose their particular service involvements, and to better understand the learning outcomes from service involvement during college.

\section{Overview of Related Literature}

This study was grounded in five distinct but related fields of research, theory and literature. The first is the broad field of student development theory. Any study seeking to contribute to the field of how or what students learn - or say they learn - during the college years is aided by placing the study in the context of what is known about student learning and growth in college.

Secondly, a broad body of literature growing primarily out of the field of sociology looks at volunteerism and motivation. This research began in the 1970's and continues through to the present in an ongoing attempt to understand broadly why people volunteer to help others outside of their immediate circles of friends and family. Little of the research has focused on the college student population, but the contributions of this broad base of research and theory can help to establish a basis for understanding college student motivations toward service and for interpreting findings of this study.

Thirdly, as this study sought to explore how students talk about their motivations toward and learning from service, a portion of the literature review looks at previous research into the impact of service on college students' growth and development - a 
number of qualitative and quantitative studies are reviewed for their contribution to what is known about the impact on students of participation in service during the college years.

Fourth, this study utilized both men and women as participants. Few studies have explored whether men and women might describe their service motivations, definitions, and learning outcomes differently. In the broadening field of gender difference research during the college years a review is useful of what is known about how men and women experience aspects of the college experience differently.

Lastly, since this study had as one subset goal an understanding of how participants relate their service experiences to a developing sense of meaning and purpose, literature in the field of sociology, specifically symbolic interactionist theory, was utilized to interpret and frame participants’ descriptions of their learning outcomes relative to a sense of meaning and purpose derived from service experiences.

\section{Student Development Theory}

It is a long held presumption and goal of higher education that students should and do grow and develop in ways other than intellectual growth through knowledge acquisition. "Development,” in this context, has generally been thought of as a "general movement toward greater differentiation, integration, and complexity in the ways that individuals think, value, and behave” (Pascarella \& Terenzini, 2005, p. 19 ).

While theorists have varied in their approach to measuring developmental change - and in the dynamics on which they focus as evidence of growth - they typically have held to this fairly common definition of development as they have sought to construct developmental theories of change and growth during the college years. In a review of the literature, two areas of interest emerged with regard to student development in college. 
The first was the varied theories used to describe development; the second was the research that has emerged around these theories as predictors or descriptors of student development.

There are three general types of theory used to describe and measure student development in college. These are: psychosocial theories, cognitive-structural theories, and typological theories.

\section{Psychosocial Theories}

The family of psycho-social theories views individual development essentially as the accomplishment of a series of developmental tasks that present themselves as a consequence of age progression and environmental influences (Pascarella \& Terenzini, 1991). Primary examples of psychosocial theory are presented by Rodgers (1989), Erikson (1959, 1963, 1968), Chickering (1969), and Chickering and Reisser (1993).

Of these, Erikson's (1968) work has perhaps been the most influential and served as the platform on which other psychosocial theories were built. His concepts of the “epigenetic principle,” developmental tasks or “crises,” and “identity versus identity confusion” (Stage 5 of his 8 stages) underlie much of the thinking of the psychosocial theorists.

The first of these concepts referred to the inevitable existence, according to Erikson (1968), of a patterned and sequential growth trajectory among humans based on each individual's biological and psychological predispositions and the effect of personal environment. “Anything that grows has a ground plan,” according to Erikson (p. 92), "and out of this ground plan the parts arise, each part having its time of special ascendancy, until all parts have arisen to form a functioning whole.” 
Second was Erikson’s (1968) concept of developmental tasks or “crises” as a part of the normal development process. Erikson established eight such crisis or task periods representing times of decision-making among particular courses of action presenting themselves during that particular period. One of these, the "ego-identity versus role confusion,” or Stage 5, he described as the dominant developmental task during the college years, whether or not enrolled in college during these years. Table 1 provides a summary of Erikson's stages and related tasks of those stages.

Table 1

Summary of Erikson's Stages of Development

\begin{tabular}{|c|c|c|c|c|c|}
\hline Stage (age) & $\begin{array}{l}\text { Psychosocial } \\
\text { crisis }\end{array}$ & $\begin{array}{l}\text { Significant } \\
\text { relations }\end{array}$ & $\begin{array}{l}\text { Psychosocial } \\
\text { modalities }\end{array}$ & $\begin{array}{l}\text { Psychosocial } \\
\text { virtues }\end{array}$ & $\begin{array}{l}\text { Maladaptations } \\
\text { \& malignancies }\end{array}$ \\
\hline $\begin{array}{l}\text { I (0-1) -- } \\
\text { infant }\end{array}$ & trust vs mistrust & mother & $\begin{array}{l}\text { to get, to give in } \\
\text { return }\end{array}$ & hope, faith & $\begin{array}{l}\text { sensory distortion - } \\
\text { - withdrawal }\end{array}$ \\
\hline $\begin{array}{l}\text { II (2-3) -- } \\
\text { toddler }\end{array}$ & $\begin{array}{l}\text { autonomy vs } \\
\text { shame and } \\
\text { doubt }\end{array}$ & parents & $\begin{array}{l}\text { to hold on, to let } \\
\text { go }\end{array}$ & $\begin{array}{l}\text { will, } \\
\text { determination }\end{array}$ & $\begin{array}{l}\text { impulsivity -- } \\
\text { compulsion }\end{array}$ \\
\hline $\begin{array}{l}\text { III (3-6) -- } \\
\text { preschooler }\end{array}$ & $\begin{array}{l}\text { initiative vs } \\
\text { guilt }\end{array}$ & family & $\begin{array}{l}\text { to go after, to } \\
\text { play }\end{array}$ & $\begin{array}{l}\text { purpose, } \\
\text { courage }\end{array}$ & $\begin{array}{l}\text { ruthlessness -- } \\
\text { inhibition }\end{array}$ \\
\hline $\begin{array}{l}\text { IV (7-12 or so) } \\
-- \\
\text { school-age } \\
\text { child }\end{array}$ & $\begin{array}{l}\text { industry vs } \\
\text { inferiority }\end{array}$ & $\begin{array}{l}\text { neighborhood } \\
\text { and school }\end{array}$ & $\begin{array}{l}\text { to complete, to } \\
\text { make things } \\
\text { together }\end{array}$ & competence & $\begin{array}{l}\text { narrow virtuosity - } \\
\text { - inertia }\end{array}$ \\
\hline $\begin{array}{l}\text { V (12-18 or so) } \\
-- \\
\text { adolescence }\end{array}$ & $\begin{array}{l}\text { ego-identity vs } \\
\text { role-confusion }\end{array}$ & $\begin{array}{l}\text { peer groups, } \\
\text { role models }\end{array}$ & $\begin{array}{l}\text { to be oneself, to } \\
\text { share oneself }\end{array}$ & $\begin{array}{l}\text { fidelity, } \\
\text { loyalty }\end{array}$ & $\begin{array}{l}\text { fanaticism -- } \\
\text { repudiation }\end{array}$ \\
\hline $\begin{array}{l}\text { VI (the 20’s) -- } \\
\text { young adult }\end{array}$ & $\begin{array}{l}\text { intimacy vs } \\
\text { isolation }\end{array}$ & $\begin{array}{l}\text { partners, } \\
\text { friends }\end{array}$ & $\begin{array}{l}\text { to lose and find } \\
\text { oneself in a } \\
\text { another }\end{array}$ & love & $\begin{array}{l}\text { promiscuity -- } \\
\text { exclusivity }\end{array}$ \\
\hline $\begin{array}{l}\text { VII (late 20’s } \\
\text { to 50’s) -- } \\
\text { middle adult }\end{array}$ & $\begin{array}{l}\text { generativity vs } \\
\text { self-absorption }\end{array}$ & $\begin{array}{l}\text { household, } \\
\text { workmates }\end{array}$ & $\begin{array}{l}\text { to make be, to } \\
\text { take care of }\end{array}$ & care & $\begin{array}{l}\text { overextension -- } \\
\text { rejectivity }\end{array}$ \\
\hline $\begin{array}{l}\text { VIII (50's and } \\
\text { beyond) -- old } \\
\text { adult }\end{array}$ & $\begin{array}{l}\text { integrity vs } \\
\text { despair }\end{array}$ & $\begin{array}{l}\text { mankind or } \\
\text { “my kind” }\end{array}$ & $\begin{array}{l}\text { to be, through } \\
\text { having been, to } \\
\text { face not being }\end{array}$ & wisdom & $\begin{array}{l}\text { presumption -- } \\
\text { despair }\end{array}$ \\
\hline
\end{tabular}

Source: Adapted from Erikson's Identity and the Life Cycle (1959) 
Arthur Chickering (1969) first sought to apply the psychosocial approach to development specifically to college student development. His model of seven "vectors of development” (p. 8) still serves today as a benchmark for measuring student growth and development in college. According to Chickering, development in college is related to increased competence in intellectual, physical, and manual skills and in social and interpersonal relations. His vectors logically range from the achievement of competence through establishment of identity and interpersonal relationships to the development of integrity (pp. 8-17).

Chickering and Linda Reisser (1993) later revised and reordered the seven vectors in order to better encompass a diversity of ages and backgrounds of college students. In the revisions, Chickering and Reisser, in their own words, "tried to use language that is gender free and appropriate for persons of diverse backgrounds” (p. 44). Developmental progress along these vectors is not stage-like, but may include movement along several vectors simultaneously. Development may become static or even regress, according to Chickering and Reisser; progress, when it occurs "brings more awareness, skill, confidence, complexity, stability, and integration” (p. 34). The vectors are “major highways toward individuation,” according to the authors (p. 35), in a process of discovering oneself and ones place within the larger community.

Figure 1 (page 22) depicts the vectors and the possibility of movement along several vectors simultaneously versus the stage-like progressions of Erikson's theory. Circular arrows connote the interconnectedness of each vector as well the assertion by Chickering and Reisser that individuals may move through the vectors at different speeds and times and may move through several vectors simultaneously. 


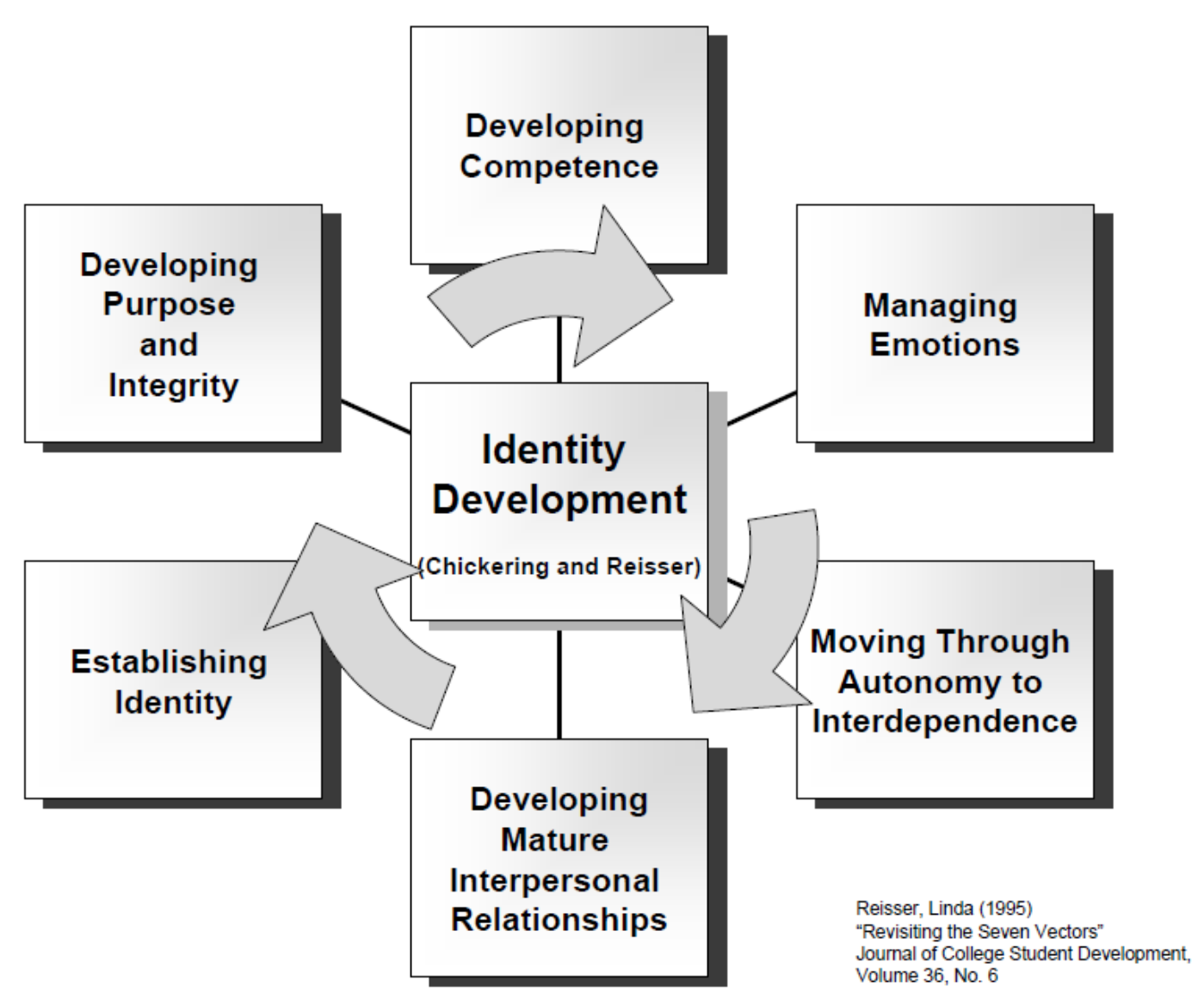

Figure 1. Chickering and Reisser’s seven vectors of development.

Each vector, according to Chickering and Reisser (1993) contains a specific set of developmental tasks. Thus, the vector of developing competence focuses on the tasks of developing intellectual, physical, manual, and interpersonal competence. In the managing emotions vector, students develop the ability to recognize and accept emotions. Students moving through autonomy to independence develop increased emotional independence and self-direction while coming to recognize the importance of interdependence. Developing mature interpersonal relationships includes the ability to recognize and appreciate difference and the ability to develop healthy and lasting 
relationships. Establishing identity includes the ability to become comfortable with one's body and appearance, gender and sexual orientation, social and cultural heritage, and a clear sense of self-acceptance and self-esteem. The vectors of developing purpose and integrity focus on the establishment of clear vocational goals and commitments and the development of a personalized value system that acknowledges and respects the beliefs of

others. In these vectors values and actions become consistent and congruent (Komives, Woodward, \& Associates, 2003, pp. 181-182)).

Additional psychosocial theories include Marcia’s “ego identity status” model (1965, 1966), Cross’s model of Black Identity Formation (1971), and Heath’s Maturity Model (1968, 1978). Each of these models incorporated the same task or “crisis” approach to developmental growth established by Erikson, each with a different focus or emphasis on the primary task or tasks associated with developmental growth and the maturation process.

\section{Cognitive-Structural Theories}

If Erikson was the father of the psychosocial theories, Jean Piaget (1964) was that to the cognitive-structural theories. The cognitive-structural theories are somewhat complementary to the psychosocial theories, focusing instead on the process of change (cognitive-structural) and the cognitive constructs people use to give meaning to change rather than on the content of change (psychosocial).

As with the psychosocial theories, there are several commonalities among the cognitive-structural theories. All posit a series of stages of development, usually arranged in a hierarchy, where one stage is reached by virtue of successful completion of the previous stage. This is in contrast to Chickering and Reisser's view of the possibility of 
development along several interrelated vectors simultaneously and in no particular order. The stages are believed to be universal and to extend across cultures, and as with the psychosocial theories, the cognitive-structural theories all assume a "chain" of stimuli and responses as the motivators of movement through the various stages (Pascarella \& Terenzini, 1991).

After Piaget's establishment of the underlying principles of cognitive-structural theory, the main proponents in bringing the theory to prominence were William Perry (1970, 1981), Lawrence Kohlberg (1972, 1984), and Robert Kegan (1982, 1994). Carol Gilligan $(1977,1982)$ presented a differing view of moral development, one less dependent upon the concepts of justice and rights central to the theories of Perry and Kohlberg and more focused on a concern with care and responsibility often felt by women (Komives, Woodward, \& Associates, p. 190). All four theories are discussed briefly here, with primary emphasis on the work of Kohlberg and Gilligan.

Perry’s model or “scheme” of intellectual and ethical development grew out of a series of interviews with male Harvard College students (1970) as he sought to map their development. His was a stage model much like the other theories examined so far, but in his case the stages were referred to as "positions” along the development continuum. He described nine positions grouped in three clusters of development moving through a dualistic orientation to the world and to learning to a relativistic orientation allowing individuals to see and hold multiple viewpoints in a pluralistic world and to establish their identities in the process. Perry’s was a model of development moving from simplistic views of right and wrong to a more complex ability to recognize the 
subjectivity of most knowledge and the ability to construct knowledge from multiple sources and personal experiences (1981, p.79).

Kegan (1982, 1994) developed a model of five “orders of consciousness” or principles of mental organization around which individuals interpreted and took meaning from their experiences. His was a lifespan model of cognitive and affective development beginning through early childhood and running through later adulthood. A summary of Kegan's orders of consciousness appears in Table 2.

Table 2

Kegan's Orders of Consciousness

\begin{tabular}{|c|c|c|}
\hline Order of Consciousness & Life Stage & Orientation/Ability \\
\hline First Order & Early childhood & Self-centered, focused on immediate needs \\
\hline Second Order & $\begin{array}{l}\text { Late childhood, adolescence, } \\
\text { early adulthood }\end{array}$ & $\begin{array}{l}\text { Development of self-concept, less focus on } \\
\text { immediate needs }\end{array}$ \\
\hline Third Order & Early adulthood & $\begin{array}{l}\text { Abstract thinking, ability to focus on the } \\
\text { needs of others, commit to set of values }\end{array}$ \\
\hline Fourth Order & Middle adulthood & $\begin{array}{l}\text { Development of core beliefs, convictions } \\
\text { that guide behavior }\end{array}$ \\
\hline Fifth Order & Late adulthood & $\begin{array}{l}\text { Systems level thinking, contradictions } \\
\text { accepted as part of life }\end{array}$ \\
\hline
\end{tabular}

Source: Compiled from Kegan $(1982,1994)$

While Perry's theory focused on intellectual and ethical development and Kegan's theory on cognitive and affective development over the life span, Kohlberg's theory was one of moral development (1972, 1984). Kohlberg's was also essentially a stage theory, with his six stages grouped into three general levels of moral reasoning, termed 
preconventional (Level I), conventional (Level II), and postconventional (Level III). Passage through these levels and the stages that they contain, for Kohlberg, essentially involved an increasingly refined and differentiated set of principles and sense of justice, with the individual moving from a focus on self and material good in the early stages through a conscience-based set of moral principles as guides to action.

Table 3

Kohlberg's Stages of Development

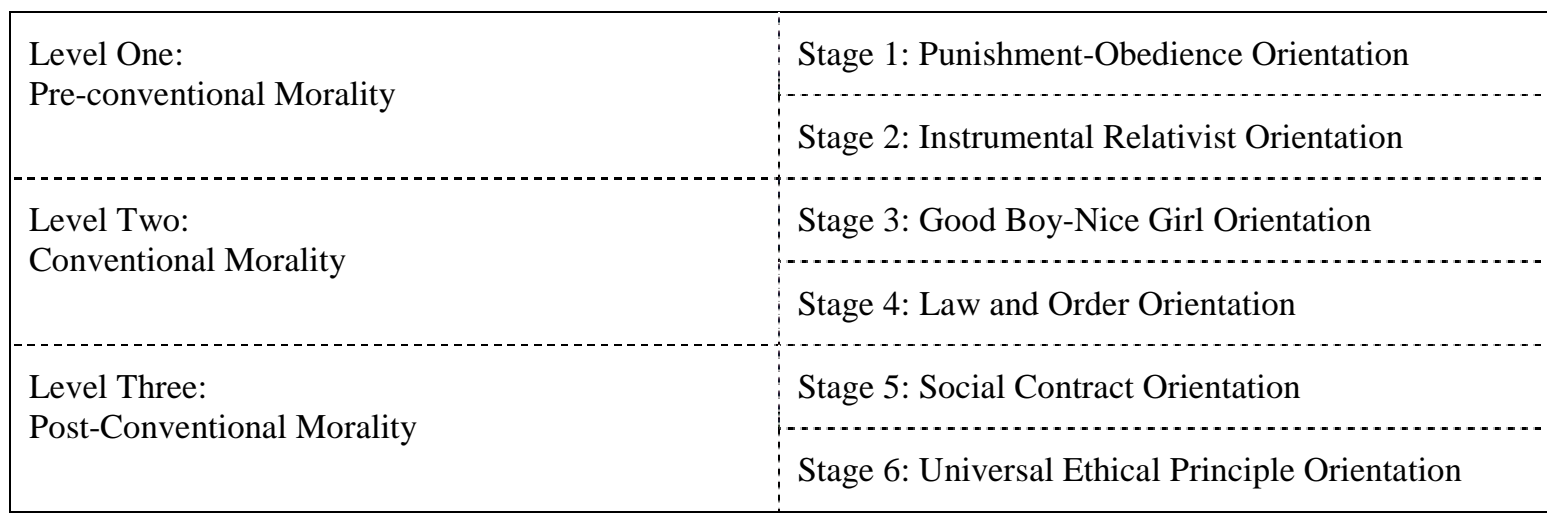

Source: Compiled from Kohlberg (1984)

In contrast to Kohlberg, Carol Gilligan (1977) proposed an alternative model of development less focused on justice and rights and more focused on care and responsibility to others. Gilligan's work grew out of a sense that the work of Perry and Kohlberg, based as it was largely on studies of male development, was not adequate to explain the development of women (Komives, Woodward, \& Associates, pp. 190-101). In reference to the previous focus chiefly on male development, Gilligan observed that "the failure of women to fit existing models of human growth may point to a problem in the representation (of previous research), a limitation in the conception of the human 
condition, and omission of certain truths about life” (Gilligan, 1982, p.2). She based her work on three studies: a college student study consisting of interviews with twenty-five randomly selected students in their senior year in college and then five years after graduation, an abortion decision study consisting of interviews with twenty-nine women ranging in age from fifteen to thirty-nine, and a rights and responsibilities study consisting of interviews with men and women across the life cycle (Gilligan, 1982, pp. 2-3). The resulting stages of development determined by Gilligan are represented below in Table 4.

\section{Table 4}

\section{Gilligan's Stages of Development}

\begin{tabular}{|c|c|c|}
\hline Approximate Age Range & Stage & Goal \\
\hline not listed & Preconventional & Goal is individual survival \\
\hline \multicolumn{3}{|c|}{ Transition is from selfishness -- to -- responsibility to others } \\
\hline not listed & Conventional & Self sacrifice is goodness \\
\hline \multicolumn{3}{|c|}{ Transition is from goodness -- to -- truth that she is a person too } \\
\hline maybe never & Postconventional & Principle of nonviolence: do not hurt others or self \\
\hline
\end{tabular}

Source: Compiled from Gilligan (1982)

Gilligan’s stages of moral development stood in contrast to those of Perry and Kohlberg chiefly in her focus on the development of self in relation to the other and for her focus on women's conceptions of caring and responsibility to others. Where earlier cognitive-structural theorists had defined and described development in the somewhat objective terms of justice and rights, Gilligan’s work introduced a more subjective focus on development, one in which one's responsibilities to care for oneself and others 
become paramount in what she described as a "moral equality between self and other" (Gilligan, 1977, p. 504). This distinction is relevant to the current study in an analysis of gender-related findings reported in Chapter Four.

Additional cognitive-structural theories have emerged, including Kitchener and King's Reflective Judgment model (1981, 1990), Loevinger's Theory of Ego Development (1976) and Baxter Magolda’s theory of Epistemological Reflection Model (1999, 2000); Baxter Magolda's work is detailed on page 40 of this chapter under theories related to service and student development. While all of the cognitive-structural theories have varied considerably in terms of the particular stages of moral and ethical development through which individuals pass, all have taken the point of view that development is chiefly a moral and ethical growth process, and one rooted in the cognitive processes of individuals as they move through life experiences.

\section{Typological Theories}

While the psychosocial and cognitive-structural theories focused on the nature and process of change, the typological family of theories have categorized individuals on the basis of differences between individuals, or 'types.' They have focused on cognitive differences, learning style differences, personal style differences, or sociodemographic differences among and between individuals. Typological models have been used to understand differences among college students and to describe or understand why students respond differently to their college experiences.

The Myers-Briggs typology is one of the most popular and historically established of the typology models. Based on the work of Carl Jung (1980), this model was developed by Isabel Briggs Myers and Katherine Cooke Briggs (Myers, 1980) as a way 
to categorize and understand human interaction with the environment on the basis of how individuals receive information and make decisions. Personality type is presumed to be dynamic based on situation and other factors in this model, with the assumption that individuals have a preference of varying strengths within these two functional areas - a preferred way to receive information and/or make decisions based on that information.

The class of Person-Environment Interaction theories focused on the effect of the environment and interactions with the environment on human behavior and development (Pascarella \& Terenzini, 1991). While they were not, strictly speaking, theories of development, they did contribute to the field of understanding human behavior in the context of student change and the effects of college on student development. A number of individual theories exist within this family (Holland, 1985, Baird, 1988; Huebner, 1989, Strange \& King, 1990), all with varying degrees of focus on the effects of environment on human behavior and development.

Similar to the above theories, physical models or theories focused on the external environment and its shaping influence on behavior, but in this case the focus was much more on the actual physical environment within which one operates. As applied to a college setting, this might include the type and quality of the residence hall, the setting of the university (e.g., rural or urban), or the quality of classrooms (large or small, amount of technology, etc.). Theories such as Barker’s theory of behavior settings (Barker, 1968) sought to determine the effect and influence of the physical environment on human behavior.

Additional schools of theory exist within the typological family, including the human aggregate models (Astin, 1968; Holland, 1966), the perceptual models (Lewin, 
1951; Moos, 1976; Murray, 1951), and the structural organizational models (Kuh, 1987). Among all of these and the various developmental theories, common themes have emerged of development as an ongoing or continuous, staged and cumulative process and one that progresses from simpler to more complex behaviors. Theories have varied in relation to the interplay of environment and more internal, cognitive processes.

\section{Summary}

A great deal of research has been conducted in relation to these various theories and their predictive or explanatory ability with regard to college student development. These range across measurements of identity development, ego development, selfconcept, and self esteem in the psychosocial theory tradition. Studies of theories focused more sharply on interaction with one's environment have sought to measure levels of autonomy and independence, locus of control, interpersonal relations, moral development, and maturity.

Research on the various forms of development alleged to occur during the college years has been broad and extensive. Most research has shown some correlation between postsecondary education and development - of identity, moral judgment, maturity, and cognitive abilities, among other areas of development. Caution has already been made about inferring the role of postsecondary education as a causative agent in this development.

Discerning the net effects of college of these types of development is, in other words, a complex matter regardless of research design. Cross-sectional studies attempt to control for confounding variables such as age and intelligence; longitudinal studies generally include a control group who do not attend college or attend for fewer than four 
years. Nonetheless, since a true experimental design is not possible, or has not yet been identified, in the study of development during the college years, readers should continue to view results of these studies as the establishment of correlative and not causative relationships.

In addition to this broad base of development theory, four specific areas of interest emerged from the literature for this particular study. The first concerns research and theory related to motivations to volunteer. The second concerns primarily sociological and social psychology research related to service learning and college student development. The third relates to gender differences in the college experience. The final area of interest is the broad field of social psychology theory known as symbolic interactionism.

\section{Motivation to Volunteer}

Beginning in the 1970’s, considerable research has been conducted into motivation to volunteer among a variety of age groups and populations. While little of this research was conducted with college student populations, it is nonetheless informative to this study to look briefly at this body of research. One recent synopsis of the research in this area defined volunteering as "any activity in which time is given freely to benefit another person, group, or organization” (Wilson, 2000), a definition suitable to the parameters of this current research on service. Wilson (2000) provided a fairly comprehensive overview of theories of volunteering developed during the 1990's based on research conducted primarily in the United States.

For the purposes of this study, Wilson's (2000) method of cataloguing volunteer motivation theories is very helpful. His analysis of theory grouped volunteer theories 
into two categories: theories that explain volunteering in reference to individual attributes of the volunteer and theories that explain volunteering in terms of social contexts (p. 215), with overlap possible of these two categories as explanatory factors of motivation to volunteer. Within the individual attribute category, Wilson further grouped theories into those emphasizing motives of self-understanding on the one hand or rational action and cost-benefit analysis on the other (p.12). These themes quite accurately correspond to the earlier study referenced on pages 2-3 in Chapter One leading to the current research. Wilson's review of theories also supported the general positive outcomes on well-being, self-esteem, educational achievement, and functional ability reported in the next section on student development and service.

Of particular interest to this current study was Wilson's earlier work in construction of an integrated theory of volunteer work (Wilson \& Musick, 1997). In that earlier survey of the literature, the authors analyzed motivation to volunteer by a number of what they termed “exogenous factors,” among them age, gender, and race (p. 697). With regard to gender, their survey predictably found women to be more likely to volunteer than men and to be more likely to be rated as more empathic and altruistic than men, both findings later confirmed by Linda Sax's recent study of gender difference at entry to college (Sax, 2008). The same survey of the literature found women’s tendencies toward volunteerism to be reflective of this type of care-giving as an extension of women's generally more nurturing roles in the family (Wilson \& Musick, 1997, p. 697).

Another important survey of volunteer motivation conducted at the same time identified two main constructs for evaluating volunteer motivation, those of egoism and 
altruism (Winniford, Carpenter, \& Grider, 1997). As conveyed by the terms those theories favoring an egoistic construct for examining service tended to emphasize service as a self-understanding activity; those adopting an altruistic focus emphasized service as an other-serving activity. Within the egoistic construct, theories of volunteer motivation tended to derive from social psychology. Researchers within the egoistic construct used such theories as Mclelland and Atkinson's expectancy motivation theory and the concept of need to achieve, Maslow's Hierarchy of Human Needs, and Herzberg's Motivation/Hygiene Theory (Winniford, \& Grider, 1997). One such study of motivations among county extension volunteers which Mclelland and Atkinson's concepts of need for achievement, need for affiliation, and need for power as explanatory factors in volunteer motivation (Mounter, 1985). Volunteers in that study scored highest on affiliation, followed by achievement and power as the basis for their volunteer involvement.

Another study (Gidron, 1983) utilized Herzberg's Motivation/Hygiene Theory to assess volunteer motivations. Herzberg's theory (1966) had been chiefly developed in observation of paid employees and had found motivating factors in the workplace to be achievement, recognition, the work itself, responsibility, and advancement. Job dissatisfaction, according to Herzberg's theory, derived from such 'hygiene' factors in the workplace as policies and administration, supervision, interpersonal relations, working conditions, and salary (Herzberg, 1966). Gidron’s (1983) study used these concepts to study the sources of job satisfaction among volunteers. His study found that overall satisfaction among volunteers was related most to the work itself and 
achievement. A sense of need for achievement emerged in both of these studies with regard to motivation to perform.

In the body of literature exploring altruistic motivation to volunteer, Smith (1981) defined altruism in this way:

Altruism is an aspect of human motivation that is present to the degree that the individual derives intrinsic satisfaction or psychic rewards for attempting to optimize the intrinsic satisfaction of one or more other persons without the conscious expectation of participating in an exchange relationship whereby those others would be obligated to make similar or related satisfaction optimization efforts in return (Smith, 1981, p,23).

According to one review of the literature on college student volunteer motivation, most college students believe and report that they are motivated to volunteer for altruistic and not egoistic reasons (Winniford, Carpenter, \& Grider, 1995).

Mixed motivation theories for volunteering include social exchange theory, the concept of social obligation, and situational or environmental factors (Winniford, Carpenter, \& Grider, 1997). Social exchange theory holds that human interactions are based on an exchange of costs, or the altruistic concept of what one gives, and the egoistic concept of rewards or what one receives (Phillips, 1982). At least two studies of volunteer behavior (Batson, 1991; Martin, 1994) concluded that often the initial motivation to volunteer is an altruistic one, while the decision to continue as a volunteer often depends on the egoistic rewards associated with continuing. Another way of framing this is to consider the initial impulse to volunteer as one focused toward the other(s), and the impulse to continue as focused on the personal gains derived from volunteering. 
In his study of the motivations and characteristics of college student volunteers, Fitch (1987) added a third concept to the altruistic and egoistic constructs - that of a sense of social obligation among volunteers. He found the strongest reason for service among students to be egoistic, or the good feeling derived from helping others. This was followed by an altruistic focus on the needs of others less fortunate combined with the egoistic fulfillment derived from affiliation with other volunteers. The third strongest reason was a sense of social obligation in the form of care of those less fortunate, a desire to "give back" to society, and a hope for reciprocation if the need ever arose (Fitch, p. 427).

Another study of college student motivations to volunteer (Serow, 1991) found that $80 \%$ of those participating in service were involved out of an egoistic sense of satisfaction from helping others; 56\% reported involvement as part of a club, organization, or class; $54 \%$ reported a sense of social obligation to correct societal problems, and the fourth highest reason for involvement relating to egoistic rewards of career advancement and experience (Serow, p. 549). Similarly, in the current study students reported a mix of motivating factors for involvement in service running this full range of egoistic, altruistic, and social obligation factors.

Clary and Snyder (1999) provided a slightly different analysis of motivations to volunteer in their analysis embedded in functional psychology. Their approach was different in that it placed more emphasis on internal psychological processes and circumstances of individuals considering volunteerism (Clary \& Snyder, 1999, p. 156) rather than assuming these to be fairly static or generic traits across the volunteering 
population. Their resulting Volunteer Functions Inventory catalogued motivations for volunteering across six functions or primary motivations Clary \& Snyder, 1999, p. 157):

- Values (acting on deeply held beliefs about the importance of helping others)

- Understanding )involvement in activities that satisfy the desire to learn)

- Career (seeking ways to explore job opportunities or advance in the work environment)

- Social (conforming to the normative influence of significant others)

- Esteem (enhancing one’s self esteem)

- Protective (escaping from negative qualities or feelings).

A close inspection of these six functional areas shows there to be less difference from the sociological and social psychology perspectives described above, however, than its authors might have suggested, with many of the same altruistic and egoistic, even social exchange and obligation parameters posited by these other theorists. The values function cited by Clary and Snyder mirror quite closely, for instance, the altruistic motives ascribed by the preceding theories. Similarly, the understanding, career, esteem, and protective values mirror the egoistic motives of the psycho-social and sociological theories cited above.

These theories regarding motivation to volunteer establish the context within which to undertake a closer review of the literature related specifically to college student development and service, outlined in the following section.

\section{Service and Student Development}

A number of studies over the past two decades have sought to add to an understanding of the relationship between service and student growth and development 
during the college years, although the implied connection between service and the development of self has roots as far back as nearly a century ago in the writing and work of such scholars as John Dewey (1916) and George Herbert Mead (1934). Both sought to establish the connection between engagement with the other and development of self. Dewey's (1916) work in education remains the seminal work in the design of active (e.g., service-based) learning in education nearly a century after he presented his model for education in a democracy.

Pascarella and Terenzini (2005) provide a summary of studies of service involvement and student development in their updated compilation of the effect of college on students (2005, pp. 193-194). These included quasi-experimental studies conducted by Batchelder and Root (1994); Eyler, Giles, Lynch and Gray (1997); Eyler, Giles, Root, \& Price (1997); and Eyler and Giles (1999) designed to measure the net effect of service involvement on students' cognitive development. These studies generally supported the hypothesis that student cognitive development is influenced by the degree to which service learning classes were well integrated and contained a reflective component (Pascarella \& Terenzini, 2005, p. 193).

Several studies have focused on why students chose to participate in service during the college years (Astin, 1991; Serow, 1991), the meaning that they made of and from this service (Jones \& Hill, 2003), and the enduring influences of service learning on college students' identity development (Jones \& Abes, 2004). Jones and Hill (2003) found the influence of peers and institutional influences to be among the external motivators for students to engage in service during college, along with the predisposition to serve following service in high school. In their qualitative study, researchers 
interviewed 12 college students who had continued their service involvement from high school to college and 12 who had discontinued their service participation in college.

Jones and Hill (2003) found the deciding factors for continued involvement in service to include a desire to focus on others, a desire to 'give back' to the community, and a perceived direct connection between development of self and service. Students also spoke about an evolving link for them between and among service, social justice and community activism. While the study included 9 male and 15 female students, no discernible differences were sought or found in this study with regard to gender of participants and reasons given for service participation.

A later study by Jones and Abes (2004) sought to understand the enduring influences of service on students’ identity development. In this study, Jones and Abes sought to understand how service-learning promotes learning about self and how or whether this is sustained over time. Their qualitative study sought explicitly to explore the influence of service learning involvement on identity development among participants. Interviews were done with 8 participants who had participated in a service learning course 2 to 4 years prior to the study. Findings were arranged within three themes of enduring learning from service: intrapersonal (or identity) learning, interpersonal (shifts in the nature of commitments) learning, and cognitive development (in the form of increased open-mindedness to new people, ideas, and experiences). In each area, Jones and Abes’ (2004) study found sustained growth among participants and found reasons to link these directly to the service experiences of participants.

Similarly, Robert Rhoades’ (1997) phenomenological narrative of meaningmaking through service connected college students' experiences in service to what he 
described as the situating of self in the world, the development of identity, and the development of a sense of 'otherness,' community orientation, and mutuality in interactions with others. Rhoades' analysis combined the perspective of symbolic interactionist theory (Mead, 1934) with what he termed the feminist writings of Gilligan (1982) and others (Chodorow, 1978; Noddings, 1984). His work grew out of his own involvement with students in service learning experiences over six years at Michigan State University in the early 1990's. In the tradition of the phenomenological narrative, Rhoades’ observations and conclusions are based largely on students' first-hand narratives of their service experiences and his own first-hand observations of students' service involvements. Rhoades' (1997) conclusions about student service and development, along with the theory of Marcia Baxter Magolda were utilized extensively in Chapter Five in the analysis of findings of this research project.

Baxter Magolda’s $(1999,2000)$ work in this area is frequently cited for its focus on the potential of service experiences to create opportunities for what she described as 'self-authorship,' or the ability to develop personal authority over one’s identity. For her this is accomplished by "an ability to construct knowledge in a contextual world, an ability to construct an internal identity separate from external influences, and an ability to engage in relationships without losing one’s internal identity” (Baxter Magolda, 1999, p. 12). She further described this process as a defining and desirable characteristic of the higher education experience.

Baxter Magolda’s work was influenced by Perry's cognitive-structural theory (1970), but also by Belenky, Clinchy, Goldberger, and Tarule (1997), who, like Carol Gilligan earlier (1977) found that women's development did not necessarily conform to 
Perry’s model of development. Her work was also informed by King and Kitchener’s Reflective Judgment Model (1981, 1990), which described a seven-stage development sequence toward the development of increasingly refined problem-solving skills.

Baxter Magolda’s own theoretical work grew out of a longitudinal qualitative study of 101 students at Miami University of Ohio (1992). She identified four qualitatively different “ways of knowing” (1992, p. 29) - absolute, transitional, independent, and contextual - associated with different expectations of the learner and instructors about how learning should be evaluated. She found gender-related patterns within the first three ways of knowing discussed at greater length in Chapter Five as an interpretive lens for gender-related findings of this study. Her longitudinal work continues with thirty-nine members of the original research cohort in the form of annual interviews related to their experiences since graduation (2001).

\section{Gender Difference in College}

While much of the literature on service in college does not seek to explore how men and women might experience service differently, a good deal of recent research has emerged relative to gender difference in college more broadly. Returning to Rhoades’ (1997) work, his was one of the few works to take on a discussion of gender difference in general identity development theory in college. Citing the work of Gilligan (1982), Noddings (1984), and the earlier pioneering work of Chodorow (1978), Rhoades (1997) discussed the thesis put forth by these and other feminist scholars, that male development is based on a process of individuation, while that of women is based in the development of connectedness and caring (or to use Chodorow's earlier terms, that male identity development is defined through separation and women's through attachment). If this is 
true, then we might expect to see differences in how men and women experience much about their college years, including how they might view, participate in, and learn from service participation.

More recent research on gender in college (Bryant, 2007; Sax, 2008) begins to reveal a broad array of gender differences of the college experience. Bryant's work (2007) explored gender difference in how men and women developed spiritually during the college years. Citing the work of Chodorow (1978), Gilligan (1982), Baxter Magolda (2000) and others, Bryant (2007) used a national and longitudinal sample of 3,680 college students surveyed with the Cooperative Institutional Research Program (CIRP) Freshman Survey (2000) and later the College Students’ Beliefs and Values (CSBV) Survey (2003) to study gender differences in 13 spiritual characteristics. Her findings were mixed with regard to gender difference in spirituality development during the college years. Perhaps of most significance for the present study, Bryant (2007) found measurable differences between men and women in their propensity toward "charitable involvement” during the college years, with women being significantly more likely to be involved than men.

In perhaps the largest study of gender difference during college to date, Linda Sax (2008) reported differences among college students both at entry to college and with regard to the impact of college on male and female student development. Her study, based on the same survey data examined by Bryant (2007), showed differences between men and women upon entry to college in political orientation (with men generally being more conservative politically upon entry than women) and optimism for social change 
through action (with women reporting a much more optimistic view of the likelihood of individual action leading to social change).

When looking at college and its impact on male and female development, Sax (2008) cited the relative absence in early student development literature of gender differentiation in the various theoretical models of college student development. She pointed to an increased focus on gender difference in the theoretical literature over the past several decades, led by such writers as Chodorow (1978), Gilligan (1982), and Belenky, Clinchy, Goldberger, and Tarule (1997). Along with Josselson (1987) and Marcia (1966), these scholars all generally posited the importance of caring and connectedness in relationships with others as critical components of women’s development in college. This was in contrast to the previously described centrality of individuation as central to the development of men (Erickson, 1968; Kohlberg, 1975; Perry, 1970).

In her discussion of the conditional effects of college (e.g., differential effects based on gender or other forms of difference), Sax (2008) cited the general absence of such information as evidenced by Pascarella and Terenzini's (1991) exhaustive study of the literature. A later update of this volume (Pascarella and Terenzini, 2005) reported more research on the conditional effects of college, but little more information on the differential effects of college on men and women. Sax's (2008) study was, arguably, the first of its kind in terms of both the depth and breadth of the sample and the research model regarding gender difference. It also had the advantage of a longitudinal perspective, with a focus both on gender difference at entry to college and over time. The Sax study suggested a number of gender based differences in development over time and 
a number of different factors in college which impact male and female student development differently. A full exploration of these differences appears in Chapters Four and Five.

The work of Nel Noddings (1984) in feminist approaches to ethical decisionmaking further informed the analysis of findings of this research. Noddings suggested that men and women tend to think differently about the basis of their ethical obligations toward others and, consequently, to structure their social commitments and individual interactions with others differently. Noddings’ concepts of empathy, receptivity, and “feeling with” (pp. 30-31) defined for her the personal nature by which women approach their interactions with others and define their social commitments. Much like the symbolic interactionist approach described on pages 38-39, Noddings felt that women particularly take meaning from their personal and individual interactions with others and view their commitments to others on a personal level, often in contrast to the more generalized notions of utilitarian or deontological frameworks employed by men in determining their social obligations. This contrast was evident in findings related to gender difference in this study, particularly with regard to motivations for service involvement, as discussed in Chapter Five.

\section{Symbolic Interactionism}

In his own extensive study of service during the college years, Rhoades relied heavily on the concept of the "social self" described by the symbolic interactionists as the central means by which individuals make meaning of their experiences (Rhoades, 1997). Rhoades’ standard bearer for this purpose was George Herbert Mead (1934). Rhoades’ (1997) approach was to combine this concept of the social self - meaning-making via our 
interactions with others - with feminist writers such as Gilligan (1982), Noddings (1984), and Belenky et al. (1997) and their conception of the "relational self” to interpret the meanings from service derived by his students.

Mead's (1934) foundational view of social psychology was that the individual's learning about self is a function of his/her interactions with the world and people around him or her. He posited that we account for "the conduct of the individual in terms of the organized conduct of the social group, rather than account for the organized conduct of the social group in terms of the conduct of the separate individuals belonging to it” ( $\mathrm{p}$. 7). Mead's early work inspired the work of social psychologists who followed in the symbolic interactionist tradition, such as Herbert Blumer, Everett Hughes, and William I. Thomas (House, 1977). Norman Denzin perhaps best encapsulated this notion of the social self with his three basic assumptions of the interactionist perspective (Denzin, 1989).

Denzin first argued that interactions with others are the means by which one makes sense of social life. Second, people are capable of self-reflective behavior in relation to these interactions and are capable of guiding their own behavior and that of others by virtue of this self-reflection. Third, that one's self-definitions and definitions of situations are dependent upon ongoing interactions with others (1989). For Denzin (1987) and the symbolic interactionists, the self is "not a thing, but a process, the self is consciousness conscious of itself (Denzin, 1987, p. 289). For the interactionists, how individuals interpret events and interactions with others is central to the process of creating meaning and constructing the self (Blumer, 1962, 1969). 
This study utilized the interactionist approach as a lens through which to interpret the lived experience of participants in service as reported by them in the qualitative phase of the research. As these students were primarily reporting on their interactions through service, along with their self-reflections about these interactions, this approach seemed both fitting and true to a research methodology aimed at exploring self-reported motivations toward service and learning outcomes from service. More on the use of this and other theoretical lenses in the interpretation of research findings appears in Chapter Five.

\section{Summary}

These various bodies of literature related to student development in college, motivation to volunteer, the relationship between service and student development, gender difference in college, and meaning-making through social interaction were applied in Chapter Five in the analysis of findings from the research. This presentation of theories and literature in Chapter Two is intended to establish context and provide the reader with an overview of relevant current and historical theoretical constructs within which to evaluate and interpret the findings of this research. The next chapter, Chapter Three, reframes the research problem, purpose, and questions and outlines the methodology of the research project. This is followed by a summary of the findings in Chapter Four and discussion of the findings in Chapter Five. 


\section{Chapter Three}

\section{Methodology}

This chapter provides a restatement of the research problem, followed by a review of the purpose of the study and research questions. The research paradigm and tradition of inquiry is discussed, followed by a description of the pilot study for the research. An overview of methodology is provided, including a description of the sampling strategy, data collection and analysis procedures, verification procedures, and discussion of ethical considerations.

\section{Restatement of the Problem}

As previously described, research shows that college student involvement in service affects student development positively in a number of ways, including cognitive and moral development, self-concept and self confidence, and general well-being (Astin \& Sax, 1998; Eyler \& Giles, 1999, Thoits \& Hewitt, 2001). Research also shows that students are involved in service during college at differential rates. Men, for instance, are less involved in service than their female counterparts (Corporation for National \& Community Service, 2007, 2008; Sax, 2008). If it is the case that service involvement impacts students positively, and that some students are more or less involved in service than others, then it may help us to understand what motivates students to engage in service during the college years, how they choose their service involvements, and how they describe their learning outcomes from service.

\section{Purpose of Study/Research Questions}

This mixed methods study explored college student involvement in service - their motivations, choices of service involvement, and reported learning outcomes. The 
purpose of this two-phase exploratory mixed methods research was to add to our understanding of the motivations toward service among college students, to get a clearer sense of how students choose their particular service involvements, and to better understand the learning outcomes from service involvement during college. The first phase of the research was a qualitative exploration of these questions via focus group and individual interviews with 24 college students in a small, Midwestern liberal arts college, details provided in sections following describing sampling and data collection strategies.

Emergent themes from these interviews were then utilized to develop a survey instrument to test a series of null hypotheses that relate to possible differences in how students describe their motivations toward service, choices of service involvement, and learning from service based on gender, year in college, and amount of service performed. The explicit aim of this exploratory study was not to develop and test a survey instrument, but rather to determine if, in this study sample, differences exist in how students describe their service motivations, choices, and learning outcomes based on the variables of gender, year in college, and amount of service performed. One thousand students at the same small liberal arts college were surveyed.

The central research question for this study was this: How do students describe their motivation toward service involvement during college and the learning outcomes of their service involvement?

Three additional emergent questions were explored in the quantitative phase of the research following completion of the phase one qualitative inquiry:

1. Is there a difference in how students describe motivation to serve, selection of service, and learning outcomes from service based on gender? 
2. Is there a difference in how students describe motivation to serve, selection of service, and learning outcomes based on year in college?

3. Is there a difference in how students describe motivation to serve, selection of service, and learning outcomes based on amount of service performed?

The specific research hypotheses corresponding to these questions were:

1. There is a difference in how students describe motivation to serve, selection of service, and learning outcomes from service based on gender.

2. There is a difference in how students describe motivation to serve, selection of service, and learning outcomes based on year in college.

3. There is a difference in how students describe motivation to serve, selection of service, and learning outcomes based on amount of service performed.

These are restated here in the traditional null hypothesis format as follows:

1. There is no difference in how students describe motivation to serve, selection of service, and learning outcomes from service based on gender.

2. There is no difference in how students describe motivation to serve, selection of service, and learning outcomes based on year in college.

3. There is no difference in how students describe motivation to serve, selection of service, and learning outcomes based on amount of service performed.

\section{Research Paradigm}

This research was conducted with an exploratory mixed methods design in the pragmatic research paradigm. In their discussion of paradigms in social science research, Creswell and Plano Clark (2008) describe four versions or applications of the paradigm concept in research. A paradigm, in their analysis, may be thought of as worldview, 
epistemological stance, a set of shared beliefs, or as a model example - or as some combination of these (pp. 32-37). The term is used here largely as a description of the epistemological stance of the current research and as the basis for combining a qualitative and quantitative approach to the research..

Pragmatism, in this context, embraces epistemological relativism and the value of both subjective and objective points of view in the research, acknowledges the subjective role of researcher values in interpretation of research results, and ontologically tempers the positivist/postpositivist belief in a single objective truth or reality with the belief that there may be multiple “truths” in our understandings of any given phenomenon (Tashakkori \& Teddlie, 1998, pp. 22-30). See Table 5, page 45 for a summary of four research paradigms. The pragmatic researcher's choice of one explanation of a given phenomenon over another, according to one author, "simply means that one approach is better than another at producing anticipated or desired outcomes” (Cherryholmes, 1992, p. 15, Table 1).

\section{Tradition of Inquiry/Rationale}

The qualitative phase of this study was conducted in the phenomenological tradition of inquiry, wherein the researcher aims to develop a deeper understanding of the phenomenon under study by in-depth inquiry into the experiences of several individuals who have shared the phenomenon under study, in this case service during the college years (Creswell, 2007, p. 60). In this approach, the reader of the research should come away with the feeling, "I understand better what it is like for someone to experience that,” in reference to the phenomenon under study (Polkinghorne, 1989, p. 46). 
Table 5

Comparison of Four Important Paradigms Used in the Social and Behavioral Sciences

\begin{tabular}{|c|c|c|c|c|}
\hline Paradigm & Positivism & Postpositivism & Pragmatism & Constructivism \\
\hline Methods & Quantitative & Primarily Quantitative & $\begin{array}{l}\text { Quantitative + } \\
\text { Qualitative }\end{array}$ & Qualitative \\
\hline Logic & Deductive & Primarily Deductive & $\begin{array}{l}\text { Deductive + } \\
\text { Inductive }\end{array}$ & Inductive \\
\hline Epistemology & $\begin{array}{l}\text { Objective point } \\
\text { of view. } \\
\text { Knower and } \\
\text { known are } \\
\text { dualism. }\end{array}$ & $\begin{array}{l}\text { Modified dualism. } \\
\text { Findings probably } \\
\text { objectively "true." }\end{array}$ & $\begin{array}{l}\text { Both objective and } \\
\text { subjective points of } \\
\text { view. }\end{array}$ & $\begin{array}{l}\text { Subjective point of } \\
\text { view. Knower and } \\
\text { known are } \\
\text { inseparable. }\end{array}$ \\
\hline Axiology & $\begin{array}{l}\text { Inquiry is } \\
\text { value-free. }\end{array}$ & $\begin{array}{l}\text { Inquiry involves values, } \\
\text { but they may be } \\
\text { controlled. }\end{array}$ & $\begin{array}{l}\text { Values play a large } \\
\text { role in interpreting } \\
\text { results. }\end{array}$ & $\begin{array}{l}\text { Inquiry is value- } \\
\text { bound. }\end{array}$ \\
\hline Ontology & Naïve realism & $\begin{array}{l}\text { Critical or transcendental } \\
\text { realism. }\end{array}$ & $\begin{array}{l}\text { Accept external } \\
\text { reality. Choose } \\
\text { explanations that } \\
\text { best produce } \\
\text { desired outcomes. }\end{array}$ & Relativism \\
\hline $\begin{array}{l}\text { Causal } \\
\text { linkages }\end{array}$ & $\begin{array}{l}\text { Real causes } \\
\text { temporarily } \\
\text { precedent to or } \\
\text { simultaneous } \\
\text { with efforts }\end{array}$ & $\begin{array}{l}\text { There are some lawful, } \\
\text { reasonably stable } \\
\text { relationships among } \\
\text { social phenomena. } \\
\text { These may be known } \\
\text { imperfectly. Causes are } \\
\text { identifiable in a } \\
\text { probabilistic sense that } \\
\text { changes over time. }\end{array}$ & $\begin{array}{l}\text { There may be } \\
\text { causal } \\
\text { relationships, but } \\
\text { we will never be } \\
\text { able to pin them } \\
\text { down. }\end{array}$ & $\begin{array}{l}\text { All entries } \\
\text { simultaneously } \\
\text { shaping each other. } \\
\text { It's impossible to } \\
\text { distinguish causes } \\
\text { from effects. }\end{array}$ \\
\hline
\end{tabular}

Source: Tashadkori \& Teddle (1998, p. 22)

It is not uncommon in phenomenological inquiry that the researcher comes to the research with a strong personal interest in the phenomenon under study and a set of assumptions about what the study may yield (Moustakas, 1994, pp. 103-104). In this 
case, based on the researcher's own experience and on research previously conducted and cited in Chapter Two, these assumptions yielded several anticipated themes from the qualitative phase of the research:

- that the service involvements of participants would yield positive developmental results;

- that participants' descriptions of their service involvements would reveal overall themes relative to these developmental impacts; and

- that thematic differences would emerge based on gender, year in college, and amount of service performed.

At the same time, as described in Chapter Four, the researcher was careful to bracket his own experiences of this phenomenon and the assumptions derived from these during data gathering and analysis.

Procedurally, emergent themes from the qualitative phase of the research were arrived at with an inductive perspective and approach (Tashakkori \& Teddlie, 1998, p. 23), the researcher attempted to establish a close relationship between himself and participants in order to elicit stories from participants in their own words (Charmaz, 2000), and qualitative data were analyzed from the perspective that knowledge is constructed through the interaction of individuals and their environments or social contexts (Crotty, 1998), in this case both historical and in relation to specific contemporary service experiences.

Miles Bryant (2004) draws a clear distinction between descriptive and exploratory research in his discussion of research design (pp. 96-99). Exploratory research, according to Bryant, seeks to tentatively explain a phenomenon or behavior; descriptive research, 
on the other hand, seeks to describe the behavior or phenomenon (p. 96). This research, while chiefly exploratory in nature, also sought to describe the behavior or phenomenon under study. In this case the researcher sought as the central research question to describe the motivations toward and learning from service, as reported by participants in the study. The researcher also sought to explore the motivations for service among participants, their specific choices of service involvement, and the relationships between and among several factors - gender, year in college, amount of service performed - and these motivations, choices, and learning outcomes.

The choice specifically of an exploratory mixed methodology - where early qualitative research results were subjected to later quantitative analysis - was driven largely by the strength of the emergent themes of the qualitative phase of the research. Creswell and others point out the utility of the exploratory mixed methods design particularly in those cases where the aim is to identify specific variables in the initial qualitative phase of the research and later to further study or analyze these variables in a later quantitative research phase (Creswell, 1999; Creswell et al., 2004). Others have pointed out the usefulness of this research design in first exploring a phenomenon qualitatively and then measuring its prevalence quantitatively (Morgan, 1998; Morse, 1991).

Bryant cautions against the use of an exploratory methodology in those cases where variables under study are already well-known or the phenomenon under study well-researched (2004, p. 96). Neither was the case in this study. While research has been conducted relative to the impacts of service on college student development, little has been written about student motivations toward service, how they choose their specific 
service involvements, or how they themselves describe their learning outcomes from service; nor has much been written of a comparative nature based on gender, year in college, or amount of service performed.

\section{Earlier Study}

In the spring of 2008 a study was conducted of college student service motivations and learning outcomes as part of a team project coursework requirement. The study was in the qualitative tradition, with a multiple case study design. That study revealed a number of outcomes consistent with the assumption the service involvement during college yields positive developmental gains for participants. The study also revealed qualitatively different types of responses from participants based on gender, year in college, and amount of service performed.

In the pilot, a team of researchers interviewed eight students at four different institutions of higher education. Institutions varied in size, location, and type. Participants in the research varied by gender, year in college, and by the amount of service performed. Researchers did not set out to discern differences in responses based on these characteristics. These emerged as researchers performed open coding of data from interviews and compared emergent themes across institutions and participant responses. Researchers did not perform an extensive analysis of these differences, as these were outside of the scope of the research. These differences did, however, serve as underlying motivation for this dissertation research. 


\section{Sampling Strategy}

\section{Qualitative Phase}

In the initial qualitative phase of the research, participants were selected for the study in two stages, both utilizing a purposeful sampling strategy (Patton, 1990). The first selection stage for the qualitative phase of research involved the identification of 12 female and 12 male participants meeting the following criteria:

- Participant must be enrolled full-time as an undergraduate student at the research site.

- Participant must have participated in service for a minimum of 25 hours in the current school year.

- Participant must be 19 years of age or older.

- Participant must complete an informed consent and agree to participate in recorded (video and audio) focus group interviews.

- Participant mix must be roughly equal numbers men and women.

Members of each single gender group were invited during focus group discussions to volunteer as participants in a subsequent mixed gender focus group. Six male and six female participants volunteered to participate in the mixed gender focus group.

In the second stage of participant selection for individual interviews, 4 male and 4 female participants were purposefully selected from the original pool of 24 participants according to the following criteria:

- Participant must meet all selection criteria for focus group selection. 
- Participant must complete an informed consent and agree to participate in recorded (audio) individual interviews.

Participants were invited to participate via e-mail introduction to the scope and purpose of the study. No incentive was provided for participation in the study. Participants read and completed informed consent forms at every stage of the qualitative research and were provided the opportunity to opt out of the study as part of the informed consent process. Invitation to participate and informed consent documents for the qualitative phase of the research are located in Appendix A (pp. 183-191).

A breakdown of participant demographics by gender, age, and year in college appears below in Table 6. Participants in individual interviews are marked by an asterisk.

\section{Quantitative Phase}

In the quantitative phase of the research, sampling was by census, with all currently enrolled full-time undergraduates at the research site aged 19 and older invited by e-mail to complete an online survey regarding their service involvements, motivations, and learning outcomes. Invitation e-mails with a link to the survey were sent to 1004 prospective participants, with 447 completed surveys, for an overall response rate of 44.5\%. Among respondents, $83 \%$ (370) had participated in some form of service in the previous year, while 17\% (77) had not. Those not completing service within the past year were asked only to respond to demographic questions and a single question pertaining to the reasons for their non-involvement in service. This was accomplished via skip logic embedded in the survey instrument. Among those who had participated in service in the previous year, response rates to individual questions on the survey ranged 
Table 6

Participant Demographics - Focus Groups and Individual Interviews

\begin{tabular}{|c|c|c|}
\hline Year in College & Gender & Age \\
\hline Senior & Male & $22 *$ \\
\hline Senior & Male & 22 \\
\hline Senior & Male & 22 \\
\hline Senior & Male & $21 *$ \\
\hline Senior & Male & 21 \\
\hline Senior & Female & 28 \\
\hline Senior & Female & $22 *$ \\
\hline Senior & Female & 21 \\
\hline Senior & Female & 21 \\
\hline Senior & Female & 21 \\
\hline Senior & Female & 21 \\
\hline Junior & Male & $20 *$ \\
\hline Junior & Male & 20 \\
\hline Junior & Female & $20 *$ \\
\hline Junior & Female & 20 \\
\hline Junior & Female & 20 \\
\hline Sophomore & Male & 20 \\
\hline Sophomore & Male & $19 *$ \\
\hline Sophomore & Male & 19 \\
\hline Sophomore & Male & 19 \\
\hline Sophomore & Male & 19 \\
\hline Sophomore & Female & $19 *$ \\
\hline Sophomore & Female & $19 *$ \\
\hline Sophomore & Female & 19 \\
\hline
\end{tabular}

*Focus Group and Individual Interview 
from $84 \%$ (312) to $100 \%$ (370). Invitations to participate included informed consent disclosures and advisories, as well as a clear statement of the voluntary nature of survey completion (see Appendix A, pp. 183-191). No incentive was provided for completion of the survey. A breakdown of respondents by gender, year in school, and hours of service completed is provided in Tables 7-9 below and on the next page.

Table 7

Participant Demographic by Gender

\begin{tabular}{clcc}
\hline$\#$ & Gender & Response & $\%$ \\
\hline 1 & Male & 201 & $45 \%$ \\
2 & Female & 246 & $55 \%$ \\
& Total & 447 & $100 \%$ \\
\hline
\end{tabular}

Table 8

Participant Demographic by Year in School

\begin{tabular}{clcc}
\hline$\#$ & Year in school & Response & $\%$ \\
\hline 1 & Freshman & 130 & $29 \%$ \\
2 & Sophomore & 103 & $23 \%$ \\
3 & Junior & 94 & $21 \%$ \\
4 & Senior & 120 & $27 \%$ \\
& Total & 447 & $100 \%$ \\
\hline
\end{tabular}


Table 9

Participant Demographic by Hours of Service

\begin{tabular}{clcc}
\hline$\#$ & Amount of Service & Response & $\%$ \\
\hline 1 & None & 54 & $12 \%$ \\
2 & $1-10$ hours & 205 & $46 \%$ \\
3 & $11-20$ hours & 72 & $16 \%$ \\
4 & $21-30$ hours & 49 & $11 \%$ \\
5 & $31-40$ hours & 18 & $4 \%$ \\
6 & More than 40 hours & 49 & $11 \%$ \\
& Total & 447 & $100 \%$ \\
\hline
\end{tabular}

\section{Data Collection}

Prior to each phase of data collection the researcher sought and received approval from the Institutional Review Board (IRB) of the university and the research site (see Appendix B, pp. 192-200). A separate proposal was submitted for the qualitative and quantitative phase of data collection. Each proposal included a study description, summary of research methods, a description of participants and the basis of their selection, recruiting procedures and documents, a copy of informed consent forms, the plan for maintaining confidentiality of records, and the data collection protocol.

\section{Qualitative Phase}

In keeping with the phenomenological tradition of inquiry, data collection in this phase consisted of several in-depth interviews. This occurred in two stages - via five 75 minute focus group interviews in stage one and eight 45-minute individual interviews in stage two. Focus groups were conducted first in single-gender groups -2 each for males and females - and then in a single mixed-gender group. Focus group interviews 
were held at the research site in a comfortable neutral setting over the course of four months. Each single-gender focus group held 12 participants and was recorded via video and audio tape. The researcher conducted a total of three hours of focus group interviews over three sessions each for men and women. The mixed gender focus group interview held six male and six female students, was also video and audio taped, and was roughly one hour in length. Scripts for all focus group interviews are provided in Appendix C (pp. 201-205).

In the second phase, individual interviews were conducted with eight participants after completion of focus group interviews. Interviews were approximately 45 minutes in length and occurred in the researcher's office. These took place over the course of approximately two weeks. As in the case of focus group interviews, participants signed informed consent forms for all interviews; the scope and purpose of the research was reiterated to all participants. All interviews were audio taped. The script for individual interviews is provided in Appendix C (pp. 201-205).

The following questions were asked of 12 participants in four single-gender focus group interviews (two each for men and women) in the qualitative phase of the research. Parenthetical notations beside each question signify correspondence to one of the qualitative research questions described above.

1. Let's first talk about service in general - what the term means to you, how you define the term, whether there are various ways to 'define’ service. Specifically, what comes to mind for you when I use the term “service?” (Q2)

2. You have each been selected to participate in this study and this focus group interview on the basis of your prior participation in what I would describe as 
service during your time in college. Tell me how you decided to become involved in service? What motivated you to serve and how did you choose what project/issue to become involved with? (Q1)

3. Have you felt that there have been either internal or external motivations to serve while in college, and what are these, if any? Similarly, have you felt there to be either internal or external inhibitors or obstacles to serve, and what are these, if any? (Q1)

4. How would you describe your learning from the service experience(s) that you have been involved in? How have these experiences changed or impacted you in the short term or long-term, do you think, if at all? (Q3)

5. Please talk about what you think were the most positive aspects of your involvement in service. What were the most challenging or negative aspects, if any? (Q3)

6. Finally, what do you think are important considerations for people involved in creating and providing service opportunities to think about? How can your experience help peers, educators, administrators in leadership roles in service programs to understand the important elements of designing these experiences?

The following questions were asked in a mixed gender focus group comprised of six men and six women from the original single-gender focus groups. These are similarly coded in relation to the research question being addressed. Not every question in this case has a direct link to a stated qualitative research question. The mixed gender focus group 
occurred after completion of single gender focus groups and anticipated the phase two quantitative questions about differences.

1. Thank you for agreeing to participate in a second focus group interview. As you can see, this one is a bit different in that we have both men and women participating. I am interested in this session in exploring whether you think that choices about service and learning from service are similar for men and women? To begin, do you think men and women define service similarly? (Q1)

2. Do you think that men and women choose their service involvements for similar reasons, different reasons, or that there is no real basis in your experience for how men and women choose their service involvements? (Q2

3. Do you think that men and women take different types of learning from their service involvements or again, that there is no basis in your experience to know or see this as a relevant question? (Q3)

4. Based on your experience(s) in service, is it sensible at all to ask about or be interested in men's experiences in service and that of women? If so, in what way does it make sense to ask about possible differences or similarities?

5. If you were able to create the perfect service opportunities for both men and women during college, what would some of the elements of those be?

Finally in this phase, eight individual interviews were conducted with four male and four female participants from the focus group interviews. The objective of individual interviews was to delve more deeply into the personal characteristics and histories of these research participants. The following questions were asked in individual interviews. 
1. Tell me a little bit about your family background. Where are you from? Were you raised by both parents? Socio-economic background? Rural/urban surroundings? School experiences? Church experiences? Other interests/organizations growing up?

2. When do you recall first becoming involved in service? What was your motivation for that? Did you continue with it through high school? Would you say that you have volunteered more or less since coming to college? Why do you think that is?

3. What are your current career aspirations? Have these changed over time? During college years? Have your service experiences impacted your aspirations? If so, how?

4. Do you find yourself drawn more toward relationships or autonomy/independence? Has this changed during college? Have your service experiences impacted this leaning?

5. Which concept would you say motivates you more toward service - the concept of justice or caring (define each)? Why do you think this is? Do you see this same leaning in others? Is there something that causes this predilection, do you think? If so, what might that be?

6. Let's talk about the qualities of empathy and nurturing. Based on your understanding of these concepts, are these things that come easily to you or not? Why or why not? When, where, and from whom do you feel that you learned any amount of these qualities? 
7. Lastly, let's talk about your sense of self and identity. How has this changed during your college years? How has this changed, if at all, in relation to your service involvements? Do you think that service helps to forge a sense of self? Why or why not? If so, how?

All interviews were transcribed verbatim by a transcription assistant approved by the Institutional Review Boards for the research sponsoring and site institutions. All records and data related to this phase of the research were stored in a locked file cabinet in the office of the researcher.

Analysis of the data followed the guide for data analysis provided by Creswell (1998). Initial open coding of the data gave way to axial coding, wherein codes were organized and sorted into categories based on their properties and similarities. Constant comparison was used throughout the coding process between participant responses and the coding, coding and categories, and categories and participant responses. Thematic categories were used to construct the survey for phase two of the research. These categories did to some extent also guide the focus of individual interview questions above, as open and axial coding had been completed by the time individual interviews were conducted (just prior to or in some cases concurrent with the survey research).

\section{Quantitative Phase}

In the quantitative phase, a 14-question survey instrument was developed from emergent themes of the qualitative phase of the research (Appendix D, pp. 206-215). The survey was distributed online to 1004 full-time undergraduate students at the research site, with four hundred and forty-seven complete responses (see Tables 6-8, pages 57-58 for demographic breakdown of respondents). Students received an e-mail invitation to 
participate and informed consent notice, along with a clear statement of the voluntary nature of their participation. No incentive was offered for completion.

The survey was tested first with participants from the qualitative phase. Participants had previously reviewed themes from focus group interviews and had affirmed these as consistent with their assessment of themes in focus group discussions. During survey construction they were asked to review the survey and comment on whether and to what extent questions and possible responses were reflective of these themes. The survey instrument was also reviewed by two professional faculty colleagues and experienced researchers at the research site, one the director of the social research center housed at the institution. Finally, the survey was reviewed by staff members at Qualtrics, Inc., the online survey software company used for survey distribution.

\section{Data Analysis}

In keeping with an exploratory mixed methods research design, data analysis was done in two phases linked sequentially to the qualitative and quantitative phases of data collection. Analysis followed the format established by Tashakkori and Teddlie (2003) for data analysis in an exploratory mixed methods design. Their sequential QUALQUAN analysis methodology calls for the identification of groups of individuals who are similar to one another in some respect in the qualitative phase (p. 133). These identified groups are then compared to one another on the QUAN data collected in the second phase of the research. In this case participant groupings were established based on gender, year in college, and amount of service performed. Comparisons were then made in the quantitative phase relative to other variables identified in the qualitative phase of the research, as described in Chapter Four. 


\section{Qualitative Phase}

Qualitative data analysis began with a careful transcription of single gender focus group interviews. Transcriptions were done by a paid research assistant approved by IRB reviews at both institutions - sponsor and site. Member checks were done with four participants (2 male, 2 female); all participants agreed with the accuracy of the interview transcriptions.

The researcher then followed the systematic process (Strauss \& Corbin, 1990) outlined by Creswell for analysis of qualitative data in the constructivist paradigm (Creswell, 2007). This began with an open coding process to identify categories or common themes of response from participants in each of the single gender focus groups. Constant comparisons were made between the codes generated and data gathered in the interviews in order to begin filling out the categories and verify relationships. The researcher then moved to axial coding of data from single gender focus groups in an effort to reassemble the data broken apart in the open coding process. At this stage the researcher utilized the memo-writing process described by Charmaz (2000) as a way to record and analyze ideas about emergent themes from the data.

Selective coding was employed in the final stage of this portion of the data analysis in order to flesh out or develop a thematic "story line” (Creswell, 2007, p. 67) hypothesizing emergent themes and relationships in the qualitative data from single gender focus groups. These themes then served as the basis for a mixed gender focus group discussion wherein participants (6 each from the single gender groups) were asked to comment and reflect on the accuracy of the themes based on their experiences and the earlier focus group discussions. This served to provide member checking regarding the 
themes and to further expand and add to them. The process above was repeated from the axial coding stage on following transcription of the mixed gender focus group. Resulting themes were then utilized for construction of the survey instrument to be utilized in the quantitative phase of the research.

Finally in this stage, verbatim transcriptions of individual interviews were also analyzed for additional emergent themes and to further flesh out the "stories" of ten of the individual participants from the focus groups - five men and five women. Participants were selected as volunteers from the original focus groups (see Table 5, p. 57 for a breakdown of participants by age, gender, and year in school). These interviews were designed more as ethnographic inquiries in an effort to provide additional in-depth background data about a select few participants for later use in discussion findings.

\section{Quantitative Phase}

In the quantitative phase, survey data were analyzed in several ways. As described below, factor analysis and coefficient alpha tests were first run to measure internal reliability of the survey instrument. Following successful establishment of reliability several steps were taken in the data analysis process. These steps focused on hypothesis testing of the three null hypotheses stated previously.

Cross tabulations were run separately for each independent variable - gender, year in college, and hours of service. The Chi-Square test for independence was utilized to test whether or not relationships existed in the case of the independent variable gender. The chi-square test is a measure of how well the data fit the hypothesis (Gravetter \& Wallnau, 2005, pp. 465-475). In this case the null hypothesis for gender was that there 
was no relationship between gender and other variables being measured. The chi-square test was specifically chosen for gender because of the nominal nature of the data.

One assumption underlying use of the chi-square statistic is that all cells contain expected frequencies of at least five (Gravetter \& Wallnau, 2005, p. 476). At frequencies less than five for the chi-square, the possibility of Type I error is increased. An initial run of the test for gender indicated twelve cells with an expected frequency less than five. An adjustment was made by collapsing the two cells at the bottom of the measurement range on a five-item Likert scale for five of the questions ('Not at all'/Very little') into a single measure. This resulted in a reduction of the number of cells with an expected frequency range $<5$ to one. Continuity corrections to significance measures were calculated for the remaining two non-Likert measurements. These were reported in the data analysis.

For the independent variables of year in school and hours of service, the Spearman test for correlation was utilized. Spearman was selected due to the ordinal nature of the data for these variables and as a means to avoid concerns described above regarding expected frequencies (an initial run of the chi-square test for these variables indicated similar problems on a larger scale, particularly for hours of service, with six ordinal categories of measure). Outcomes for both the chi-square and Spearman tests were evaluated for statistical significance at an alpha of 0.05 .

Data were first subjected to a Pearson Chi-Square correlation test via a cross tabulation procedure. The chi-square test for independence was utilized to test whether or not there was a relationship between variables (Gravetter \& Wallnau, 2005, pp. 465-475). The null hypotheses speculated no relationship between the variables being tested. Three independent variables were identified for three separate cross tabulations, coinciding with 
the research questions and hypotheses. Cross tabulations were run separately for gender, year in college, and amount of service performed, with chi-square scores arrived at for all other variables. Outcomes were evaluated for statistical significance at an alpha value of 0.05 .

\section{Verification Procedures}

As pointed out by Creswell, the act of combining qualitative and quantitative data raises a number of validity questions unique to the mixed methods design (Creswell, 2004). Mixed methods research validity has been identified by others as in many ways the most important aspect of the research project (Tashakkori \& Teddlie, 2003). What makes it so seems in part to stem from the very act of mixing the data types. Even more potentially problematic in the exploratory mixed methods design is the use of data from the qualitative phase as the foundation and basis of the quantitative phase. Without some measure of validity of the qualitative data, the entire research enterprise risks being seen as a house of cards, with unreliable data derived from unreliable data.

A number of recommendations guided the researcher's approach to validity testing in this study (Creswell \& Plano Clark, 2007). These included:

- report and discuss validity within the context of both quantitative and qualitative research;

- define validity, in the scope of a mixed methods study, as the ability of the researcher to draw meaningful and accurate conclusions from all of the data;

- view the triangulation of data types as a strength of the research that can lead to better than either dataset might have furnished individually (sometimes 
referred to as ‘consequential validity’ or ‘triangulation validity', Creswell and

Plano Clark, 2004, p. 146); and

- discuss potential threats to validity inherent to each stage of the research.

A summary of potential threats to validity in mixed methods research and

means of minimizing risks is provided in Table 10.

Table 10

Potential Threats to the Validity of Sequential Designs in Mixed Methods Research

\author{
Sequential Designs \\ (Explanatory, Exploratory, Embedded)
}

Minimizing the Threat
Data collection issues

- $\quad$ Selecting the same or different individuals for the qualitative and quantitative data collection

- Using the same sample sizes for the qualitative and quantitative data collection

- Not choosing participants for the follow-up who help explain significant results

- Not designing an instrument with sound psychometric (i.e., validity and reliability) properties

Data analysis issues

- Choosing weak quantitative results to follow up on qualitatively

- Choosing weak qualitative findings to follow up on quantitatively

- $\quad$ Not addressing validity issues
- Select the same individuals for an Explanatory Design and different individuals for the Exploratory Design

- Use large sample for quantitative and small sample size for qualitative

- Choose same individuals for the qualitative follow-up and the quantitative first phase

- Use rigorous procedures for developing and validating the new instrument

- Choose significant results or strong predictors to follow up on

- Use major themes as the basis for the quantitative follow-up

- Address both quantitative and qualitative validity

Source: Creswell \& Plano Clark (2004, p. 148) 


\section{Qualitative Validity}

Verification procedures, or validity, in qualitative research ensures that the study accurately understands the knowledge and meaning of that which is being examined or explored. In other words, verification procedures provide a degree of confidence that the researcher "saw what s/he believes s/he saw" during the research. These procedures provide confirmation that the constructs, categories, explanations and interpretations of the research and of the phenomenon being studied are accurate (Creswell, 2007, pp. 207209).

Specific verification procedures employed for the qualitative phase of this study included triangulation, member checking, and peer debriefing. Triangulation of data collection was achieved through single and mixed-gender focus groups and individual interviews. Member checking involved asking participants to review draft findings and emerging themes from the research to assess and garner feedback about the accuracy of the interpretations. Peer debriefing was performed as an external check of the research by a graduate colleague, who reviewed and asked questions about the research to ensure that the study made sense and that researcher interpretations from the data were plausible and accurate.

External audit of the study was performed by a colleague at the research site, director of the Social Research Center. The audit process involved a full review of all files and records of the study along with a review of data analysis and interpretation strategies and outcomes of the study. A report from the auditor appears in Appendix E (pp. 216-218). 


\section{Quantitative Validity}

The survey instrument developed in this study was subjected to review for content validity by two external experts and faculty colleagues at the research site, one the director of the Center for Social Research. The survey was also reviewed by a technical assistant of the survey distribution company, Qualtrics, Incorporated, a leading survey software company. Participants in the qualitative phase of the research also reviewed the survey prior to its distribution, confirming an accurate representation of the themes discussed in the qualitative phase of the research.

The researcher consulted with staff of the Nebraska Evaluation and Research Center (NEAR) in the data analysis phase to determine with reasonable assurance the construct and predictive validity of the instrument. Construct validity was determined in the quantitative phase following Tashakkori and Teddlie’s guidelines to statistically analyze data in this phase to either confirm or expand the inferences obtained in the qualitative phase (2003, p. 134).

Reliability and internal consistency of the survey instrument were confirmed by factor analysis and calculation of the coefficient alphas for all questions. The Cronbach's Alpha scores for all ordinal data questions ranged from a low score of .962 to a high of .997, yielding a high level of confidence that the instrument indeed measured the construct of community involvement consistently across participants. Scores for individual questions are displayed in Chapter Four.

\section{Ethical Considerations}

The researcher and research participants practiced reciprocity throughout the research (Hatch, 2002). The researcher was explicit with participants about the purpose of 
the research project. Participants were guaranteed confidentiality in return for honest, candid, and open responses to research questions. Aliases were provided to protect anonymity of research participants (Creswell, 2007). Parameters of this reciprocity are identified in the informed consent letter approved by the Internal Review Board both of the university and the research site; all aspects of the research protocol were disclosed and approved. Participants were assured both anonymity and confidentiality of responses and were afforded the opportunity not to have information that they furnished included in the final report of the study. 


\section{Chapter Four}

\section{Findings}

\section{Overview}

In this chapter, the purpose of the study and research questions are reviewed, followed by an overview of qualitative questions asked during focus group and individual interviews. Analysis is then provided of the qualitative data. This is followed by an overview of the quantitative survey instrument construction and administration and an analysis of quantitative data.

\section{Introduction}

The purpose of this study was to add to our understanding of the motivations toward service among college students, to get a clearer sense of how students choose their particular service involvements, and to better understand the learning outcomes from service involvement during college. Underlying philosophical assumptions of the

study were that service involvement during college contributes in several positive ways to student development, and that student descriptions of their motivations, choices, and learning from service vary based on gender, year in college, and amount of service performed.

The first phase of the research was a qualitative exploration of these questions via focus groups and individual interviews with 24 college students in a small, Midwestern liberal arts college. In the second phase of the research, emergent themes from these interviews and focus groups were utilized to develop a survey instrument to test a series of hypotheses that relate to possible differences in how students describe their motivations toward service, choices of service involvement, and learning from service 
based on gender, year in college, and amount of service performed. One thousand students at the same small liberal arts college were surveyed in the quantitative phase.

The central research question for this study was: How do students describe their motivation toward service involvement during college and the learning outcomes of their service involvement?

Three specific qualitative research questions flowed from this central question:

1. What factors motivated students to become involved in service during college?

2. How did students in the study choose their particular service involvements?

3. How did students describe the learning outcomes from their service involvements?

Three additional emergent questions were explored in the quantitative phase of the research following completion of the phase one qualitative inquiry:

1. Is there a difference in how students describe motivation to serve, selection of service, and learning outcomes from service based on gender?

2. Is there a difference in how students describe motivation to serve, selection of service, and learning outcomes based on year in college?

3. Is there a difference in how students describe motivation to serve, selection of service, and learning outcomes based on amount of service performed?

The specific research hypotheses corresponding to these questions were:

1. There is a difference in how students describe motivation to serve, selection of service, and learning outcomes from service based on gender. 
2. There is a difference in how students describe motivation to serve, selection of service, and learning outcomes based on year in college.

3. There is a difference in how students describe motivation to serve, selection of service, and learning outcomes based on amount of service performed.

These are restated here as they were in Chapters One and Three in the traditional null hypothesis format:

H1. There is no difference in how students describe motivation to serve, selection of service, and learning outcomes from service based on gender.

H2. There is no difference in how students describe motivation to serve, selection of service, and learning outcomes based on year in college.

H3. There is no difference in how students describe motivation to serve, selection of service, and learning outcomes based on amount of service performed.

\section{Qualitative Phase}

\section{The Participants}

Twenty-four participants were selected in this phase of the research from a single research site, a small private Midwestern liberal arts college described in Chapters One and Three, utilizing a purposeful sampling strategy (Patton, 1990). Criteria for selection were as follows:

- Participant must be enrolled full-time as an undergraduate student at the research site.

- Participant must have participated in service for a minimum of 25 hours in the current school year. 
- Participant must be 19 years of age or older.

- Participant must complete an informed consent and agree to participate in recorded (video and audio) focus group interviews.

- Participant mix must be roughly equal numbers men and women.

In participant selection for individual interviews, four male and four female participants were purposefully selected from the original pool of 24 participants according to the following criteria (see Table 6, p.51):

- Participant must meet all selection criteria for focus group selection.

- Participant must complete an informed consent and agree to participate in recorded (audio) individual interviews.

\section{Analysis of Focus Group Responses}

Focus group questions were each coded and analyzed independently. Questions are listed below first for single gender focus groups, then for the mixed gender focus group discussion. Each question is followed by a discussion of responses. Tables are provided wherever axial coding exposed distinct categories across properties and dimensions and where the question bears directly on the central research questions of the study. Tables do not provide weighted responses for the specified dimensions. A weighted summary of coded responses is provided in Appendix F (pp. 219-222). Where there were discernible differences in response patterns based on the three independent variables of gender, year in school, or amount of service performed these are highlighted by incorporating memo references to such differences. No attempt was made at this stage of the data analysis to report these differences in table form. Direct quotations were frequently provided to support the data analysis. 


\section{Single Gender Focus Group Findings}

Question \#1: Let's talk about service in general - what the term means to you, how you define the term, whether there are various ways to 'define' service. Specifically, what comes to mind for you when I use the term "service?" Definitions of service varied fairly widely among participants. Initial open coding of responses yielded multiple codes. These were analyzed and compared across participant responses to yield 12 different definitional dimensions. Further comparisons resulted in categorizing these 12 dimensions into 3 definitional properties: contributing to others, sharing skills and knowledge, and improving self. Table 11 shows how the twelve dimensions supported the three properties for definition of service.

Table 11

Coding Definition of Service

\begin{tabular}{|c|c|c|}
\hline Category & Properties & Dimensions \\
\hline \multirow[t]{3}{*}{ Definition of Service } & Contribute to Others & $\begin{array}{l}\text { Change the world } \\
\text { Meet a need } \\
\text { Provide for others } \\
\text { Accomplish a good }\end{array}$ \\
\hline & Share skills/knowledge & $\begin{array}{l}\text { Share gifts } \\
\text { Use skills } \\
\text { Teach others } \\
\text { Provide for others }\end{array}$ \\
\hline & Improve Self & $\begin{array}{l}\text { Follow one's heart } \\
\text { Learn from others } \\
\text { Listen to others } \\
\text { Find one's self }\end{array}$ \\
\hline
\end{tabular}

The three properties were roughly equally weighted in participant responses taken as a whole. Men tended to concentrate their responses more notably within the property 
of sharing skills and knowledge, while women's responses were more heavily concentrated within the properties of contributing to others and improving self. For hours of service, the greater the number of hours served the higher the concentration of responses within the properties of 'sharing skills and knowledge' and 'improving self.' There was little variance in responses based on year in school.

There was much discussion particularly in the male focus group discussion about the ‘self versus other’ dynamic of service. Men particularly seemed to view service to others as an enactment of a duty or responsibility to share their skills or gifts with others. Examples of statements made by men in support of this notion of duty or responsibility included the following: "service is something you should do for the community," "it’s just my responsibility if I am able to do it,” and “it’s my duty to share my skills and talents with others, that's just how I was brought up.” And while there was no clear opposition to the reciprocal nature of service - the sense that the one serving gains as well - men did not focus in any strong way on this dynamic of the service relationship outside of a fairly common acknowledgment that engaging in service gave them a "good feeling” about their contributions and a better sense of their place in the world.

Accomplishment was also a key definitional dynamic for men in the discussion of service and its definition. Service "just gives you a nice feeling of 'wow, I accomplished this or got this done,"” summarized a common thread of discussion among men focused on service as 'getting things done.' This was consistent with the male focus on sharing skills and knowledge. The overarching theme that emerged in male discussion of the definition of service was one of 'I have something to offer, give, or teach, and something will be accomplished by my sharing that with others.' Further, men spoke about the 
offering of the skill or gift as a somewhat obligatory duty based in their familial, religious, or educational upbringing.

In contrast, women were more likely in their responses to focus not on obligation, but on reciprocation. Women characterized service more as a voluntary giving and getting back, with rewards more intrinsic than extrinsic. They focused in their comments less on service as accomplishment and more on service as growth for self and the other(s) in the service relationship. Relationship was a key aspect of women’s definition of service, both in terms of motivations to serve (to be covered later) and in terms of the very definition of service. Service was defined by many women as the act of learning from and listening to the other. In common with men, women spoke about the broadening of sense of self and one's place in the world, but for women this emerged as a central definitional aspect of service.

Service is about "connecting to self and reflection," according to one woman. "I think that we're just so connected as human beings that in order to fully understand our humanness we all need to learn how to take care of each other,” said another. This statement summarized a host of similar statements about the definition of service in the women's focus group discussions. The idea being presented here was that service is an embodiment of what it means to be in the world as a caring human being. The concept of caring received much attention in women's discussion of service, again in some contrast to the male discussion of duty. Chapter Five devotes considerable attention to this distinction, among several others.

As will be discussed later in this Chapter and in Chapter Five, the constant comparative analysis of focus group responses was done both within and across 
questions. Some of the properties and themes discussed above resurfaced across several questions in the focus group phase of the research, both in terms of gender differences and in terms of commonalities among respondents. These themes, in turn, were utilized and further explored in the second, quantitative phase of the research, as will be discussed.

Question \#2: You have each been selected to participate in this study and this focus group interview on the basis of your prior participation in service during your time in college. Tell me how you decided to become involved in service? What motivated you to serve and how did you choose what project/issue to become involved with? This question essentially involved two constructs within the overarching topic of service involvement - those of motivation to serve and choice of service involvement. The researcher acknowledges the complexity of addressing two constructs within the framework of a single question and, for the sake of ease of interpretation and analysis of results, would have broken this into two distinct and separate questions if repeating the research. Analysis below was done as if this had been two questions; responses are categorized separately in Tables 12 (p. 82) and 13 (p. 85).

In responses to this question, many similar responses to those in Question 1 about definition of service emerged. When discussing motivation to serve, respondents’ descriptive language about service was naturally similar to their descriptions of service itself (e.g., if a definition of service for a given student was “contributing to others," it was not surprising to learn that a motivation to serve for that same individual might be “to contribute to others”). Still, the researcher did and does consider these two separate 
constructs worthy of separate measure - one definitional and the other descriptive of motivating factors.

Table 12 shows findings for the first portion of the question - what motivated you to serve.

Table 12

Coding Motivation to Serve

\begin{tabular}{|c|c|c|}
\hline Category & Properties & Dimensions \\
\hline \multirow[t]{4}{*}{ Motivation to Serve } & Requirement & $\begin{array}{l}\text { Class requirement } \\
\text { Team requirement } \\
\text { Part of a student organization }\end{array}$ \\
\hline & Develop Skills/Career & $\begin{array}{l}\text { Gain leadership skills } \\
\text { Add to resume } \\
\text { Explore a career field }\end{array}$ \\
\hline & Intrinsic & $\begin{array}{l}\text { Gain a sense of meaning } \\
\text { Desire to contribute } \\
\text { Fulfill a responsibility } \\
\text { Calling or duty }\end{array}$ \\
\hline & Extrinsic & $\begin{array}{l}\text { Social justice or inequity } \\
\text { Accomplish a good } \\
\text { Friends' involvement } \\
\text { Past experience }\end{array}$ \\
\hline
\end{tabular}

As can be seen, coded responses sorted into four fairly distinct properties of requirement, skill development, intrinsic, and extrinsic motivation. An argument can be made that the second property, that of skill or career development, is an extrinsic motivator. To the researcher there was qualitative difference enough between the dimensions of skill and career development and those of addressing inequities and injustices to treat these as properties distinct from one another. In the same way, one could argue that some dimensions under the extrinsic property can be thought of as 
intrinsic motivators. The coding distinction here for the researcher was in the language used to express each dimension, as discussed below.

Of the 14 overall dimensions in the category of motivation to serve, past experience was the most commonly reported motivational factor leading to respondents' involvement in service in college. This was not a surprising finding, given research cited in Chapter Two indicating a predisposition to serve based on previous service experiences (Jones \& Hill, 2003; Sax, 2008). Leading motivating factors reported by men in focus groups were service as part of a team, class or student organization, followed by the desire to gain leadership skills, past experience, and friends’ involvement. For women, feeling strongly about a cause or issue, gaining a sense of meaning, and a desire to contribute were the leading motivating factors for involvement.

Students in the sample were more likely as sophomores (there were no freshmen in the sample) to become involved for extrinsic reasons (part of a team or class requirement) than for intrinsic reasons (sense of meaning, desire to contribute). This trend was confirmed in the quantitative phase of the research and is discussed in some depth in Chapter Five. One senior summed up this trend this way:

As a freshman I was less confident, more confused and uncertain about what I had to offer; if it wasn't for someone making me get involved in service I probably wouldn't have. As a senior I have a clearer sense of what I have to offer and of my responsibility to give back to those less privileged than me. I realize that it is a luxury for me to be able go to college; I just have more of a desire to contribute now than before.

This trend held even for those with past experience in service. Research has shown that even though past experience is a strong predictor of future involvement in service, service involvements tend to at least initially decline among college students early in their college careers when compared to their reported levels of service during 
high school (Sax, 2008, p. 43, Table 2.10). More discussion of this trend occurs in Chapter Five.

Gender differences were less pronounced in response to this question than the previous question. As mentioned above, men tended toward the properties of required service and service for skill development, while women tended to report motivating dimensions contained in the intrinsic and extrinsic properties. These differences were not pronounced, but note was made of the differences by the researcher in memo form for further investigation in latter stages of the qualitative phase of the research and in the quantitative phase.

The second part of this question asked students how they chose their particular service involvements. Here the fact that some students reported service as a requirement might have confounded the notion of choice-making, but this turned out largely not to be the case. Even in those cases where service was done as a requirement, the researcher found that students often had some say in what type of service project was undertaken or had a choice among several projects.

Table 13 (p. 85) describes the dimensions and properties which emerged from the coding of data in the category of choice of service involvement.

Male respondents tended toward dimensions of choice-making contained in the properties of skill matching, type of project, and outcomes. Female respondents tended toward those contained in subjective interest as well as outcomes. Data coding suggested in this case that men in the sample tended to make choices about their service involvement based on an objective assessment of their skills, the application of these to a 
Table 13

Coding Choice of Service Involvement

\begin{tabular}{lll}
\hline Category & \multicolumn{1}{c}{ Properties } & \multicolumn{1}{c}{ Dimensions } \\
\hline Choice of Service Involvement & Match of Skills & $\begin{array}{l}\text { Right skills for the job } \\
\text { What I could offer } \\
\text { Career related }\end{array}$ \\
& & $\begin{array}{l}\text { Physical nature of work } \\
\text { Type of Project }\end{array}$ \\
& $\begin{array}{l}\text { Social nature of work } \\
\text { One-time project } \\
\text { Ongoing commitment }\end{array}$ \\
& Subjective Interest & Passion for the cause \\
& Importance of need \\
& What I could learn \\
& Personal interest \\
& Friends were involved \\
& Potential for impact \\
& Breadth of impact \\
\hline
\end{tabular}

specific project, and the potential for impactful outcomes of their service. One male respondent put it this way: "I have limited time. I'd like to be sure when choosing a service involvement that it is something I'm good at, a project that can use my skills, and one where we'll get something accomplished.”

Contrasting quotes from female respondents included references such as these: "it has to be something that moves me," "I chose a project that just interested me," "my friends were involved," and "I just want to give my time where the most need exists.” As in the first section of this question related to motivation to serve, some discrepancies emerged based on year in college. Sophomores were more likely to cite subjective interests and were less likely to be outcomes driven or concerned with matching skills to the project in their choice-making process than were seniors. This discrepancy emerged 
also in the quantitative phase of the research and is discussed later in this Chapter and in Chapter Five.

Question \#3: Have you felt that there have been either internal or external motivations to serve while in college, and what are those, if any? Similarly, have you felt there to be either external or internal inhibitors to serve, and what are those, if any? This question was less central to the research question and asked more as a practical matter of exploration of incentives and disincentives to serve among respondents in their particular college setting. The premise for asking this question related to a stated assumption of the research - that involvement in service during college is beneficial to students - and as a means to explore students’ own perceptions of structural motivations or obstacles to service in the research setting - a typical small private liberal arts college. Analysis of responses to this question were abbreviated and were not presented in table form.

The chief items listed as obstacles to service among respondents were lack of time, student apathy, not being aware of service opportunities, and not being invited to serve. Chief structural motivational factors were predictably somewhat the opposite of these, with course requirement leading the list, followed by requirement of a team or student group, well-established, visible, and accessible means toward involvement (e.g., community service office, volunteer opportunity postings, presentations about social issues and how to become involved, etc.). These structural aspects of motivations toward or impediments to service are returned to in the discussion and recommendations section of Chapter Five. 
Question \#4: How would you describe your learning from the service experience(s) that you have been involved in? How have these experiences changed or impacted you in the short term or long term, if at all? This question, like Questions 1 and 2, was central to the key research questions of the study. With this question, the researcher sought to explore themes central to students’ self-reported learning from service. Discussion in focus groups was rich and yielded a number of themes common to all respondents as well as several themes of learning more particular to specific segments of the respondent group. In almost all cases respondents reported more types of learning, and deeper levels of learning, based on hours of service performed. In other words, learning correlated positively with service involvement - the more service, the more reported learning.

Table 14 summarizes the central thematic dimensions and properties of the category of learning from service.

Table 14

Coding Learning from Service

\begin{tabular}{|c|c|c|}
\hline Category & Properties & Dimensions \\
\hline \multirow[t]{4}{*}{ Learning from Service } & Interpersonal Learning & $\begin{array}{l}\text { Learned about others } \\
\text { Learned about myself } \\
\text { Learned about relationships }\end{array}$ \\
\hline & Organizational Learning & $\begin{array}{l}\text { Learned about leadership } \\
\text { Learned about organizations } \\
\text { Learned about community }\end{array}$ \\
\hline & Social Justice Learning & $\begin{array}{l}\text { Learned about justice } \\
\text { Learned about social issues } \\
\text { Learned about duty }\end{array}$ \\
\hline & Emotional Learning & $\begin{array}{l}\text { Learned about caring } \\
\text { Learned about love }\end{array}$ \\
\hline
\end{tabular}


Nearly all respondents reported learning in more than one of the properties described above. Most prevalent was learning related to one’s place in the world, captured most specifically in the two dimensions of learning about self and learning about community. Nearly all participants in the focus groups, regardless of gender, year in school, or amount of service performed either commented on or responded positively to comments about this type of learning. Comments contained statements such as: "I learned about my place in the world; how my actions affect others," "service made me see how my life connects to the lives of others,” we're all interconnected; service helped me to see that," and "service has helped me to see that it doesn't all revolve around me.” These statements bear a direct connection to key aspects of student development theory and the relationship of service and development explored in depth in Chapter Five.

Women in the sample reported their learning from service to be concentrated within the properties of interpersonal learning and emotional learning, although not exclusively or universally. Some spoke of their learning about social justice and social issues. The majority, however, described their learning from service as being about self, others, caring, community, and love. The researcher recalled the statement made by a female participant in the pilot study, who when asked what she had learned about service said simply "I learned what love is.” This question evoked many similar statements from the women who participated: "being in service to others teaches about love and caring, about what it means to just be in the world," "I learned more about myself than in any class I’ve taken in college,” and “it’s amazing to watch the power of love and caring unfold - and it goes both ways - when you get out and work with others in need.” 
Men reported learning within these properties of interpersonal and emotional learning as well, but tended to concentrate their responses more within the properties of organizational and social justice learning. Men in the sample reported learning chiefly about leadership, social issues, duty, and justice. They spoke about righting societal wrongs, about their duty or obligation to contribute, and about the importance of leadership - again most commonly as the fulfillment of obligation. One male student summed it up this way.

If I see a wrong, something unfair, and I have the ability to impact that person or situation and I do nothing, then I have failed as a person and as a leader. It's just how I was brought up - it's my duty to offer what I have, particularly where an injustice is there. If I don't act I have failed.

This sense of duty and obligation pervaded male discussion of their learning in both positive and negative ways. Men in the sample were more apt than women to report frustrations from their service experiences - frustrations about being unable to "fix" the problems that their service was designed to address. This is perhaps not surprising given the earlier discussion of motivations for service, where men were more apt to focus on outcomes of service and potential for impact than women when choosing their service commitments. Women in the sample were more apt to discuss their experiences as process oriented experiences leading to learning about how to be in relationship and to reflect on the relationship of self to other. Men were more apt to assess their learning and the quality of their service experience in light of what they were able to accomplish in the experience. More discussion of this occurs below in response to question five, later in this chapter in analysis of the mixed gender focus group discussion, and in Chapter Five in discussion of findings. 
Question \#5: Please talk about what you think were the most positive aspects of your involvement in service. What were the most challenging or negative aspects, if any. As in the case of Question 3, this question was less central to the research questions and aimed more at fully understanding students’ experiences in service. Question 3 sought to explore perceived obstacles of incentives to service in college among the sample population. This question similarly sought to understand perceived challenges and successes of the service experiences themselves as reported by students.

Returning to comments made by students in Question 4, most students commented or agreed with comments that one negative aspect of their service experience was a feeling of frustration or futility that their involvement did not 'solve' or 'fix' the problem(s) at hand. This was sometimes expressed as a feeling of hopelessness and even anger about the apparent intractability of the larger social injustice issues in play: "it was all well and good to package lunches for the homeless three Saturdays in a row, but what about the larger issue of why people are hungry and homeless in this country while others have so much?” Students sometimes voiced a concern even about whether their service efforts added to or somehow enabled the larger issue or issues of inequity to persist: "I wonder sometimes if by doing this volunteer work we are just making it possible for injustices to continue - you know, we don’t have to question policies or reduce housing costs, someone will step in and help out.”

Still, some students pointed to the very fact of discovering the inequity as a success of their service experience, something that would empower them to become more involved at deeper levels. One student put it this way.

I hear the argument that we're just providing a band-aid and that we're often not doing anything to address the larger issues of poverty, homelessness, 
environmental waste, or hunger. But I look at it this way. In order to apply a band aid I have to look at the wound, to stay with that metaphor. And by looking at the wound I have an opportunity to use this as a wake-up call, you know? I think 'O.K., what can I do to prevent this same injury from happening again.' I can lobby for new policies, I can write my senator, I can pursue a career in environmental law ... you get the idea. I can decide to not resign myself to the problem, and I can remember that I might not have seen it or learned about it if not for service.

Other students took this challenge of discovery of the larger social issues and inequities through service as a more personal learning opportunity. “As hard as it is, I’ve learned how my actions affect someone half a world away - whether that's what I consume, how I spend my time, or where I focus my attention - it matters in ways that I previously didn’t think about.”

Students pointed to several other successes and challenges of their service experience, ranging on the success side from gaining leadership skills to feeling better about themselves. On the challenge side, students spoke about carving out and maintaining time for their service involvements, balancing that time with their studies and other interests, and frustrations with why their peers were not more involved. Students in the sample spoke openly about apathy as a problem, whether among their peers or in the broader culture. There was a palpable frustration with why more people are not involved in service and a related disappointment in the possibility that this non-involvement represents a tacit complicity with or approval of the perceived injustices at hand.

Question \#6: Finally, what do you think are important considerations for people involved in creating and providing service opportunities to think about? How can your experience help peers, educators, administrators in leadership roles in service programs to understand the important elements of designing these experiences? This 
final question of the single gender focus groups was designed with practical application in mind. Participants were selected for this phase of the study based on their involvement in service chiefly as a means to understand their motivations toward service and their learning from service. In a study with possible practical implications for involving students in service the researcher felt that it was important to ask students in this sample how practitioners might accomplish that aim. Suggestions and recommendations were many and are presented briefly here. Full discussion of these is presented in Chapter Five in the recommendations section.

One finding of the quantitative phase of the study was that men cite as the two chief reasons for their non-involvement in service that they are not aware of service opportunities and they are not invited to participate in service. This finding had a direct relationship to many of the suggestions and recommendations from students in response to this question. Universally, students indicated that service in college among their peers is best accomplished by creating and communicating opportunities for service. Some went further to suggest that service should be more routinely required as part of coursework, team sports, and by student organizations such as clubs, fraternities and sororities. Many students in the sample lamented the fact that few classes incorporated a service learning component and commented on the fact that the courses they had taken with a service component were among the most satisfying and challenging learning experiences they had had in college.

Students in the sample pointed to the fact that too often service in college is seen as the purview of certain students and not of others. Many of the students in the sample were part of a Vocation \& Values program that encouraged and supported service 
opportunities as a means of exploring the self, values, and life purpose. These students expressed concern that similar supports and encouragements did not exist more broadly at the research site: "Sometimes I worry that those students spending their time playing video games and living on Facebook are completely out of touch with the real world why is no one inviting them, challenging them, requiring them to get involved?” Other students were even more direct: "We are privileged to be here at a good private college; we should be required to give something back. Everyone here should be required to serve at some point as a graduation requirement.”

Other less invasive strategies for involving more students in service included the creation of special college-wide service days, providing more exposure in classes and through lectures and presentations about social needs and causes and ways to get involved in these causes, highlighting the accomplishments of student volunteers more regularly, and involving career services in the creation of service portfolios that would enhance students' overall portfolios for future job seeking and career pursuits. These and other suggestions and recommendations for practitioners are included in the recommendations section of Chapter Five.

\section{Mixed Gender Focus Group Findings}

This portion of the qualitative phase of the research built upon the work from the single gender focus group interviews and occurred chronologically after completion of the single gender groups. Six male and six female participants were selected for the single mixed gender focus group interview by self-selection. All participants in the single gender focus groups were invited to participate. Six men and six women accepted the invitation. The mixed gender focus group interview was roughly 75 minutes in length and 
occurred in a neutral location in the library at the research site. As in other phases of the research, participants were offered no incentive to participate; in this case food was provided for the meeting.

This section is reported on more briefly than the findings of the single gender focus groups. There was considerably less time spent in the mixed gender group and the findings were less central to the research questions. The main purpose for inclusion of a mixed gender focus group interview was to provide opportunity for men and women to discuss their service experiences and observations together. In this case the researcher also fed back to this group some of the results reported above in order to perform member checking of these findings. Finally, the mixed gender group was utilized as one means of verification of the validity of the survey instrument administered in the quantitative phase of the research. Tables are not presented in support of findings from the mixed gender interview.

Question \#1: I am interested in exploring whether you think that choices about service and learning from service are similar for men and women? To begin, do you think men and women define service similarly? Responses here revealed differences and commonalties in the definition of service among and between men and women. Men and women agreed that common definitions included the opportunity to provide for another. Both also agreed that men in the sample tended to focus more on service as a duty or obligation and women more as an expression of an internal impulse to care - not in an obligatory fashion, but as a natural expression of what it means to be human. Discussion about this difference yielded speculation about whether this was more a linguistic difference than a substantive definitional difference. One student asked "is there really a 
difference if I define service as an obligation or an impulse - is there that big a difference between those two words; don't they both express an internal sense of what I owe to others?” This discussion is taken up in the implications section of Chapter Five.

Both men and women also agreed that women in the sample had tended to define service more in reciprocal and process terms and less in terms of a one-directional providing for or outcomes, language more commonly used by men in the sample to define or describe service. One woman speculated with regard to this perceived definitional difference about how deeply ingrained gender-based thinking is and how this might be present in thinking about service: “women approach things more emotionally while men approach things more logically and rationally and I don't know if its wrong when you say that, but I think that.”

Question \#2: Do you think that men and women choose their service involvements for similar reasons, different reasons, or that there is no real basis in your experience for how men and women choose their service involvements? Here again men and women in the mixed gender focus group interview were privy to the data that had emerged from single gender focus groups regarding how students in those groups reported choosing service involvements. As in Question 1, there was general agreement among members of the mixed gender group that men tended to choose service involvements based more on potential outcomes and a drive to achieve social justice. “The guys feel like it's their duty to correct things and achieve justice," one woman remarked, "women are more apt to choose their involvement based on an emotional reaction, not a sense of power imbalance or a need to 'correct' something." 
A great deal of discussion occurred around this notion of emotional reaction as a choosing mechanism for service involvement. One male described his own experience this way:

I've seen starving children on TV and I have no emotional reaction to that whatsoever. I've been thinking about this a lot lately, but I will never know what it's like to be that starving child and in my head I logically can't get to a point where I can personalize that, but I can say in a very legalistic sort of mindset that whoever is placing those children in that situation needs to be stopped.

This was in contrast to this comment from a woman: "When I see starving kids on TV I think 'what if they were my kids' and I relate to it myself, very personally.” Another woman made this distinction in the motivation to serve and the notion of obligation or duty versus impulse to care: “The words 'have to' wouldn't describe how I choose a service involvement - I don’t think I have to fix something when I become involved, I just want to become involved.” A male student countered this way: "When I see hungry children, what makes me motivated is not that I'm sad, but I have to do it (become involved) because there is something that needs to be done, not because of any emotion.” This apparent distinction is returned to in the discussion of findings in Chapter Five.

Similarly, much discussion occurred around the concepts of process versus outcomes of service - framed often in terms of doing 'for' versus doing 'with.' That conversation was summed up by one male this way.

Charity is a kind of a swear word for me because of the connotations that I mentioned earlier about the paternalistic attitude that we need to go to these other countries and even in our own community and lift these people up because we are so high and mighty. This is different than finding some solidarity with who we help - the downtrodden or whatever we want to say about those we are working with. I see that more with women than I do with men. In our male focus group it was a lot like 'we need to go help these people and we need to go build this building or do this thing for them' as opposed to with women, who seem to say 'we should help them do this or work with them' and that is not as belittling. 
This apparent distinction is also a focus of discussion of findings in Chapter Five.

Question \#3: Do you think that men and women take different types of learning from their service involvements or again, that there is no basis in your experience to know or see this as a relevant question? Responses to this question centered more around commonalities than differences. All students in the mixed gender focus group agreed that service opportunities had provided them a means to learn about social justice issues, other people, and about themselves. They cited growth in skills and in knowledge about particular social issues. All students agreed that service had provided them with a very powerful vehicle for learning, in many cases more powerful than the learning that occurred in many classroom situations for them. One student provided a very common summary of this sentiment: "I learned more from that one service experience than I've learned in any single class here; I don't know why more classes don't require service as part of the learning experience.” This theme is explored further in the implications section of Chapter Five.

Question \#4: Based on your experience(s) in service, is it sensible at all to ask about or be interested in men's experiences in service and that of women? If so, in what way does it make sense to ask about possible differences or similarities? This question produced redundant responses to those already cited above in terms of perceived differences in how men and women in the sample thought about, defined, and made choices about service involvements. Men and women in the mixed gender group observed that it might make sense to be interested in or talk about these apparent differences if, in doing so, men and women could better understand their own approaches to service and/or better process their learning from service experiences. Responses to this 
question also anticipated the final mixed gender focus group question regarding designing service opportunities suited to both men and women. Men and women articulated a number of differential design factors for service opportunities based on gender, with the goal of maximizing the participation in service and learning from service for both men and women. These factors included opportunities for both one-time and ongoing service involvements, opportunities for service of a physical nature as well as a relational nature, requiring service as part of a class, team, or student organizations, and ensuring opportunities to process and discuss service experiences.

As a final activity of the mixed gender focus group participants were asked to review questions for a survey to be conducted in the quantitative phase of the research. Participants were told that the survey would be administered to all students at the research site and were asked to verify that the questions addressed themes and topics that had been discussed in either the single or mixed gender focus groups and that responses were consistent with the range of responses that had emerged in those focus group discussions. Participants were allowed to take the survey with them and were asked to respond to the researcher regarding the accuracy of both themes and potential responses. All participants contacted the researcher to verify that the survey accurately represented the themes and range of responses that had been covered in focus group interviews.

\section{Individual Interviews}

In the final portion of the qualitative phase of the research individual interviews were conducted with four men and four women from the sample for the qualitative phase. As in the case of the mixed gender focus group, participants self-selected for interviews. All participants in the mixed gender focus group were invited to participate in an 
individual interview. Four men and four women chose to participate. The interviews took place in the researcher's office at a time convenient to each interviewee. Interviews were approximately 45 minutes in length. Interviews were audio-taped and transcribed verbatim. For males, three seniors and a junior participated in individual interviews; for women participants included one senior, two juniors, and a sophomore. As in focus group interviews, no incentive was offered for participation in individual interviews.

The purpose of the individual interviews was three-fold. First, the researcher sought to do further member checking of the themes that had emerged from focus group interviews. This was done by asking participants in individual interviews to comment further and on a more individual basis about their own service experiences and to relate these to the themes that had been discussed particularly in the mixed gender focus group interview. Secondly, the researcher sought to gain a deeper understanding of these individuals' backgrounds, service histories, motivations for service, and the impacts of service on their sense of self and identity and on their life and career aspirations. Thirdly, the researcher sought to explore in-depth several of the themes that had emerged from focus groups - specifically caring, justice, empathy, and nurturing - as motivations toward and/or learning outcomes from service.

\section{Analysis of Individual Interview Responses}

A synopsis of individual interview responses is provided here. These responses are referenced also in Chapter Five throughout the implications section as a means to illustrate or otherwise augment points made in the interpretation of findings of the research. 
Question \#1: Tell me a little bit about your family background? Where are you from? Were you raised by both parents? Talk about your socio-economic background, rural/urban surroundings, school experiences, church experiences, other interests growing up. Among the eight participants in individual interview there was a roughly even split between those coming from larger urban areas and those coming from smaller, more rural areas, with a related split in the size of high schools attended. Nearly all participants reported having been raised by both parents in a middle class to upper middle class family. All participants reported regular attendance at church and involvement in youth activities of the church. Most reported their first experiences in service as being church or school affiliated, most often as part of a youth group. All were involved in clubs and activities in high school; most performed service throughout their high school years. All reported having been good students academically in high school.

Question \#2: When do you recall first becoming involved in service? What was your motivation for that? Did you continue with it through high school? Would you say that you have volunteered more or less since coming to college? Why do you think that is? Half of the eight students reported their first service experiences being in connection with church; two indicated that they began their service experiences in middle or high school as a school activity. The remaining two reported growing up doing service with their families. All reported doing service throughout high school, either with family, their church, or as a school activity. Responses to the question of involvement in college in comparison to high school were varied. Two students reported a decline in their service involvements in college due to time constraints. Two indicated an increase in their first two years in college and a decline in the last two years due to time constraints. 
The remaining four students reported service involvement in college at about the same or an increased level, but added that their service in college has been of a different sort or at a different level. All four indicated that their college service has been at a “deeper” level, with a greater understanding of the social issues being addressed and with more leadership-related activities.

Question \#3: What are your current career aspirations? Have these changed over time during your college years? Have your service experiences impacted your aspirations? If so, how? Students reported a number of changes to their career aspirations over time, none of these specifically related to their service involvements. Most changes resulted from a change in academic major and/or interests over time while in college.

Question \#4: Do you find yourself drawn more toward relationships or autonomy/independence? Has this changed during college? Have your service experiences impacted this leaning? This question derived from student development literature and preliminary results of focus group interviews. The researcher sought with this and remaining individual interview questions to explore several dimensions of student development and the possible relation of these to service involvement. In response to this question, six of eight individual interview participants cited independence and autonomy as more central to their lives at present. The remaining two indicated that relationships were more primary to their lives. Most students (7 of 8) reported some change over time during college, in most cases moving from relationships as primary to autonomy and independence as primary. One student reported no change in her focus primarily on the importance of relationships. None of the students reported any 
clear connection between their service involvements and their leaning toward either relationships or autonomy/independence or in their movements from one to the other focus. One male student comment, however, did link his answer back to service, recalling earlier comments about the basis of involvement in service particularly for men: "I’ve got to lean toward autonomy/independence. It (service) wasn’t really about the relationships or being around people; it was more towards doing good and helping and providing a service by putting my skills into action.”

Question \#5: Which concept would you say motivates you more toward service the concept of justice or caring? Why do you think this is? Do you see this same leaning in others? Is there something that causes this predilection, do you think? If so, what might that be? Reponses to this question yielded a distinct difference between men and women. All four of the men who responded identified the concept of justice as central to their involvement in service. For the women, caring was identified as the more central concept, but several also indicated that they felt some mix of the two concepts as motivators toward service or some movement from one to the other during their college years. One woman described the evolution of her thinking this way:

I think it (service involvement) started off as more towards the caring side of things, more toward the 'this is nice if we did this, this is something good - I'll feel good about it when I'm done with it, these are things that are manageable,' but I think I'm tending to move more in the direction of justice because I've realized how hard the system sometimes works against efforts of caring.

She went on to clarify her thoughts further.

I feel like in order for things to really change we have to address them at a level that's really going to change them and not merely find a remedy for a short period of time, which is what caring is. 
This conceptual difference between justice and caring as motivational factors toward service involvement was analyzed in the Chapter Five implications section both in terms of possible gender difference in motivation to serve and more broadly as a means to understand students' involvement in service.

Question \#6: Let's talk about the qualities of empathy and nurturing. Based on your understanding of these concepts, are these things that come easily to you or not? Why or why not? When, where, and from whom do you feel that you learned any amount of these qualities? Several trends were evident in responses to this question. First, men tended to report more familiarity and comfort with the concept of empathy than with nurturing. All students reported deriving these qualities, to the extent that they possessed them, from parents, most particularly their mothers. Students tended to define empathy as the ability to 'feel with' the other and nurturing as the ability to actively care in response to the perceived needs of the other. Six students - male and female - reported a growing sense of their ability to nurture and related this to their service involvements and a growing sense of their own maturity and capability in relationships.

This question sought to further explore concepts frequently linked to service and to assess the extent to which these qualities were present in the individual interview sample population. This was linked, in turn, to the researcher's interest in motivations toward service during college. Considerable attention was paid in Chapter Five discussion to these concepts as contributing factors to and learning outcomes from service. 
Question \#7: Lastly, let's talk about your sense of self and identity. How has this changed during your college years? How has this changed, if at all, in relation to your service involvements? Do you think that service helps to forge a sense of self? Why or why not? If so, how? The sample population for individual interviews contained four seniors, three juniors, and a sophomore. All students indicated that their sense of self and identity had changed during their college years. Four students of the eight in the sample indicated that their service experiences during college had been substantial contributors to their changing sense of self. One student described the changes related to service this way.

On the surface level I've become much more focused on social justice issues than I ever have been. That I think is a huge change in my personality and what I do and how I define myself than who I was in high school.

The same student recalled her concerns and fears about change during her college years.

I remember my senior year in high school being told by so many people that I was going to go to college and change and that would infuriate me. I hated being told I was going to change because I liked who I was. I did not want people to tell me that I was going to go to college and change. Why did I need to change? I mean, was there something wrong?

She answered her own questions in the course of the interview this way, "But I get it now. It's growing and experience and meeting people and being challenged - and that fosters change and that doesn't have to be a bad thing and I don't think it has been a bad thing."

Another student summarized the impact of service on his sense of self and identity this way.

I had a very singular sense of self when I came to college. I thought I knew who I was. Of course that is what a lot of people experience about college. In my case the calling toward service was a calling into poverty so deep that it can not be named. Nothing has power over it, so I just kind of gave up on this concept of self 
- like I'm not a single person, I don't need to be a single person to function in the world.

As for the previous conceptual questions, this question was returned to in the implications section of Chapter Five. In that section the researcher sought to interpret this implied relationship between service and identity development during the college years.

\section{Summary of Qualitative Findings}

A summary of Tables 11-14 is provided on pages 106-107. The properties and dimensions represented in these tables served as the basis for construction of the survey instrument used in the quantitative phase of the research, with the fourteen properties serving as the basis for the fourteen survey questions and the accompanying dimensions as response options in each case (see Table 15, pp. 106-107).

\section{Quantitative Phase}

Following completion of the single gender focus groups and initial coding and analysis of results, the researcher constructed a 14-question survey based on the emergent themes from the focus group data. The survey was subjected to member checks with participants in the mixed gender focus group and was judged by members of that group to be an accurate representation of the themes from focus group discussions.

\section{The Participants}

Sampling in this phase was by census, with all currently enrolled full-time undergraduates at the research site aged 19 and older invited by e-mail to complete an online survey regarding their service involvements, motivations, and learning outcomes. Invitation e-mails with a link to the survey were sent to 1004 prospective participants. Four hundred and forty seven students responded, for an overall response rate of $44.5 \%$. Among respondents 83\% (370) had participated in some form of service within the 
Table 15

Focus Group Coding Summary

\begin{tabular}{|c|c|c|}
\hline Category & Properties & Dimensions \\
\hline \multirow[t]{3}{*}{ Definition of Service } & Contribute to Others & $\begin{array}{l}\text { Change the world } \\
\text { Meet a need } \\
\text { Provide for others } \\
\text { Accomplish a good }\end{array}$ \\
\hline & Share skills/knowledge & $\begin{array}{l}\text { Share gifts } \\
\text { Use skills } \\
\text { Teach others } \\
\text { Provide for others }\end{array}$ \\
\hline & Improve Self & $\begin{array}{l}\text { Follow one's heart } \\
\text { Learn from others } \\
\text { Listen to others } \\
\text { Find one’s self }\end{array}$ \\
\hline \multirow[t]{4}{*}{ Motivation to Serve } & Requirement & $\begin{array}{l}\text { Class requirement } \\
\text { Team requirement } \\
\text { Part of a student organization }\end{array}$ \\
\hline & Develop Skills/Career & $\begin{array}{l}\text { Gain leadership skills } \\
\text { Add to resume } \\
\text { Explore a career field }\end{array}$ \\
\hline & Intrinsic & $\begin{array}{l}\text { Gain a sense of meaning } \\
\text { Desire to contribute } \\
\text { Fulfill a responsibility } \\
\text { Calling or duty }\end{array}$ \\
\hline & Extrinsic & $\begin{array}{l}\text { Social justice or inequity } \\
\text { Accomplish a good } \\
\text { Friends’ involvement } \\
\text { Past experience }\end{array}$ \\
\hline \multirow[t]{2}{*}{ Choice of Service Involvement } & Match of Skills & $\begin{array}{l}\text { Right skills for the job } \\
\text { What I could offer } \\
\text { Career related }\end{array}$ \\
\hline & Type of Project & $\begin{array}{l}\text { Physical nature of work } \\
\text { Social nature of work } \\
\text { One-time project } \\
\text { Ongoing commitment }\end{array}$ \\
\hline
\end{tabular}

Table 15 continues 


\begin{tabular}{|c|c|c|}
\hline Category & Properties & Dimensions \\
\hline & Subjective Interest & Passion for the cause \\
\hline & & Importance of need \\
\hline & & What I could learn \\
\hline & & Personal interest \\
\hline & & Friends were involved \\
\hline & Outcomes Driven & Potential for impact \\
\hline & & Breadth of impact \\
\hline \multirow[t]{11}{*}{ Learning from Service } & Interpersonal Learning & Learned about others \\
\hline & & Learned about myself \\
\hline & & Learned about relationships \\
\hline & Organizational Learning & Learned about leadership \\
\hline & & Learned about organizations \\
\hline & & Learned about community \\
\hline & Social Justice Learning & Learned about justice \\
\hline & & Learned about social issues \\
\hline & & Learned about duty \\
\hline & Emotional Learning & Learned about caring \\
\hline & & Learned about love \\
\hline
\end{tabular}

preceding year, while $17 \%$ (77) had not. Those not participating in service within the previous year were asked only to respond to demographic questions and a single question pertaining to their non-involvement in service within the previous year. Among those who had participated in service in the previous year, response rates to individual questions on the survey ranged from $84 \%$ (312) to $100 \%$ (370). Invitations to participate included informed consent disclosures and advisories, as well as a clear statement of the voluntary nature of survey completion (see Appendix A, pp. 183-191). No incentive was provided for completion of the survey. See Tables 7-9, pages 58-59 for respondent demographics. 


\section{Survey Construction and Testing}

A full version of the survey instrument appears in Appendix D (pp. 206-215).

Following several demographic questions (gender, age, year in school) the survey sought to measure levels of involvement in service, definitions of service, choices about service, motivations toward service, and learning outcomes from service. The survey was constructed from the emergent themes of the qualitative phase of the research. The survey was administered in an online format utilizing a platform provided by Qualtrics, Inc., a survey software company specializing in the delivery of online survey instruments.

Coefficient alpha analysis of internal reliability yielded Chronbach’s Alpha scores in the range of .962 to .997 . Chronbach’s coefficient alpha is an accepted measure of internal reliability for a quantitative survey instrument such as this one (Tashakkori \& Teddlie, 1998, p.85). Table 16 provides a summary of Cronbach’s Alpha scores for the non-demographic, ordinal data questions contained in the survey.

Table 16

Chronbach’s Alpha Scores for Ordinal Data Questions

\begin{tabular}{lcc}
\hline Question & Chronbach's Alpha & N of items \\
\hline Question 5 & .962 & 10 \\
Question 7 & .988 & 14 \\
Question 8 & .990 & 15 \\
Question 9 & .997 & 12 \\
Question 11 & .991 & 11 \\
\hline
\end{tabular}


The survey instrument was subjected to review for content validity by two external experts and faculty colleagues at the research site; one, the director of the Center for Social Research at the research site. The survey was also reviewed by a technical assistant of the survey distribution company. Participants in the qualitative phase of the research also reviewed the survey prior to its distribution, confirming an accurate representation of the themes discussed in the qualitative phase of the research.

\section{Descriptive Analysis}

Returning to the central research question, the researcher was interested in how students described their motivation toward service involvement during college and the learning outcomes of their service involvement. Three specific qualitative research questions flowed from this central question:

1. What factors motivated students to become involved in service during college?

2. How did students in the study choose their particular service involvements?

3. How did students describe the learning outcomes from their service involvements?

These are discussed individually below.

Question 1: What factors motivated students to become involved in service

during college? This study sought to explore both internal and external motivators toward service in college. The aim was not to quantify or order these in terms of importance, but to identify factors that led to service involvement in this sample population. Recalling the summary of coding outcomes for question two in the focus group discussions (see Table 15, p. 106), motivating factors were grouped into four 
properties of requirement, develop skills/career, intrinsic motivators, and extrinsic motivators. In the quantitative phase, this question was also asked. The resulting array of responses is shown in Table 17.

\section{Table 17}

Factors Contributing to Involvement

\begin{tabular}{|c|c|c|c|c|c|c|c|c|}
\hline$\#$ & Question & $\begin{array}{l}\text { Not at } \\
\text { All }\end{array}$ & $\begin{array}{l}\text { Very } \\
\text { Little }\end{array}$ & Somewhat & Significantly & $\begin{array}{l}\text { Very } \\
\text { Much }\end{array}$ & Responses & Mean \\
\hline 1 & $\begin{array}{l}\text { Felt strongly about a } \\
\text { cause or issue }\end{array}$ & 17 & 24 & 120 & 125 & 82 & 368 & 3.63 \\
\hline 2 & Course requirement & 80 & 52 & 84 & 97 & 57 & 370 & 3.00 \\
\hline 3 & $\begin{array}{l}\text { Part of a team or } \\
\text { organization }\end{array}$ & 40 & 21 & 79 & 152 & 77 & 369 & 3.56 \\
\hline 4 & Friends & 48 & 61 & 122 & 93 & 45 & 369 & 3.07 \\
\hline 5 & Gain leadership skills & 29 & 49 & 115 & 137 & 38 & 368 & 3.29 \\
\hline 6 & Career advancement & 45 & 86 & 100 & 86 & 48 & 365 & 3.02 \\
\hline 7 & Add to my resume & 44 & 74 & 99 & 91 & 58 & 366 & 3.12 \\
\hline 8 & Past experience & 33 & 53 & 135 & 100 & 46 & 367 & 3.20 \\
\hline 9 & Followed my heart & 27 & 54 & 106 & 110 & 70 & 367 & 3.39 \\
\hline 10 & $\begin{array}{l}\text { Just wanted to } \\
\text { contribute }\end{array}$ & 19 & 36 & 111 & 130 & 68 & 364 & 3.53 \\
\hline 11 & $\begin{array}{l}\text { Other (please } \\
\text { specify) }\end{array}$ & 39 & 2 & 12 & 7 & 6 & 66 & 2.08 \\
\hline
\end{tabular}

The leading reason given for involvement in the larger sample was 'felt strongly about a cause or issue,' followed by 'part of a team or organization,' just wanted to contribute,' and 'gain leadership skills.' Three of the four leading reasons for involvement in this larger sample, then, were what we would consider intrinsic motivators, or those motivators that derive from an internal impulse to involvement. The fourth, 'part of a team or organization,' fit the property of external motivation to serve. 
Motivations ranged, however, across all properties established earlier in the focus group discussions. Results varied for this response by gender, year in school, and hours of service; these were discussed in a later section.

\section{Question 2: How did students in the study choose their particular service}

involvements? Once students made the decision in college to become involved in service, whether externally or internally motivated, how did they choose their particular service involvements? Here again, a look at both types of data was informative and here again, a mix of choice factors was evident ranging from subjective interests to potential for impact, match of skills with the project, and the type of project. In the qualitative sample, the following coded properties of response emerged in response to the focus group question regarding choice of project(s): match of skills, type of project, subjective interest, outcomes driven.

When these were measured further in the quantitative phase, the following results were found (see Table 18, p. 112).

The leading factors influencing choice of a particular service project concentrated in the qualitative property of Subjective Interest ('passion for the cause,' 'personal interest,' 'importance of the need,' ‘ what I could learn’), with the remaining influencing factors spreading fairly evenly across the three other properties listed above. Here, too, differences emerged related to gender, year in school, and hours of service. As in the case of motivation to become involved, results of a measure of factors involved in choice of service pointed to an array of factors, some intrinsic and some extrinsic, some objective and some subjective. 
Question 3: How did students describe the learning outcomes from their service

involvements? Learning outcomes in the qualitative phase were identified in four areas:

interpersonal, organizational learning, social justice learning, and emotional learning.

\section{Table 18}

Factors in Choice of Service Project(s)

\begin{tabular}{|c|c|c|c|c|c|c|c|c|}
\hline$\#$ & Question & $\begin{array}{l}\text { Not at } \\
\text { All }\end{array}$ & $\begin{array}{l}\text { Very } \\
\text { Little }\end{array}$ & Somewhat & Significantly & $\begin{array}{l}\text { Very } \\
\text { Much }\end{array}$ & Responses & Mean \\
\hline 8. & \multicolumn{8}{|c|}{$\begin{array}{l}\text { Please rate below how influential each factor was in choosing the particular service project(s) that you } \\
\text { have been involved in: }\end{array}$} \\
\hline 1 & $\begin{array}{l}\text { Right skills for the } \\
\text { job }\end{array}$ & 18 & 37 & 129 & 82 & 51 & 317 & 3.35 \\
\hline 2 & Passion for the cause & 9 & 15 & 94 & 112 & 88 & 318 & 3.80 \\
\hline 3 & Potential for impact & 7 & 21 & 9 & 120 & 71 & 318 & 3.71 \\
\hline 4 & $\begin{array}{l}\text { Importance of the } \\
\text { need }\end{array}$ & 5 & 9 & 85 & 135 & 81 & 315 & 3.88 \\
\hline 5 & Breadth of impact & 7 & 44 & 137 & 94 & 33 & 315 & 3.32 \\
\hline 6 & Depth of involvement & 14 & 37 & 127 & 104 & 34 & 316 & 3.34 \\
\hline 7 & One-time project & 45 & 55 & 111 & 82 & 22 & 315 & 2.94 \\
\hline 8 & Ongoing commitment & 23 & 56 & 112 & 77 & 46 & 314 & 3.21 \\
\hline 9 & What I could offer & 7 & 23 & 106 & 119 & 60 & 315 & 3.64 \\
\hline 10 & What I could learn & 8 & 21 & 107 & 113 & 66 & 315 & 3.66 \\
\hline 11 & $\begin{array}{l}\text { Physical nature of } \\
\text { work }\end{array}$ & 41 & 44 & 123 & 74 & 34 & 316 & 3.05 \\
\hline 12 & Social nature of work & 15 & 30 & 113 & 108 & 47 & 313 & 3.45 \\
\hline 13 & Time available & 16 & 21 & 108 & 108 & 61 & 314 & 3.56 \\
\hline 14 & Career related & 34 & 59 & 90 & 86 & 46 & 315 & 3.16 \\
\hline 15 & Personal interest & 12 & 15 & 87 & 121 & 79 & 314 & 3.76 \\
\hline 16 & $\begin{array}{l}\text { Other (please } \\
\text { specify) }\end{array}$ & 22 & 1 & 11 & 9 & 5 & 48 & 2.46 \\
\hline
\end{tabular}


Learning reported in the quantitative phase was roughly equally divided across these

properties, seen in Table 19. Interpersonal learning, organizational learning, and

emotional learning particularly were strong, with means for dimensions of

learning contained by these properties ranging from 3.38 for learning about love to 3.98

for learning about people.

Table 19

Learning from Service

\begin{tabular}{|c|c|c|c|c|c|c|c|c|}
\hline \# & Question & $\begin{array}{l}\text { Not at } \\
\text { All }\end{array}$ & $\begin{array}{l}\text { Very } \\
\text { Little }\end{array}$ & Somewhat & Significantly & $\begin{array}{l}\text { Very } \\
\text { Much }\end{array}$ & Responses & Mean \\
\hline \multicolumn{9}{|c|}{ 9. Please rate below how well each phrase describes your learning from service: } \\
\hline 1 & Learned about others & 5 & 14 & 81 & 126 & 88 & 314 & 3.89 \\
\hline 2 & Learned about myself & 10 & 26 & 90 & 105 & 83 & 314 & 3.72 \\
\hline 3 & $\begin{array}{l}\text { Learned about } \\
\text { leadership }\end{array}$ & 9 & 20 & 74 & 130 & 81 & 314 & 3.81 \\
\hline 4 & $\begin{array}{l}\text { Learned about } \\
\text { relationships }\end{array}$ & 9 & 24 & 86 & 119 & 76 & 314 & 3.73 \\
\hline 5 & $\begin{array}{l}\text { Learned about } \\
\text { organizations }\end{array}$ & 6 & 22 & 102 & 103 & 79 & 312 & 3.73 \\
\hline 6 & Learned about people & 5 & 5 & 74 & 138 & 92 & 314 & 3.98 \\
\hline 7 & Learned about justice & 24 & 61 & 103 & 74 & 52 & 314 & 3.22 \\
\hline 8 & Learned about caring & 6 & 17 & 80 & 122 & 89 & 314 & 3.86 \\
\hline 9 & $\begin{array}{l}\text { Learned about social } \\
\text { issues }\end{array}$ & 12 & 21 & 89 & 112 & 80 & 314 & 3.72 \\
\hline 10 & $\begin{array}{l}\text { Learned about } \\
\text { community }\end{array}$ & 9 & 18 & 84 & 114 & 89 & 314 & 3.82 \\
\hline 11 & Learned about duty & 14 & 34 & 109 & 102 & 54 & 313 & 3.47 \\
\hline 12 & Learned about love & 31 & 42 & 90 & 80 & 71 & 314 & 3.38 \\
\hline 13 & $\begin{array}{l}\text { Other (please } \\
\text { specify) }\end{array}$ & 22 & 1 & 9 & 8 & 6 & 46 & 2.46 \\
\hline
\end{tabular}


A second question in the quantitative phase of the research sought to measure learning impact specifically on what have traditionally been thought of as markers for student development during the college years, such as the development of a sense of meaning, the ability to develop and maintain relationships, and a sense of autonomy in decision-making. Question 11 of the survey asked students to rate the impact of service on a number of personal skills or characteristics. Results are below in Table 20.

Table 20

Impact of Service on Development

\begin{tabular}{|c|c|c|c|c|c|c|c|c|}
\hline$\#$ & Question & $\begin{array}{c}\text { Not at } \\
\text { All }\end{array}$ & $\begin{array}{l}\text { Very } \\
\text { Little }\end{array}$ & Somewhat & Significantly & $\begin{array}{l}\text { Very } \\
\text { Much }\end{array}$ & Responses & Mean \\
\hline
\end{tabular}

11. Please indicate below the extent to which each of these personal skills or characteristics was impacted positively by your service experience(s).

\begin{tabular}{|c|c|c|c|c|c|c|c|c|}
\hline 1 & Sense of competence & 10 & 28 & 111 & 99 & 54 & 302 & 3.53 \\
\hline 2 & $\begin{array}{l}\text { Ability to manage } \\
\text { emotions }\end{array}$ & 18 & 38 & 126 & 80 & 40 & 302 & 3.28 \\
\hline 3 & $\begin{array}{l}\text { Sense of autonomy in } \\
\text { decision-making }\end{array}$ & 10 & 31 & 121 & 87 & 53 & 302 & 3.47 \\
\hline 4 & $\begin{array}{l}\text { Ability to develop } \\
\text { and maintain } \\
\text { relationships }\end{array}$ & 11 & 29 & 108 & 93 & 61 & 302 & 3.54 \\
\hline 5 & $\begin{array}{l}\text { Sense of my own } \\
\text { identity }\end{array}$ & 19 & 39 & 98 & 96 & 50 & 302 & 3.39 \\
\hline 6 & $\begin{array}{l}\text { Sense of meaning or } \\
\text { purpose }\end{array}$ & 10 & 25 & 93 & 107 & 67 & 302 & 3.65 \\
\hline 7 & $\begin{array}{l}\text { Sense of my place in } \\
\text { the world }\end{array}$ & 17 & 40 & 110 & 81 & 53 & 301 & 3.38 \\
\hline 8 & Sense of duty & 13 & 30 & 110 & 92 & 55 & 300 & 3.49 \\
\hline 9 & Ability to nurture & 12 & 39 & 108 & 93 & 48 & 300 & 3.42 \\
\hline 10 & $\begin{array}{l}\text { Commitment to } \\
\text { social justice }\end{array}$ & 33 & 48 & 108 & 62 & 47 & 298 & 3.14 \\
\hline
\end{tabular}


Discussion of these descriptive analysis findings occurrs in Chapter Five. Several of these skills or characteristics were chosen for their acceptance as a measure of development during the college years. Specifically, readers familiar with the work of Chickering and Reisser (1993) will note that the response categories in several cases represent their seven vectors of development, a widely accepted measure of student development during the college years (see Figure 1, page 22). Discussion in Chapter Five utilized the work of Chickering and Reisser among other theorists in interpreting findings related to student development outcomes.

Analysis of findings next moved on to testing of the three research hypotheses for this study. These were:

1. There is a difference in how students describe motivation to serve, selection of service, and learning outcomes from service based on gender.

2. There is a difference in how students describe motivation to serve, selection of service, and learning outcomes based on year in college.

3. There is a difference in how students describe motivation to serve, selection of service, and learning outcomes based on amount of service performed.

These are restated here as they were in Chapters One and Three in the traditional null hypothesis format:

H1. There is no difference in how students describe motivation to serve, selection of service, and learning outcomes from service based on gender.

H2. There is no difference in how students describe motivation to serve, selection of service, and learning outcomes based on year in college. 
H3. There is no difference in how students describe motivation to serve, selection of service, and learning outcomes based on amount of service performed.

\section{Summary of Quantitative Findings}

In null hypothesis testing, cross tabulations were run separately for each independent variable - gender, year in college, and hours of service. The Chi-Square test for independence was utilized to test whether or not relationships existed in the case of the independent variable gender. The chi-square test is a measure of how well the data fit the hypothesis (Gravetter \& Wallnau, 2005, pp. 465-475). In this case, the null hypothesis for gender was that there was no relationship between gender and motivation to serve, selection of service, and learning outcomes from service. The chi-square test was specifically chosen for gender because of the nominal nature of the data for this independent variable. Outcomes for the chi-square test were evaluated for statistical significance at an alpha value of .05.

One assumption underlying use of the chi-square statistic is that all cells contain expected frequencies of at least five (Gravetter \& Wallnau, 2005, p. 476). At frequencies less than five for the chi-square, the possibility of Type I error increases. Type I error describes the rejection of the null hypothesis when it is true (Gravetter \& Wallnau, p. 475). An initial run of the test for gender indicated 12 cells with an expected frequency less than five. An adjustment was made by collapsing the two cells at the bottom of the measurement range on a five-item Likert scale for five of the questions ('Not at all'/Very little') into a single measure. This resulted in a reduction of the number of cells with an expected frequency range $<5$ to a single cell; this resulting single cell was not used in 
analysis due to its statistical unreliability as a finding. Continuity corrections to significance measures were calculated for the remaining two non-Likert measurements.

For the independent variable year in school the Spearman test for correlation was utilized. The Spearman test was also chosen for the variable hours of service. Spearman was selected as the appropriate statistical test for these variables due to the ordinal nature of the data and as a means to avoid concerns described above regarding expected frequencies (an initial run of the chi-square test for these variables indicated similar problems on a larger scale, particularly for hours of service, with six ordinal categories of measure). As for the chi-square test in the case of gender, Spearman tests were evaluated for statistical significance at an alpha of 0.05 .

The chi-square test yielded a total of 35 cases of statistically significant relationships for gender at an alpha of .05 of a possible 70 cases, as described in Table 21 below. The Spearman yielded 21 cases of statistical significance for year in school and 59 for hours of service. Appendix G (pp. 223-227) provides a complete summary of statistically significant findings, with significance level, chi-square score, degrees of freedom and/or standard error provided for each case of significant finding.

Table 21

Summary of Statistically Significant Findings

\begin{tabular}{lcc}
\hline Independent Variable & \# of Cases/Total Cases & Percent of Total Cases \\
\hline Gender & $35 / 70$ & $50 \%$ \\
Year in School & $21 / 70$ & $30 \%$ \\
Hours of Service & $59 / 70$ & $84 \%$ \\
\hline
\end{tabular}


There were seven question categories on the survey (Questions 5 through 11) designed to measure several constructs related to factors leading to service involvement, type of service involvement, the definition of service, choice of particular service involvement, learning from service, comparative statements about service, and impact of service on student development. In five of the seven questions respondents were asked to respond on a Likert scale with response categories ranging from 'Not at all' to 'Very Much' in terms of that factor's influence on the item being measured. In Question 6 respondents could check as many categories as desired in description of type(s) of service that they had been involved in. In Question 10, respondents had a forced choice pairing of descriptors of service. The breakdown of statistically significant responses based on gender, year in school, and hours of service performed are described below for these seven questions.

$$
\text { Gender }=\text { G, Year in School }=\text { YiS, Hours of Service }=\text { HoS }
$$

Q.5. Please rate below the extent to which each of the factors contributed to your involvement in community service.

Q.5.1. Felt strongly about a cause or issue

Q.5.2 Course requirement

Q.5.3 Part of a team or organization

Q.5.4. Friends

Q.5.5. Gain leadership skills

Q.5.6. Career advancement

Q.5.7. Add to my resume

Q.5.8. Past experience

Q.5.9. Followed my heart

Q.5.10 Just wanted to contribute
Significance at $p \leq .05$

G, YiS, HoS

YiS

YiS

YiS, HoS

HoS

None

YiS

HoS

G, HoS

G, HoS 
For question five, corresponding to factors contributing to involvement in service, statistically significant findings emerged chiefly for hours of service (6 of 10 factors) and year in school (5 of 10 factors). Reasons for involvement correlated most closely with amount of prior involvement and year in school of the respondent. Feeling strongly about a cause, following one’s heart, and wanting to contribute all yielded statistically significant responses based on gender.

Q.6. The following best describes the type of service that I have been involved in during college (check all that apply):

Q.6.1. Physical labor

Q.6.2. Mentoring/tutoring

Q.6.3 Advocacy

Q.6.4. Peer education

Q.6.5. Leadership of a student group

Q.6.6. Environmental work

Q.6.7. Office work

Q.6.8. International service

Q.6.9. Domestic service

Q.6.10. Ongoing project(s)

Q.6.11. One-time project(s)

Significance at $p \leq .05$
G
YiS, HoS
G, YiS, HoS
HoS
G, YiS, HoS
None
None
None
G
G, YiS, HoS
G

For question six, corresponding to type of service, gender yielded the largest number of statistically significant responses (5 of 11), with year in school and hours of service each yielding four statistically significant responses.

Q.7. Please rate below how well each statement defines the concept of service for you.

Q.7.1. Providing for others

Significance at $p \leq .05$

Q.7.2. Being with others

G, HoS

Q.7.3. Meeting a need

G, YiS, HoS

Q.7.4. Using my skills

G, HoS

Q.7.5. Sharing my gifts

HoS 
Q.7.6. Following my heart

Q.7.7. Changing the world

Q.7.8. Broaden my thinking

Q.7.9. Adding my voice

Q.7.10. Listening to others

Q.7.11. Teaching others

Q.7.12. Learning from others

Q.7.13. Accomplishing a good

Q.7.14. Finding myself
G, HoS

G, HoS

G, HoS

HoS

G, HoS

YiS, HoS

G, HoS

G, HoS

HoS

For question seven, corresponding to definition of service, hours of service yielded statistically significant differences for all fourteen factors. Gender yielded eight of fourteen statistically significant differences. Year in school yielded only two statistically significant differences.

Q.8. Please rate below how influential each factor was in choosing the particular service project(s) that you have been involved in.

Q.8.1. Right skills for the job

Q.8.2. Passion for the cause

Q.8.3. Potential for impact

Q.8.4. Importance of the need

Q.8.5. Breadth of impact

Q.8.6. Depth of involvement

Q.8.7. One-time project

Q.8.8. Ongoing commitment

Q.8.9. What I could offer

Q.8.10. What I could learn

Q.8.11. Physical nature of work

Q.8.12. Social nature of work

Q.8.13. Time available

Q.8.14. Career related

Q.8.15. Personal interest
Significance at $p \leq .05$

HoS

G, YiS, HoS

HoS

YiS, HoS

HoS

HoS

G, YiS, HoS

HoS

HoS

HoS

None

None

None

G

G, HoS 
For question eight, corresponding to factors influencing choosing a particular service project, hours of service yielded eleven of eighteen statistically significant responses, gender only four and year in school three.

Q.9. Please rate below how well each phrase describes your learning from service.

Q.9.1. Learned about others

Q.9.2. Learned about myself

Q.9.3. Learned about leadership

Q.9.4. Learned about relationships

Q.9.5. Learned about organizations

Q.9.6. Learned about people

Q.9.7. Learned about justice

Q.9.8. Learned about caring

Q.9.9. Learned about social issues

Q.9.10. Learned about community

Q.9.11. Learned about duty

Q.9.12. Learned about love
Significance at $p \leq .05$

HoS

YiS, HoS

YiS, HoS

YiS, HoS

YiS, HoS

HoS

HoS

G, HoS

$\mathrm{G}, \mathrm{HoS}$

G, YiS, HoS

HoS

G, HoS

For question nine, corresponding to learning from service, hours of service provided statistically significant responses for all twelve factors. Year in school yielded five statistically significant responses and gender yielded four.

Q.10. In each pairing below, check the circle closest to the word or phrase that best describes how you think about your service choices and experiences (e.g., think about how you would complete this sentence - "When I think about service, I tend to think of it as a(n) activity.”).

Q.10.1. Emotional - Rational/Analytical

Q.10.2. Subjective/Objective

Q.10.3. Justice-oriented - Caring-oriented

Q.10.4. Personal - Impersonal
Significance at $p \leq .05$

G

G

None

G 
Q.10.5. Societal duty - Personal commitment

G

Q.10.6. Individual - Relational

G

For question ten, corresponding to how students think about service, only gender provided a finding of statistically significant difference in the pairings provided. Q.11. Please indicate below the extent to which each of these personal skills or characteristics was impacted positively by your service experience(s).

Q.11.1. Sense of competence

Q.11.2. Ability to manage emotions

Q.11.3. Sense of autonomy in decision-making

Q.11.4. Ability to develop/maintain relationships

Q.11.5. Sense of my own identity

Q.11.6. Sense of meaning or purpose

Q.11.7. Sense of my place in the world

Q.11.8. Sense of duty

Q.11.9. Ability to nurture

Q.11.10 Commitment to social justice

Significance at $p \leq .05$
HoS
HoS
HoS
G, HoS
HoS
YiS, HoS
G, HoS
HoS
G, HoS
HoS

For question eleven, pertaining to skills or characteristics impacted by service, hours of service again yielded statistically significant responses in for all factors. Gender yielded three measures of statistical significance and year in school only one.

As discussed in Chapter Five, measures of relationship in the quantitative phase of the research were consistent with thematic similarities derived from the coding of qualitative data. In the case of the chi-square test for independence, direction of relationship was determined by a comparison of expected versus actual means. The Spearman test for correlation provides both a measure of both strength and direction of relationship between those variables being tested for correlation. Strength of relationship is indicated by the Spearman value itself; direction of the relationship (e.g., positive or 
negative correlation) by the positive or negative value assigned to the Spearman value. In both cases, direction of relationship was consistent with that indicated in the qualitative findings.

For the independent variable of gender, measures of correlation existed in these data chiefly in the categorical areas of type of service involvement, definition of service, factors influencing service project selection, descriptors of service, and learning from service. For the independent variable of year in school, measures of correlation emerged chiefly in type of service involvement and learning from service. For the independent variable hours of service, multiple correlations were found in all categories except descriptors of service.

The initial focus of the research had been on the independent variable of gender more heavily in qualitative data gathering in terms of sampling strategy, interview methodology, and question framing. The emergence of additional measures of correlation particularly of the number found for the independent variable hours of service served the purpose of broadening the discussion boundaries for findings of the research. Data analysis and discussion was now broadened to include a discussion of relationships among variables based on year in school and hours of service performed.

A summary of raw data, means, variances, and standard deviations is provided in Appendix H (pp. 228-240). This is provided for the data as a whole and by crosstab for gender, year in school, and hours of service. An analysis of the crosstab data revealed that, in those cases where chi-square calculations were in the range of statistical significance, means varied as would be expected in relation to the independent variable in each case based on earlier assumptions created by qualitative findings. In other words, 
findings in the quantitative phase with regard to gender were consistent with those in the qualitative phase of the research. This is discussed further in Chapter Five.

Figure 2 and Table 22 on the following page provide an illustration of mean differences for those cases of statistically significant findings for the independent variable gender.

Similar significant chi-square values were found for a total of 50 response categories, or $50 \%$ of the total response categories. As shown in Table 18, (p. 112), significant differences were found in male/female response to questions related to factors influencing service involvement (shown above), type of service performed, definition of service, factors influencing choice of service project, learning from service, and selfdescribed impact of service on development. In all cases of difference, variance of actual response frequencies from expected response frequencies was seen to be in the direction consistent with findings in the qualitative phase of the research. Analysis and interpretation of these differences occurs in Chapter Five.

For the independent variables year in school and hours of service, the Spearman test for correlation yielded similar measures of relationship. For year in school, 21 measures of correlation were found in 70 question categories. Correlations were found in every question category except Question 10, which asked students to respond to a forcedchoice pairing of descriptors of service. Relationships were predominantly centered in questions related to factors influencing service involvement, type of service involvement, and learning from service. For hours of service, 59 Spearman values showed significance at $\underline{p}<.05$. As in the case of year in college, measures of significance spanned all question 


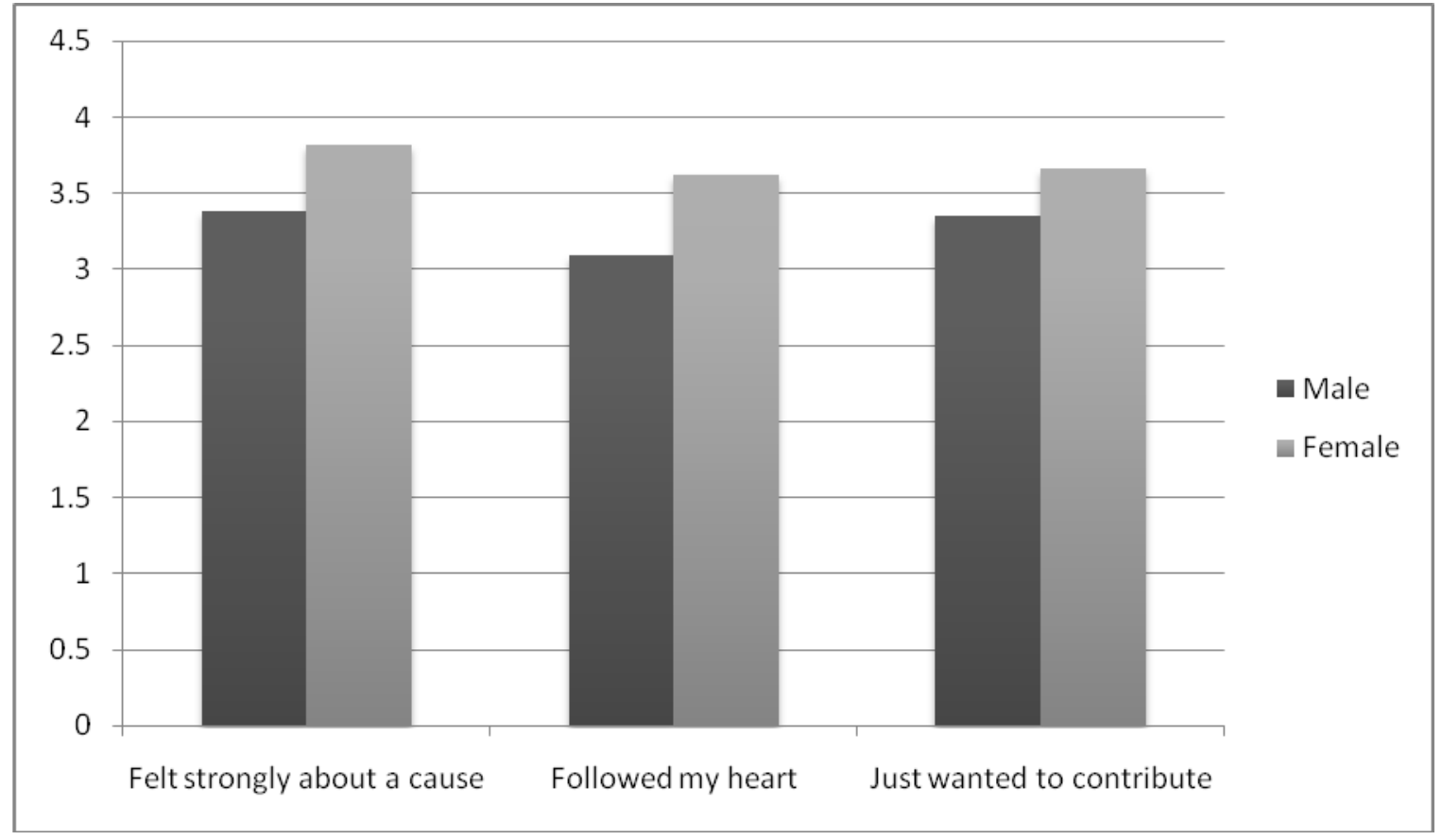

Figure 2. Mean comparisons Q.5. Factors contributing to involvement in service.

Table 22

Mean Comparisons Q.5. Factors Contributing to Involvement in Service, $p \leq .05$

\begin{tabular}{llccc}
\hline \multirow{2}{*}{ Gender } & \multicolumn{1}{c}{ Statistic } & $\begin{array}{c}\text { Felt Strongly About a } \\
\text { Cause or Issue }\end{array}$ & Followed my Heart & $\begin{array}{c}\text { Just Wanted to } \\
\text { Contribute }\end{array}$ \\
\hline \multirow{2}{*}{ Male } & Mean & 3.38 & 3.09 & 3.35 \\
& Variance & 1.14 & 1.36 & 1.19 \\
& Standard Deviation & 1.07 & 1.17 & 1.09 \\
& Total Responses & 160 & 159 & 157 \\
\multirow{3}{*}{ Female } & Mean & 3.82 & 3.62 & 1.06 \\
& Variance & 0.97 & 1.24 & 1.03 \\
& Standard Deviation & 0.99 & 1.11 & 207 \\
\hline
\end{tabular}


categories except Question 10, where no significant Spearman values were found. Only measures related to gender yielded statistically significant measures for Question 10. The most prolific findings of significance were found for this independent variable both in terms of number and magnitude. This and the lack of significant findings for question ten are discussed at length in Chapter Five.

As in the case of findings for gender, relationships found for year in school and hours of service were directionally consistent (e.g., correlated similarly) with qualitative findings. In the case of the Spearman test, significant direct relationship was indicated by a positive Spearman score at a level of significance of $p \leq .05$; significant inverse relationship was indicated by a negative Spearman value at the same level of significance. For year in school, one-third of significant findings indicated negative correlation or inverse relationship between variables. For hours of service, 57 of 59 significant measures indicated a positive correlation or direct relationship (see Appendix G, pp. 223-227).

\section{Caveats in Interpretation}

When interpreting the quantitative data, the researcher took into account several potentially limiting factors related to the statistics employed, sample size, and potential overlap of independent variable measures. In using the chi-square statistic, caution must be exercised regarding expected frequency counts in all cells. In those cases where the expected frequency is $<5$ in one or more cells, the chi square test may not be a reliable measure and may lead to an increase in the likelihood of Type I error, the rejection of a null hypothesis that is true. In the case of this research, the researcher did not use the chi-square statistic for year in school or hours of service, both of which contained a 
number of cells with expected frequencies $<5$. In the case of gender, steps were taken as previously described to reduce low expected frequency instances to a single case, which was not included in the data reporting. Additionally, continuity corrections were reported for all 2 x 2 cell cases.

Effect size, the measure of the significance of the effect that the independent variable has on the dependent variable, is another important measure of relationship between variables. A relatively small effect can be statistically significant in a large enough sample (Gravetter \& Wallnau, 2005, pp. 473-475), creating potentially misleading interpretations of magnitude of relationship between variables. In the case of the chi-square statistic, when the data form a 2 x 2 matrix, the phi-coefficient can be calculated as an alternative to the chi-square statistic (p. 474), yielding a reliable measure of strength of relationship between variables. For gender as an independent variable, 12 of the 35 measures of significance allowed for calculation of the phi-coefficient. For remaining measures - those with larger than a 2 x 2 matrix - Cramer's V was used as a measure of strength of relationship (p. 475). Coefficient-phi scores for gender ranged from .12 to .28 with a mean phi-coefficient score of .15 , indicating a low to moderate strength of relationship for these significant measures. Cramer’s V scores were slightly lower, ranging from .09 to .17 with a mean score of .13 for the 23 cases of significant measure with larger than 2 x 2 matrix. These scores indicated a low strength of relationship between variables.

For the Spearman statistic, the Spearman value itself revealed the strength of the relationship as well as its direction. The Spearman values in those cases of significant findings ranged from .111 to .462. According to Cohen (1988), a correlation measure of 
.1 indicates a small effect size, . 3 indicates a medium effect size, and .5 or larger equals a large effect size. Findings in this research with regard to the Spearman test of correlation were in the small to medium effect size range.

The third caveat in interpretation of quantitative findings was the existence of overlap among independent variables. The ordinal measurement category of '>40 hours' within the hours of service variable, for instance, contained a high representation of respondents from within the categories of 'female' for gender (at $71 \%$ of respondents within this category) and 'senior' for year in school (at 61\% of respondents within this category). The researcher found this to be an acceptable phenomenon, given the limited nature and type of inferences drawn from the data, and proposed the further separation and isolation of these variables and their effects as a subject for further research. The researcher was cautious in reporting results regarding both strength and attribution of outcomes, and was explicit in acknowledging measures of effect size and cases where overlap of independent variables might contribute to outcomes.

\section{The Null Hypotheses}

With these caveats in mind, the researcher made the following determinations with regard to the three null hypotheses:

Reject H1. There is no difference in how students describe motivation to serve, selection of service, and learning outcomes from service based on gender.

In the case of $\mathrm{H1}, 50 \%$ (35 of 70) measures of relationship were significant at $p \leq .05$ as measured by chi-square values of low to moderate effect size. This was sufficient for the researcher to determine that relationship did exist at a level to justify rejection of the null hypothesis and acceptance of the research hypothesis that there was a difference in how students in the sample described motivation to serve, selection of service, and learning outcomes from service. 
Fail to Reject H2. There is a difference in how students describe motivation to serve; there is no difference in selection of service and learning outcomes based on year in college.

In the case of H2, 30\% (21 of 70) measures of relationship were significant at $p \leq .05$ as measured by Spearman values of low to moderate magnitude. This was insufficient evidence to support rejection of the null hypothesis of no relationship.

Reject H3. There is no difference in how students describe motivation to serve, selection of service, and learning outcomes based on amount of service performed.

In the case of H3, 84\% (59 of 70) measures of relationship were significant at $p \leq .05$ as measured by Spearman values of low to moderate magnitude. This was sufficient for the researcher to justify rejection of the null hypothesis and acceptance of the research hypothesis that there was a difference in how students in the sample described motivation to serve, selection of service, and learning outcomes from service.

\section{Summary of Findings}

This chapter began with an overview and reintroduction of the research methodology. This was followed by a description of all questions asked in focus group and individual interviews. Participants in the qualitative phase of the study were described for both focus group and individual interviews. An analysis of focus group interview responses was followed by analysis of individual interview responses. Results of the qualitative phase of the research were summarized prior to description of the survey instrument and an analysis of quantitative research results.

In this study of students’ motivations toward service, choices of service, and learning from service similar themes of difference and relatedness emerged from both sets of data. Substantial evidence existed in both phases of research for the existence of differences in how students in the sample attributed their motivations toward service, 
defined and described their service experiences, and described the learning and impact of their service based on gender and hours of service performed. The latter independent variable category, hours of service, yielded the most numerous measures of statistically significant relationship in the quantitative phase, followed by gender and year in school. It was noted, however, that this category of hours of service co-varied with both of the other independent variables. That is, those reporting more hours of service in the past year were also more likely to be women and seniors.

The researcher did not set out to establish a theory of service involvement or learning from service. Rather, the objective of the current research was to discern whether there relationships appeared to exist between the measures of gender, year in school, and hours of service on the one hand and motivations, choices, definitions, and learning outcomes from service on the other. The researcher concluded that such relationships did exist in the sample population at low to moderate levels. In other words, the researcher concluded that gender, year in school, and hours of service performed did, to differing degrees, affect how students described their motivations to become involved in service, how they chose and described their service involvements, and how they described their learning from service.

In the case of gender and hours of service, these effects were found to be statistically significant to a level sufficient to reject the null hypothesis of no relationship. In the case of year in school, while statistically significant measures were found, these were insufficient in magnitude or frequency to allow the research to confidently reject the null hypothesis. These findings were discussed in Chapter Five with reference to the 
literature related to gender, service, college student development, and the symbolic interactionist approach to how individuals make meaning in their lives.

Chapter Five is broken into several sections. First, an overall restatement of findings was presented related to the research questions and acceptance or rejection of the null hypotheses. Secondly, findings of the research were analyzed for each of the three independent variables of gender, year in school, and hours of service. Next, overall findings and conclusions were presented. This was followed by discussion of practical implications of findings for researchers and practitioners. Finally, recommendations for further study were made. 


\section{Chapter Five}

\section{Discussion}

\section{Introduction}

The purpose of this study was to explore college student involvement in service their motivations, choices of service involvement, and reported learning outcomes. The aim of this research was to add to our understanding of the motivations toward service among college students, to get a clearer sense of how students choose their particular service involvements, and to better understand the learning outcomes from service involvement during college. The first phase of the research was a qualitative exploration of these questions via focus group and individual interviews with 24 college students in a small, Midwestern liberal arts college.

Emergent themes from these interviews were then utilized to develop a survey instrument to test a series of hypotheses that relate to possible differences in how students describe their motivations toward service, choices of service involvement, and learning from service based on gender, year in college, and amount of service performed. The explicit aim of this exploratory study was not to develop and test a survey instrument, but rather to determine if, in this study sample, differences existed in how students described their service motivations, choices, and learning outcomes based on the variables of gender, year in college, and amount of service performed. One thousand and four students at the same small liberal arts college were surveyed, with a response rate of $44.5 \%$ (447 responses). 
The central research question for this study was: How do students describe their motivation toward service involvement during college and the learning outcomes of their service involvement?

Several specific qualitative research questions flowed from this central question:

1. What factors motivated students to become involved in service during college?

2. How did students in the study choose their particular service involvements?

3. How did students describe the learning outcomes from their service involvements?

Three additional emergent questions were explored in the quantitative phase of the research following completion of the phase one qualitative inquiry:

1. Is there a difference in how students describe motivation to serve, selection of service, and learning outcomes from service based on gender?

2. Is there a difference in how students describe motivation to serve, selection of service, and learning outcomes based on year in college?

3. Is there a difference in how students describe motivation to serve, selection of service, and learning outcomes based on amount of service performed?

The specific research hypotheses corresponding to these questions were:

1. There is a difference in how students describe motivation to serve, selection of service, and learning outcomes from service based on gender.

2. There is a difference in how students describe motivation to serve, selection of service, and learning outcomes based on year in college. 
3. There is a difference in how students describe motivation to serve, selection of service, and learning outcomes based on amount of service performed.

These were restated in the traditional null hypothesis format as follows:

H1. There is no difference in how students describe motivation to serve, selection of service, and learning outcomes from service based on gender.

H2. There is no difference in how students describe motivation to serve, selection of service, and learning outcomes based on year in college.

H3. There is no difference in how students describe motivation to serve, selection of service, and learning outcomes based on amount of service performed.

In this chapter discussion of research findings are presented in the following format. First, an overview of findings for each research questions was provided. Secondly, findings for each related quantitative research question or hypothesis were presented and discussed. The chapter concludes with a discussion of practical implications of the findings and recommendations for further study.

\section{Discussion of Findings}

This section was divided into discussion of qualitative questions first followed by discussion of research hypotheses. Discussion was informed by the pertinent literature in each case. Specific data citations and references were made where appropriate; data from the qualitative and quantitative phases of the research were both used in discussion of all sections of this chapter (e.g., discussion of qualitative research questions includes findings in the quantitative data where this is appropriate). Lastly, discussion of findings 
related to the three independent variables of gender, year in school, and hours of service is summarized.

\section{Motivation to Serve}

A review of the literature revealed that, while there has been considerable attention given in the literature to volunteer motivation, there has been little specifically written about college students’ motivation to become involved in service. Still less has been written about motivational differences within the college student population attributable to gender, year in college, or hours of service previously performed. This study sought to add to what is known specifically about college students' motivation to serve during their time in college. The earlier literature on volunteer motivation does provide a useful backdrop for this current study and tended to have some predictive and affirmative value with regard to the findings on motivation of this study.

Wilson (2000) catalogued theories of volunteer motivation into two primary categories of individual attributes of the volunteer and social context. Within the category of individual attributes, he further grouped theories into those emphasizing motives of self-understanding and those emphasizing rational action and cost-benefit analysis (Wilson, 2000, p.12). Another survey of volunteer motivation survey identified two main constructs for evaluating volunteer motivation, those of egoism, or serving the self, and altruism, or serving the other (Winniford, Carpenter, \& Grider, 1997). Two studies of volunteer behavior concluded that often the initial motivation to volunteer is an altruistic one, while the decision to continue often depends on egoistic rewards from volunteering (Batson, 1991; Martin, 1994). Fitch (1987) added a third construct to altruism and egoism, that of social obligation, or the impulse to "give back" to society. 
All of these theoretical constructs were borne out in the current research and are highlighted in this section on motivation to serve.

One study within this body of literature focused on college students' motives toward community service (Serow, 1991) and applied much of the existing motivation theory specifically related to egoism, altruism, social exchange and social obligation as motivating factors toward volunteerism. Serow’s study utilized a 51-item survey to assess volunteer motivations among 759 students across four public universities in the southern and Midwestern sections of the United States (Serow, 1991, p. 546). Of this group, 260 students identified themselves as community service participants. From this group, 42 students were individually interviewed following survey completion about their service involvements. Findings of the study indicated that the top reasons for involvement in community service reported by these students were: a sense of satisfaction from helping others (80\%), involvement as part of a club, activity, or class (56\%), a sense of duty to correct societal problems (54\%), a desire to meet people (49\%), and a desire to acquire new career skills and experience (42\%) (Serow, 1991, p. 549). Serow concluded from this study that service involvement among college students in the sample was based on a mix of altruism (desire to help others), egoism (acquire skills, meet people) and societal obligation (duty to correct societal problems). He did not report these findings by characteristics within the population, such as age, race, gender, or year in college.

One more recent study cited the influence of peers, institutional influences (e.g., course requirements, graduation requirements), and experiences in service prior to college as the chief external motivators for involvement in service in college (Jones \& 
Hill, 2003). This qualitative study conducted in-depth interviews with twenty-four students across six member colleges of the Ohio Campus Compact. Twelve of the students were involved in service at their respective colleges and twelve were not involved. All of the participants had been involved in service in high school.

Researchers sought to discern the basis of continued service in college for some and not for others in the sample population (Jones \& Hill, 2003, p. 519). This study identified the deciding factors for involvement in service during college to include a desire to focus on others, a desire to give back to the community, and a perceived connection between service and development of self, again clearly a mix of altruism, egoism, and social obligation as motivating factors among those involved in service. In this study, the social context (influence of peers, institutional influences) emerged as the primary determinant of which students went on to serve in college after high school and which did not.

Both phases of the current study found the range of possible motivating factors toward service to be a mix of external/extrinsic motivations - or what might be thought of as a mix of altruism, social obligation, and social context - and internal/intrinsic motivations, or what might be thought of in terms of the earlier research as egoistic motivations. This was consistent with the earlier finding of Jones and Hill (2003) of a similar mix of extrinsic motivations based on friends' involvement, earlier experiences in service, institutional influences and intrinsic motivations related to giving back, focusing on others, and identifying one's own growth as association with service. Statements in focus groups and individual interviews were consistent with the themes of involvement found by Jones and Hill, where students indicated that they became involved in service in college "in order to give something back," or because "I decided that it was time to focus 
on others less fortunate than me,” and “I recognize that when I give my time to others I grow and learn every bit as much as they do.”

In the quantitative sample, the chief reasons given for involvement in service were the same mix of extrinsic and intrinsic motivations. Ordered by mean in the total population, the top three reasons for involvement were: (a) felt strongly about a cause or issue, (b) part of a team or organization, and (c) just wanted to contribute.

This outcome varied when broken down by gender, with the extrinsic motivator 'part of a team or organization’ emerging as the leading motivator for men in the sample, followed by ‘felt strongly about a cause’ and ‘just wanted to contribute.' For women in the sample, the extrinsic motivator 'part of a team or organization' was not in the top three reasons given for involvement; women cited feeling strongly about an issue, wanting to contribute, and following their hearts as the chief reasons for their involvement in service. All three of these factors were measured as statistically significant differences between how men and women in the sample responded to this question about motivation, with women rating these significantly higher as motivating factors in each case (see mean comparisons in Table 22, p. 125).

Table 23

Motivation to Serve by Gender

\begin{tabular}{lccc}
\hline Question & Chi-Square & Degrees of Freedom & Sig. level \\
\hline 5.1 Felt strongly & 16.471 & 3 & $.001^{* *}$ \\
5.9 Followed my heart & 18.472 & 3 & $.000^{* *}$ \\
5.10 Contribute & 9.736 & 3 & $.021^{*}$ \\
\hline
\end{tabular}
$\mathrm{p} \leq .05^{*} \quad \mathrm{p} \leq .001^{* *}$ 
Men were more likely to indicate external factors as a motivation to become involved in service than were women. The literature on gender difference in college would support this finding of difference for men and women. Linda Sax (2008) reported substantial differences between men and women at entry to college regarding their likelihood to engage in service without some form of external motivation such as a course or team requirement. Using survey data from over 270,000 students at over 393 campuses, Sax found that $73.1 \%$ of women held a commitment to helping others to be 'very important' or 'essential,' compared to 58.9\% of men. When predicting future volunteer work, a similar gender gap emerged, with 34.6\% of women predicting involvement in volunteer or community service work compared to only $17 \%$ of men (Sax, 2008, p. 43).

One logical conclusion from a comparison of Sax's data to the data of this study was that women are predisposed to become involved in service during their college years for intrinsic reasons and without external motivation; men are more likely to become involved, at least initially, if prompted by some external motivator such as a course requirement or as part of a team or organization. This, coupled with the finding by Jones and Hill (2003) that social context (institutional characteristics, peer influences) played an important role in the continuation of service involvement from high school to college, has important practical implications for involving students in service and is discussed in the implications section of this chapter.

For hours of service the extrinsic motivator 'part of a team or organization' was the top reason given for involvement by those who had served 1-10 hours in the past year. This dropped to second on the list among those who had served 11-20 hours in the 
past year and disappeared from the top three list altogether for those in the remaining categories of hours of service, ranking as low as $8^{\text {th }}$ out of the 10 reasons for involvement in higher categories of hours of service. Statistically significant Spearman values for hours of service and motivation are shown in Table 24. Note the strength of the Spearman values for the three internal factors. These again emerged as primary motivational factors, in this case in direct relationship with hours of service performed.

\section{Table 24}

Motivation to Serve by Hours of Service

\begin{tabular}{lccc}
\hline Question & Spearman & Standard Error & Sig. level \\
\hline 5.1 Felt strongly & .462 & .041 & $.000^{* * *}$ \\
5.4 Friends & -.125 & .051 & $.016^{*}$ \\
5.5 Leadership skills & .241 & .050 & $.000^{* * *}$ \\
5.8 Past experience & .136 & .051 & $.009^{* *}$ \\
5.9 Followed my heart & .270 & .048 & $.000^{* * *}$ \\
5.10 Contribute & .300 & .048 & $.000^{* * *}$ \\
\hline
\end{tabular}

$\mathrm{p} \leq .05^{*} \quad \mathrm{P} \leq .01^{* *} \quad p \leq .001^{* * *}$

For the independent variable year in school, the extrinsic motivator 'part of a team or organization' emerged as the top reason given by freshmen for their involvement and declined steadily as a reason for involvement for sophomores through seniors. Significant Spearman values for year in school and motivation to serve are presented in Table 25 on the following page. Note that all measures but 'felt strongly about a cause' indicate an inverse relationship between year and school and factor measured. Direct relationships, 
though not of statistically significant value, existed for year in school for the factors 'gain leadership skills,' followed my heart,' and 'just wanted to contribute.'

Table 25

Motivation to Serve by Year in School

\begin{tabular}{lccc}
\hline Question & Spearman & Standard Error & Sig. level \\
\hline 5.1 Felt strongly & .187 & .050 & $.000^{* * *}$ \\
5.2 Course requirement & -.188 & .048 & $.000^{* * *}$ \\
5.3 Team or organization & -.131 & .050 & $.012^{*}$ \\
5.4 Friends & -.131 & .051 & $.012^{*}$ \\
5.7 Add to my resume & -.138 & .052 & $.008^{* *}$ \\
\hline
\end{tabular}

$P \leq .05^{*} \quad P \leq .01^{* *} \quad p \leq .001^{* * *}$

General findings for motivation to serve described an inverse relationship between external motivators and both year in school and hours of service. This was in addition to the significant differences found for men and women. Just as women were more likely than men to become involved in service for intrinsic reasons and without need for external motivation, upperclassmen and those who had served a greater number of hours were less likely to cite external factors as motivating and more likely to identify intrinsic motivations for service. This finding is consistent with earlier findings (Batson, 1991; Martin, 1994) that volunteers tend initially to become involved for altruistic reasons and based on social obligation and social context, and tend to continue based on egoistic rewards. 
Since there was a direct relationship in the sample between hours of service and year in college, and since hours of service correlated directly with student development measures discussed below, general student development theory would support an interpretation of this trend in motivational factors as related to student moral development over time during the college years. Virtually all of the cognitive-structural and psychosocial theories of college student development propose movement toward greater integration, differentiation, and complexity in how students think, feel and behave (Pascarella \& Terenzini, 2005, p. 19). Consistent with this movement is what Marcia Baxter Magolda has referred to as “self-authorship” (Baxter Magolda, 1999) and Robert Kegan referred to as “social maturity” (Kegan, 1994). Baxter Magolda cited Kegan’s work on social maturity in her own articulation of a theory of self-authorship.

Regarding specifically the orientation toward self-initiation represented in a trend toward intrinsic motivation for service, Baxter Magolda cited Kegan’s description of a socially mature individual. Socially mature adults are expected to "invent or own our work . . . to be self-initiating, self-correcting, self-evaluating . . . to be guided by our own visions . . . to take responsibility for what happens to us” (Kegan, 1994, in Baxter Magolda, 1999, P.10). These expectations require self-authorship, according to Baxter Magolda, "because they require the ability to construct our own visions, make informed decisions . . . act appropriately, and to take responsibility for those actions” (Baxter Magolda, 1999, p. 10).

These attitudes and behaviors, this movement toward greater self-initiation, responsibility, and independent decision-making would seem likely explanations for the trends in motivation to serve identified in this study. Research findings did not suggest 
that students would be more likely to serve as they became more socially mature or selfauthored, but that they would be more likely to make choices about their involvement independent of externally motivating factors - in other words, the decision to become involved in service or not became more internally governed and guided. Implications are rich for practical application of this finding for understanding college student motivation to serve in relation to hours of service previously performed, year in college, and gender. These implications are explored in depth later in this chapter.

\section{Choosing Service}

Once students made the decision in college to become involved in service, whether externally or internally motivated, how did they choose their particular service involvements? Here again, a look at both types of data was informative and here again, a mix of choice factors was evident ranging from subjective interests to potential for impact, match of skills with the project, and the type of project.

The leading factors influencing choice of a particular service project concentrated in the qualitative property of Subjective Interest ('passion for the cause,' 'personal interest,' 'importance of the need,' ‘ what I could learn’), with the remaining influencing factors spreading fairly evenly across the other properties listed above. Here, too, differences emerged related to gender, year in school, and hours of service. As in the case of motivation to become involved, results of a measure of factors involved in choice of service pointed to an array of factors, some intrinsic and some extrinsic, some objective and some subjective.

A review of measures of significant relationship in the quantitative data for this question showed the following statistically significant outcomes. For gender, there were 
four statistically significant measures among the 15 factors for this question as shown in Table 26.

Table 26

Choice of Service by Gender

\begin{tabular}{lccc}
\hline Question & Chi-Square & Degrees of Freedom & Sig. level/Correction \\
\hline 8.2 Passion for cause & 13.409 & 3 & $.004^{* *}$ \\
8.7 One-time project & 10.615 & 3 & $.014^{*}$ \\
8.14 Career related & 7.931 & 3 & $.047^{*}$ \\
8.15 Personal interest & 11.174 & 3 & $.011^{*}$ \\
\hline
\end{tabular}

$p \leq .05^{*} \quad p \leq .01^{* *}$

For year in school, there were three significant measures.

Table 27

Choice of Service by Year in School

\begin{tabular}{lccc}
\hline Question & Spearman & Standard Error & Sig. Level \\
\hline 8.2 Passion for cause & .124 & .056 & $.027^{*}$ \\
8.4 Importance of need & .111 & .057 & $.049^{*}$ \\
8.7 One-time project & -.183 & .052 & $.001^{* *}$ \\
\hline
\end{tabular}

$p \leq .05^{*} \quad p \leq .001^{* *}$ 
For hours of service, nearly all measures within this question were statistically significant.

Table 28

Choice of Service by Hours of Service

\begin{tabular}{lccc}
\hline Question & Spearman & Standard Error & Sig. Level \\
\hline 8.1 Right skills for job & .133 & .053 & $.018^{*}$ \\
8.2 Passion for cause & .265 & .053 & $.000^{* * *}$ \\
8.3 Potential for impact & .191 & .054 & $.001^{* * *}$ \\
8.4 Importance of need & .262 & .053 & $.000^{* * *}$ \\
8.5 Breadth of impact & .153 & .055 & $.006^{* *}$ \\
8.6 Depth of Involv. & .157 & .057 & $.005^{* *}$ \\
8.7 One-time project & -.219 & .054 & $.000^{* * *}$ \\
8.8 Ongoing commit. & .175 & .057 & $.002^{* *}$ \\
8.9 What I could offer & .185 & .056 & $.001^{* * *}$ \\
8.10 What I could learn & .267 & .054 & $.000^{* * *}$ \\
8.15 Personal interest & .241 & .053 & $.000^{* * *}$ \\
\hline
\end{tabular}

$p \leq .05^{*} \quad p \leq .01^{* *} \quad p \leq .001^{* * *}$

Several interpretations of these data were important for the purposes of this study. Note that the only inverse relationship for year in school and hours of service is in the factor 'one-time project.' Students in the quantitative sample indicated in their responses to this question that they were less likely to choose a one-time service commitment the later their year in school or the more service they had previously engaged in. In the case of hours of service, results showed a nearly equal and opposite response for 'ongoing 
commitment.' This same dynamic held for year in school, though at a lesser, statistically non-significant level. Students in the sample were more likely to choose service projects with an ongoing commitment than a one-time focus the later they were in their college careers and the more hours they had served previously. Men were also more likely to choose one-time service projects over ongoing commitments than were women in the sample, and to choose projects that were related to their planned careers. Implications of these findings are discussed later in this chapter.

Another noteworthy finding related to male participation and reasons for non-participation in service. In focus group discussions, men reported that the amount of time they had for service involvement was limited, and that this factor led to the selection of service projects more often than not when service was selected. In the survey, those men reporting that they had not engaged in service in the past year cited 'Not enough time’ as the chief reason for non-involvement. Similarly, when asked why men are less frequently involved than women in service during college, respondents of both genders cited 'Not enough time' in the top three reasons for male non-involvement. Also in response to these two questions, respondents of both genders indicated that men were generally 'Not aware of service opportunities' and that 'No one asks' for their involvement as reasons for male non-involvement. The group of top four answers to this question was rounded out by 'Just not interested,' again a high frequency response for both genders about male non-involvement.

Returning to the work of Linda Sax regarding gender difference in college, she noted the following uses of leisure time among men and women responding to a national survey of over 270,000 students, as summarized in Table 29 on the following page. 
Table 29

Gender Differences in Leisure Time among First-Year Students, Fall 2006

\begin{tabular}{lccc}
\hline & Women (\%) & Men (\%) & Diff. (W-M) \\
\hline Activities (6-hours per week) & & & \\
Exercising or sports & 44.0 & 58.9 & -14.9 \\
Watching TV & 22.6 & 30.8 & -8.02 \\
Reading for pleasure & 12.2 & 8.5 & -3.7 \\
Partying & 18.9 & 25.6 & -6.7 \\
Playing video/computer games & 3.8 & 22.0 & -18.2 \\
Activities (frequently or occasionally) & & & -11.2 \\
Drinking beer & 37.3 & 48.5 & -1.8 \\
Drinking wine/liquor & 47.8 & 49.6 & -0.8 \\
Smoking cigarettes & 4.9 & 5.7 & \\
\hline
\end{tabular}

Note: Weighted national norms abstracted from Pryor et al. (2006).

Source: Sax (2008, p. 31)

In this large sample of college men, men reported spending considerably more of their leisure time than did women exercising, watching TV, playing video/computer games, and drinking beer. Males in focus groups in this research project reported essentially the same phenomenon when asked why their peers were less likely to become involved in service. As one student commented about his male peers, "sometimes I worry that those students spending their time playing video games and living on Facebook are completely out of touch with the real world - why is no one inviting them, challenging them, requiring them to get involved?” 
Based on the evidence, men would seem to have as much time as their female peers to engage in service during college, but choose often to use their free time differently. If time constraints prohibitive of involvement in service were not as real as perceived or reported, then the fact that men reported that they were not aware of service opportunities or had not been invited to participate might be evidence either of a supported and accepted social norm of male non-involvement in service and/or a need to reach out more effectively to men in the promotion and marketing of service opportunities. This is discussed in the implications section of this chapter.

\section{Description of Service}

Though not directly related to the central research question, sub-questions, or hypotheses, the researcher included a question in the survey related to emergent themes of difference in perception of service based on gender. Question 10 asked students to identify their sense of service as more closely related to one or the other of two paired descriptors. The pairings were:

10.1 Emotional or Rational/Analytical

10.2 Subjective or Objective

10.3 Justice-oriented or Caring-oriented

10.4 Personal or Impersonal

10.5 Global-societal duty or Personal commitment

10.6 Individual or Relational

Responses to this question were analyzed for all independent variables, with the expectation based on focus group discussions that differences would emerge based on gender and with no expectation of difference for year in school or hours of service. Responses followed this pattern precisely, with no significant differences emerging for the latter two variables and significant differences in five of the six pairings for gender. 
As can be seen, the $2 \times 2$ format of these data allowed for calculation of continuity corrections to compensate for any problems related to expected frequency. In each case of difference, the difference was in the direction anticipated based on qualitative findings. Women were more likely to view service as an activity based in emotional and subjective reality and to see service as an inherently personal commitment and one based in relationship. Men were more likely to view service as a rational/analytical activity and one based in objective realities. The majority of males described service as impersonal, a manifestation of global/societal duty, and an individual versus relational activity.

Table 30

Description of Service by Gender

\begin{tabular}{lccc}
\hline Question & Chi-Square & Degrees of Freedom & Sig. level/Correction \\
\hline 10.1 Emot./Rat. & 20.442 & 1 & $.000 / .000^{* * *}$ \\
10.2 Subject./Object. & 4.823 & 1 & $.028 / .039^{*}$ \\
10.4 Pers./Impers. & 9.270 & 1 & $.002 / .004^{* *}$ \\
10.5 Global/Personal & 6.413 & 1 & $.011 / .016^{*}$ \\
10.6 Indiv./Relat. & 6.378 & 1 & $.012 / .017^{*}$ \\
\hline$p \leq .05^{*} \quad p \leq .01^{* *}$ & $p \leq .001^{* * *}$ & &
\end{tabular}

Earlier reference to the work of feminist theorists such Chodorow (1978), Gilligan (1982), and Noddings (1984) would have predicted these outcomes of difference based on gender. These writers made the case that female development did not necessarily follow the same path as that of men and argued that many of the student development 
theories of the day did not adequately account for gender difference in development (Pascarella \& Terenzini, 2005, pp. 43-44). Noddings particularly proposed an alternate framework for ethical analysis with her concept of "caring” as a construct within which women think, reason, and act in matters related to social responsibility and ethical response to need (Noddings, 1984). Noddings proposed that women tend to think about and respond to the perceived needs of the other in a personal and purposefully subjective manner, as a matter of personal commitment as one enters into a caring relationship with the other.

Similarly, Carol Gilligan’s model of women’s moral development proposed an alternate conception of the developmental processes for women to that of the 'one size fits all’ models of her predecessors (Gilligan, 1982). Gilligan observed consistent discrepancies between the traditional theories of moral development proposed by Piaget, Erikson, Kohlberg and women’s concepts of self and morality. She suggested that the problem lay in the inherently gender-biased nature of the traditional theories, all of which had relied almost exclusively on studies of male subjects and which purported to explain a universal development process for men and women (Gilligan, 1977, 1982). Gilligan argued that these traditional theories did not adequately or accurately describe women's experiences or bases for moral reasoning. Kohlberg's theory, for instance, she felt focused on the "subordination of the interpersonal to the societal definition of the good" (Gilligan, 1977, p. 489), when in fact women’s perception’s of self were “tenaciously embedded in relationships with others” and women’s moral judgments were “insistently contextual” (1977, p. 482). 
These distinctions were clearly played out for men and women in response to this question regarding perception or description of service and arguably in previous questions regarding motivations to service, choice of service, and learning from service. Women tended to focus in responses to these questions on relationship, personal connection, and subjective thought processes whether in reference to motivation to serve, definition of service, or learning from service. Men tended to focus on objective decisionmaking, societal good, and ethical obligation. These distinctions were palpable in focus group discussion and individual interviews.

“The guys feel like it’s their duty to correct things and achieve justice," one woman remarked, "women are more apt to choose their involvement based on an emotional reaction, not a sense of power imbalance or a need to 'correct' something." Another young woman framed it this way, "women approach things more emotionally while men approach things more logically and rationally and I don't know if its wrong when you say that, but I think that.” These distinctions were also evident and measurably significant in survey responses. Distinctions continued to be evident in measurements of learning from service.

\section{Learning from Service}

Several recent studies have sought to explore the affect of service on student learning and development. Pascarella and Terenzini offered a summary of studies of service involvement and student development in their updated compilation of the effect of college on students (2005, pp. 193-194). These included quasi-experimental studies conducted by Batchelder and Root (1994); Eyler, Giles, Lynch and Gray (1997); Eyler, Giles, Root, and Price (1997); and Eyler and Giles (1999) designed to measure the net 
effect of service involvement on students’ cognitive development. This research generally supported the hypothesis of the researchers that student cognitive development is influenced by the degree to which service learning classes were well integrated and contained a reflective component (Pascarella \& Terenzini, 2005, p. 193).

Alexander Astin and Linda Sax catalogued the affects of service participation on 3,450 students across 42 institutions as part of their study on the affects of college on students (Astin \& Sax, 1998). Their research indicated enhancement of students’ academic development, life skill development, and sense of civic responsibility as a result of service involvement during college (p. 251). Students in the study showed positive gains on all 35 outcomes measures across these broad categories of learning in everything from grade point average to leadership skills and plans for additional service work (p. 251).

Jones and Abes (2004) sought to understand the enduring influences of service on students' identity development. In this study, Jones and Abes sought to understand how service-learning promotes learning about self and how or whether this is sustained over time. Their qualitative study utilized in-depth interviews of seven students (six female and one male) who had participated in a college level service learning course several years prior to the 2004 study and sought explicitly to explore the enduring influence of service learning involvement on identity development among participants (p. 149). Their findings were arranged within three themes of enduring learning from service: intrapersonal (or identity) learning, interpersonal (shifts in the nature of commitments) learning, and cognitive development (in the form of increased open-mindedness to new people, ideas, and experiences). In each area, Jones and Abes study found sustained 
growth among participants and found reasons to link these directly to the service experiences of participants (p. 149).

Similarly, Robert Rhoades’ (1997) phenomenological narrative of meaningmaking through service connected college students' experiences in service to what he terms the situating of self in the world, the development of identity, and the development of a sense of 'otherness,' community orientation, and mutuality in interactions with others. Rhoades’ analysis combined the perspective of symbolic interactionist theory (Mead, 1934) with what he termed the feminist writings of Gilligan (1982). Rhoads’ work was based on extensive contact, first-hand observations, and interviews with students involved in service at Michigan State University over the course of a decade.

Baxter Magolda's (2000) work in this area is frequently cited for its focus on the potential of service experiences to create opportunities for what she described as 'selfauthorship,' or the ability to develop personal authority over one's identity. For her this is accomplished by "an ability to construct knowledge in a contextual world, an ability to construct an internal identity separate from external influences, and an ability to engage in relationships without losing one’s internal identity” (Baxter Magolda, 1999, p. 12).She further described this process as a defining and desirable characteristic of the higher education experience. A summary of Baxter Magolda’s research methodology is provided on pages 39- 40 of Chapter Two.

Baxter Magolda’s work was influenced by Perry’s cognitive-structural theory (1970), but also by Belenky, et. al. (1987), who, like Carol Gilligan earlier (1977) found that women's development did not necessarily conform well with Perry's theory. Her work was also informed by King and Kitchener’s Reflective Judgment Model (1981), 
which described a seven-stage development sequence toward the development of increasingly refined problem-solving skills. Baxter Magolda’s theoretical work grew out of a longitudinal qualitative study lasting more than a decade with more than 70 students at Miami University in Ohio.

Findings of this current research regarding learning from service reflected many of the findings of these earlier studies. As in the Astin and Sax study (1998), the most revealing aspect of this study was in the universal finding of positive learning impacts in direct correlation with amount of service performed. The summary of significant measures of learning by hours of service is in Table 31, page 155.

Of the 12 measures of possible learning from service posed in Question 9, all 12 revealed significant differences in reported learning based on hours of service performed, most of these gains measured at moderate to high magnitudes and very high significance levels, as seen above. It may be considered to be presumptive that such learning would occur through these experiences. These results, however, demonstrate the presumption conclusively. Students who have engaged in more hours of service report learning at higher levels in every category measured than those with fewer hours of service involvement. There was, in other words, a significant difference in how strongly students in this sample described their learning from service.

Most of these measures could be classified as some combination of cognitive or skill-based learning. A second measure of impact of service was employed in this research seeking to measure developmental impact on participants. Question 11 of the survey asked students to describe the impact of their service experiences on a number of 
Table 31

Learning from Service by Hours of Service

\begin{tabular}{lccc}
\hline Question & Spearman & Standard Error & Sig. Level \\
\hline 9.1 Others & .258 & .052 & $.000^{* *}$ \\
9.2 Myself & .366 & .048 & $.000^{* *}$ \\
9.3 Leadership & .325 & .050 & $.000^{* *}$ \\
9.4 Relationships & .303 & .052 & $.000^{* *}$ \\
9.5 Organizations & .322 & .052 & $.000^{* *}$ \\
9.6 People & .296 & .051 & $.000^{* *}$ \\
9.7 Justice & .338 & .052 & $.000^{* *}$ \\
9.8 Caring & .231 & .053 & $.000^{* *}$ \\
9.9 Social issues & .319 & .051 & $.000^{* *}$ \\
9.10 Community & .238 & .054 & $.000^{* *}$ \\
9.11 Duty & .263 & .053 & $.000^{* *}$ \\
9.12 Love & .256 & .053 & $.000^{* *}$ \\
\hline
\end{tabular}

$\mathrm{p} \leq .001^{* *}$

personal skills or characteristics commonly associated with personal development. Once again, measures of significant difference in impact were universally significant based on hours of service, with all ten measures being of statistically significant values. Table 32 on the following page depicts this outcome.

As in the case of Question 9 and in the Astin and Sax (1998) study, students universally reported impact in these developmental areas at statistically significant levels. By design, several of these areas represented the seven vectors of development conceived and later modified by Chickering and Reisser (1993) - specifically items 11.1 through 
Table 32

Impact of Service by Hours of Service

\begin{tabular}{lccc}
\hline Question & Spearman & Standard Error & Sig. Level \\
\hline 11.1 Competence & .205 & .056 & $.000^{* *}$ \\
11.2 Manage emotions & .257 & .055 & $.000^{* *}$ \\
11.3 Autonomy & .252 & .054 & $.000^{* *}$ \\
11.4 Relationships & .230 & .054 & $.000^{* *}$ \\
11.5 Identity & .329 & .052 & $.000^{* *}$ \\
11.6 Purpose & .314 & .052 & $.000^{* *}$ \\
11.7 Place in world & .211 & .056 & $.000^{* *}$ \\
11.8 Sense of duty & .165 & .057 & $.004^{* *}$ \\
11.9 Nurture & .162 & .056 & $.003^{* *}$ \\
11.10 Social Justice & .251 & .055 & $.000^{* *}$ \\
\hline
\end{tabular}

$\mathrm{p} \leq .01^{* *}$

11.6 above. These vectors, according to Chickering and Reisser, were indicators of identity development and describe the dynamics that lead to and follow from the development of identity (1993). In contrast to these results for hours of service, few significant measures emerged for gender or year in school in response to this question. For gender, 11.4, 11.7, and 11.9 showed chi-square values at statistically significant levels. For year in school, only 11.6 registered a statistically significant Spearman value in the low to moderate range of magnitude.

Factor 11.5 in Table 28 (p. 145) points out the strength of relationship between hours of service and sense of identity. This factor was measured as the strongest selfreported impact of service by students in the sample. Both qualitative measures and 
survey data indicated that students in both phases of this study attributed their service involvements as a major element in the formation of their sense of identity, meaning, and purpose while in college, and that there was a strong and positive correlation between hours of service involvement and overall sense of identity, purpose, and meaning. In interpreting meaning from service, Robert Rhoades’ study of college student service relied on Herbert Mead's (Mead, 1934) social theory of the self in his discussion of the impact of service on development of self and identity (Rhoades, 1997). Mead and those who followed in the field of symbolic interactionism identified the process of interaction as key to the development of sense of self and identity. "Interacting individuals produce and define their own definitions of situations," according to Norman Denzin, a leading proponent of symbolic interactionism (Denzin, 1989, p. 5). As pointed out by Rhoades (1997, pp. 26-27) symbolic interactionism theory has much utility in interpreting students' self-explorations through service. Service is inherently interactive, students often have positive feelings reflected back to them through service, and students tend toward reflection - formally organized or personal - in response to their interactions in service to others. This was made evident in this study in focus group discussions and individual interviews.

There was a direct relationship between hours of service involvement and reported learning from service across all measures of learning in the survey for the sample population. This finding supported the findings of previous research seeking to measure the impact of service on learning and development in college and provided ample basis to continue to promote service in college as a tool to promote student learning and development. As previous researchers had found, there was a direct and 
measurable impact on students' perceptions of their own learning via service. Discussion of the implications of this finding are included in the section that follows.

\section{Significance of Findings}

This study allowed the researcher to draw a number of conclusions regarding college students and their student involvements. These conclusions apply to this research site and the study sample, but would possibly be replicable in other settings and with other student populations, as is suggested in the closing section of this chapter. The conclusions drawn from this study appear below. These are not ordered by strength or importance.

\section{Conclusions}

The researcher concluded the following about the sample population with regard to research questions of this study:

1. There was a difference between men and women in how students described factors leading to their involvement in service, how they selected service involvements, and how they described learning from service.

2. Men were more likely to consider potential outcomes of service, external motivators, and limited time commitment in their contemplation of service involvement and choice of project(s).

3. Women were more likely to be motivated by internal and more subjective compulsions to contribute through service and to "follow their hearts" in a determination of specific service involvements. They were also more likely to become involved in service as an ongoing commitment over time. 
4. External motivators to serve (e.g., as a course requirement or part of a team or organization) diminished in importance by year in school and hours of service and were replaced with internal motivators such as feeling strongly about a cause and wanting to contribute. In both cases, however, external motivators were important initial motivations toward service.

5. Similarly, one-time project opportunities appeared to be a more likely selection for those earlier in their college careers and for those who had served few to no hours previously; this selection diminished in favor of ongoing service commitments as students advanced through their college careers and gained more service experiences.

6. Men were universally thought to be less inclined to become involved in service than women during their college years; chief reasons given for this were lack of time, insufficient interest, lack of awareness of service opportunities, and not being invited to participate.

7. Men and women described service differently, with men describing it as an individual and impersonal activity based in rational and objective enactments of societal duty and women describing service predominantly as a relational activity based in emotional and subjective personal commitments.

8. A strong and positive relationship existed between hours of service previously performed and nearly all measures in this study, most notably with regard to description of learning from service in measures of cognitive development, skill development, and identity development. 
These conclusions affirmed much of what has been written about the impact of service on student learning and development. The conclusions added to this body of knowledge particularly with regard to emerging research on gender difference in college, strength of relationship between service and identity development, and the relative weight of internal and external motivators toward service in college based on gender, year in college, and hours of service previously performed. Implications of these findings are substantial for practitioners in the field of service learning and for educators and administrators generally in higher education. These are discussed in the following section, followed by recommendations for further study.

\section{Implications}

In framing a discussion of implications, it was important for the researcher to establish a context based within which recommendations were framed. The context was grounded both in the findings of this study and in historical assumptions and knowledge about the importance of service to student learning and development.

Nearly a century of research, theory, and study has demonstrated the powerful effect of service as a pedagogical tool as well as the connections between social interaction and development and the tendencies of humans to develop in direct relationship to the depth and breadth of their experiences (Dewey, 1916; Mead, 1934; Piaget, 1964). More recent research has demonstrated the effects of service learning on college student learning and development (Astin \& Sax, 1998; Jones \& Abes, 2004; Jones \& Hill, 2003; Rhoades, 1997). Still more recent attention has been paid to gender difference in college (Sax, 2008), adding to earlier research into women’s moral 
development (Chodorow, 1978; Gilligan, 1982; Noddings, 1984) in relation to that of men.

This study was conceived, framed, and designed within this context. The study sought to explore the effects of service on participants and to understand differences in how students describe their experiences in service based on gender, year in school, and hours of service. Findings of the study affirmed much of what had been written earlier about college students and service - their motivations to serve and their learning from service. Findings expanded our knowledge about the effects of service as reported by students and added to our understanding of differences - in gender, year in school, and amount of service - and how these impact students' perceptions about and reported learning from service. Implications of these findings are explored below with these added understandings at their center.

It was useful first to explore recommendations from a recent comprehensive study of service and college students. Robert Rhoades (1997), in the concluding chapter of his study of college students and service, identified several strategies designed to, in his words, advance community service to center stage (pp. 222-228). It was difficult not to repeat many of those recommendations here. His recommendations extended to institutional leaders, faculty, student affairs professionals, and student leaders. To these groups might be added external organizations whose purpose is to promote and develop service opportunities on college campuses. Given the rather comprehensive quality of Rhoades' treatment of this section, his recommendations were summarized for each group below, followed by additional recommendations derived from the present study. 
For institutional leaders, Rhoades proposed that community service be given a public forum, with institutional leaders taking opportunities to promote and encourage service among students (1997, p. 222). He also proposed that leaders engage in service themselves as role models for an ethic of service, and that they reward students and employees who participate in service (p. 223). For the faculty, Rhoades urged faculty to add service components to their courses, encourage students’ involvement in service outside of course requirements, and devote scholarly attention to the role of service in learning (pp. 223-224). For student affairs professionals, Rhoades encouraged implementation of service learning programs, development of service initiatives throughout student affairs departments, and use of service activities in residential programming (pp. 224-225). Finally, for student leaders, Rhoades proposed that students encourage peers to get involved in service, provide support for service activities, and act as role models for other students (p. 225).

Rhoades (1997) went on to suggest several structural changes that might be necessary in order to advance service in college and university settings. These included making community service central to the mission of the institution, making service a vital component of the formal curriculum, formalizing expectations of faculty to foster service opportunities for students, and working to bridge the gap between academic and student affairs through joint involvement in service activities (pp. 226-227).

The findings of this study supported all of Rhoades' recommendations for the various groups he identified and his proposed structural changes. The researcher would observe that many of these structural changes have in fact been made or at least have been widely recognized as best practices in promoting student learning, growth, and 
development through service. In addition to the recommendations made by Rhoades, the following specific recommendations were identified from the current study. Here the term educators is used broadly to include faculty, service learning program personnel, and student life personnel.

1. Educators should recognize that gender does play a role in how students think about, choose, and describe their learning from service involvements during college. In seeking to involve more male students in service, educators should be careful to avoid affirmation of a stereotype based in fact - that men are less likely to serve than women - and should seek to reach out and "market" service opportunities to male students equally aggressively with outreach to women. Men reported in this study that they did not feel invited to serve or were unaware of service opportunities; that is one perceived obstacle to service involvement that is easily removed.

2. Just like parents, children, and vegetables, educators often do know what is best for their students. This study demonstrated that men, students earlier in their college careers, and those who had not served substantially previously were more likely to become involved in service because of a requirement, but that once involved they were more likely to continue and even expand their involvement. Educators should strive to introduce service opportunities to students early and often, and to find ways to inject service into orientation programs, first-year seminars, and residential programs.

3. In recruitment to service, language is important, particularly where gender is concerned. One service learning director at the research site recently reported 
having removed the word 'service' from a course description and replaced it with 'work.' Coincidentally or not, the course enrolled more men than was typically the case. Men and women in focus group discussions pointed out on numerous occasions that they gravitated toward certain conceptions of service more than toward others, and that differences did tend to exist between men and women in what drew them to service involvement. Educators should craft language to describe service opportunities in ways that appeal to established motivating factors from this and other similar studies. This might mean crafting language related to career exploration and advancement, social obligation, or personal fulfillment.

4. Type of service project is important, particularly in the recruitment of students early in their careers, those who have not served previously, and men, according to results of this study. One-time projects are more likely to attract involvement from these groups. Special service days, college-wide or residential unit projects, and one-time projects delivered in the venues described in number two above may be the key to early involvement and the cultivation of a service ethic among students less likely to serve. Purists in the service world might argue that this is a 'dumbed down' version of service, with little potential for reflection, learning or impact. The aim, however, is to set the hook, get students interested who might not otherwise have been, and to make it clear that all are invited to service, that serving is not the purview of the core of students on every campus devoted to social justice causes and community involvement. 
5. In terms of learning from service, most research into the impact of service on student learning has found that learning impact is maximized by adding a reflection component to the service experience (Astin \& Sax, 1998; Pascarella \& Terenzini, 2005). This is a long-established fact in the service learning world but is often neglected in practice, particularly for the kinds of early, one-time projects described above. Even for those experiences, a brief conversation during or following the service activity can serve to plant a seed, raise a question, or excite further interest among participants. Providing this opportunity assures that it will be more likely that participants will take maximum advantage from the experience.

6. Institutionally, the researcher echoes the recommendations of Rhoades with regard to making service central to the mission of the college or university, blending and blurring academic and student affairs distinctions in service opportunities, role modeling and rewards for service throughout the institution, and encouraging and rewarding faculty for inclusion of service within the curriculum. These are tried and tested strategies for growing service opportunities and an ethic of service at institutions across the county.

These suggestions, grounded in the findings of this study, are for the most part not new. They build on best practices already in place at many institutions. As more information becomes available regarding students' motivations to serve, their choices of service involvement, and their learning from service, practitioners should continue to use what is known to maximize student involvement in service. Going forward, more can be 
learned about college students and service. The concluding section suggests some possible additional paths of inquiry.

\section{Summary}

This study sought to explore how students described their motivations toward service involvement, their choices of service involvement, and their learning from service. The study sought further to discern if there were differences in how students described these things based on gender, year in school, and hours of service performed. Findings indicated that students spoke in very rich and varied terms about their service involvements and choices, and that differences did exist in their description of aspects of their service experiences based on gender, hours of service, and to some extent year in college.

Properties emerged from the focus groups are shown in Table 33 on pages 168169.

In terms of the specific hypotheses with regard to difference, the following outcome decisions were reached:

Reject H1. There is no difference in how students describe motivation to serve, selection of service, and learning outcomes from service based on gender.

Fail to Reject H2. There is a difference in how students describe motivation to serve; there is no difference in selection of service and learning outcomes based on year in college.

Reject H3. There is no difference in how students describe motivation to serve, selection of service, and learning outcomes based on amount of service performed.

Recommendations for further study conclude the report of the research. 
Table 33

\section{Summary of Focus Group Properties}

\begin{tabular}{|c|c|c|}
\hline Category & Properties & Dimensions \\
\hline \multirow[t]{3}{*}{ Definition of Service } & Contribute to Others & $\begin{array}{l}\text { Change the world } \\
\text { Meet a need } \\
\text { Provide for others } \\
\text { Accomplish a good }\end{array}$ \\
\hline & Share skills/knowledge & $\begin{array}{l}\text { Share gifts } \\
\text { Use skills } \\
\text { Teach others } \\
\text { Provide for others }\end{array}$ \\
\hline & Improve Self & $\begin{array}{l}\text { Follow one's heart } \\
\text { Learn from others } \\
\text { Listen to others } \\
\text { Find one's self }\end{array}$ \\
\hline \multirow[t]{4}{*}{ Motivation to Serve } & Requirement & $\begin{array}{l}\text { Class requirement } \\
\text { Team requirement } \\
\text { Part of a student organization }\end{array}$ \\
\hline & Develop Skills/Career & $\begin{array}{l}\text { Gain leadership skills } \\
\text { Add to resume } \\
\text { Explore a career field }\end{array}$ \\
\hline & Intrinsic & $\begin{array}{l}\text { Gain a sense of meaning } \\
\text { Desire to contribute } \\
\text { Fulfill a responsibility } \\
\text { Calling or duty }\end{array}$ \\
\hline & Extrinsic & $\begin{array}{l}\text { Social justice or inequity } \\
\text { Accomplish a good } \\
\text { Friends' involvement } \\
\text { Past experience }\end{array}$ \\
\hline \multirow[t]{2}{*}{ Choice of Service Involvement } & Match of Skills & $\begin{array}{l}\text { Right skills for the job } \\
\text { What I could offer } \\
\text { Career related }\end{array}$ \\
\hline & Type of Project & $\begin{array}{l}\text { Physical nature of work } \\
\text { Social nature of work } \\
\text { One-time project } \\
\text { Ongoing commitment }\end{array}$ \\
\hline
\end{tabular}




\begin{tabular}{|c|c|c|}
\hline Category & Properties & Dimensions \\
\hline \multirow{7}{*}{$\begin{array}{l}\text { Choice of Service Involvement } \\
\text { (cont'd) }\end{array}$} & Subjective Interest & Passion for the cause \\
\hline & & Importance of need \\
\hline & & What I could learn \\
\hline & & Personal interest \\
\hline & & Friends were involved \\
\hline & Outcomes Driven & Potential for impact \\
\hline & & Breadth of impact \\
\hline \multirow[t]{11}{*}{ Learning from Service } & Interpersonal Learning & Learned about others \\
\hline & & Learned about myself \\
\hline & & Learned about relationships \\
\hline & Organizational Learning & Learned about leadership \\
\hline & & Learned about organizations \\
\hline & & Learned about community \\
\hline & Social Justice Learning & Learned about justice \\
\hline & & Learned about social issues \\
\hline & & Learned about duty \\
\hline & Emotional Learning & Learned about caring \\
\hline & & Learned about love \\
\hline
\end{tabular}

\section{Recommendations for Further Study}

A number of possible studies building on this and other recent studies of college students and service might be considered for further study. The researcher also discovered ways in which replications of this study could be improved. These are covered first below, followed by suggestions for further research.

This study benefitted from a mixed methodology in ways previously described. The mix of qualitative and quantitative methods allowed for both in-depth exploration and analysis of motivations, choices, and learning outcomes from service and a testing of these outcomes within a larger sample. The multiple data gathering strategies allowed for repeated triangulation of data gathered at each stage. At the same time, particularly in the qualitative phase of the research, the redundancy of data became excessive. If 
conducting a similar study again, the researcher would most likely eliminate individual interviews from the qualitative data gathering strategy. While these interviews did allow for member checking as described earlier, they did not yield significantly new or impactful data to the study.

The researcher considered and rejected use of a larger or different sample population in the quantitative phase of the study, chiefly as a means to broaden and diversify the sample population beyond a single institution, thereby potentially strengthening the generalizability of findings of the study. While this would likely have added to the strength of findings, constraints of time and a lack of funding for the study made such an expansion unfeasible. Future studies may consider broadening the scope of the research and increasing sample size, as suggested below.

This study was conducted at a small private college in the Midwest. It would be useful to conduct a similar study or studies at institutions of varied size, type, and location. While this study makes no claim to replicability or generalizability of findings to other settings, the assumption of the researcher is that results would indeed be similar at other institutions unlike the research site. In other words, findings of this research are assumed to be related to student experiences in service and not to specific institutional settings.

This study did not seek to control for the possible cross-over effects of gender, year in college, and hours of service, as previously mentioned. Subsequent studies could seek to dissect the effects of these various factors on student learning and development. Were some of the statistically significant measures for hours of service in this study, for instance, attributable in part to gender or year in college? For the sake of findings 
reported in this study, this distinction was largely irrelevant. Such a study could, however, contribute further to our understanding of differential effects of gender, year in school, and hours of service.

While this study measured impact of service based on hours of service, it did not seek to establish a control group or pre- post-measures of impact. It could be useful to compare impact on student development in either a longitudinal study with pre- and postmeasures, tracking students through their college careers based on their involvement in service during those years. Alternately, a comparative study of those involved in service and those not involved could be conducted specifically aimed at discerning developmental differences between the two samples. Such a study could potentially yield more conclusive evidence of the impact of service involvement on student development during the college years.

It might be useful in a broader sense to track students beyond their college years to discern whether service patterns or behaviors in college continued beyond college or whether these changed qualitatively or quantitatively. A related study would be to examine the extent to which service behaviors and commitments in college carried over in any measurable way to career choices after college.

Regardless of particular directions of further study, interest in student learning and development is not likely to diminish in an age of rising college costs and calls for accountability in higher education. Several constituencies - students, parents, legislators, accrediting and funding bodies - will continue to be interested in how students learn, what they learn, and how well they learn and prepare for productive citizenship while in college. As a substantial contributor to student learning and growth while in college, 
service opportunities and their impacts will be of continued interest to these groups and to researchers and educators.

Similarly, interest in the differential experiences in college of students based on gender will continue. Recent studies such as that done by Linda Sax (2008) have been received with great interest in the higher education community. These studies have as one primary aim the ability to maximize the development of men and women during the college years by understanding better the differences at entry to college and the differential impacts of college on men and women. 


\section{References}

Astin, A. (1968). Personal and environmental determinants of student activism. Measurement and Evaluation in Guidance, 1, 149-162.

Astin, A. (1997). Liberal education and democracy: The case for pragmatism. In R. Orrill (Ed.), Education and Democracy: Re-imagining liberal learning in America (pp. 210-211). New York: College Entrance Examination Board.

Astin, A., \& Sax, L. (1998). How undergraduates are affected by service participation. Journal of College Student Development, 39(3), 251-263.

Astin, A., Vogelgesang, L., Ikeda, E., \& Yee, J. (2000). How service learning affects students. Los Angeles: Higher Education Research Institute, University of California, Los Angeles.

Baird, L. (1988). The college environment revisited: A review of research and theory. In J. Smart (Ed.), Higher education: Handbook of theory and research. New York: Agathon.

Barker, R. (1968). Ecological psychology: Concepts for studying the environment of human behavior. Stanford, CA: Stanford University Press.

Batchelder, T., \& Root, S. (1994). Effects of an undergraduate program to integrate academic learning and service: Cognitive, prosocial cognitive, and identity outcomes. Journal of Adolescence, 17, 341-355.

Baxter Magolda, M.B. (1992). Knowing and reasoning in college: Gender-related patterns in students’ intellectual development. San Francisco: Jossey-Bass. 
Baxter Magolda, M. B. (1999). Creating contexts for learning and self-authorship: Constructive-developmental pedagogy. Nashville, TN: Vanderbilt University Press.

Baxter Magolda, M. B. (2000). Interpersonal maturity: Integrating agency and communion. Journal of College Student Development, 41(2), 141-156.

Baxter Magolda, M.B. (2001). Making their own way: Narratives for transforming higher education to promote self-development. Sterling, VA: Stylus.

Belenky, M. F., Clinchy, B. M., Goldberger, N. R., \& Tarule, J. M. (1997). Women’s ways of knowing: The development of self, voice, and mind. New York: Basic Books.

Berger, P. L., \& Luckman, T. (1967). The social construction of reality. New York: Doubleday.

Best, J.H. (Ed.) (1962). Benjamin Franklin on education. New York: Teachers College Press.

Blumer, H. (1962). Society as symbolic interaction. In A.M. Rose (Ed.), Human behavior and social processes (pp. 179-192). Boston: Houghton-Mifflin.

Blumer, H. (1969). Symbolic interactionism: Perspectives and method. Berkely: University of California.

Bryant, A. N. (2007). Gender differences in spiritual development during the college years. Sex Roles, 56, 835-846.

Bryant, M. T. (2004). The portable dissertation advisor. Thousand Oaks, CA: Sage. 
Charmaz, K. (2000). Grounded theory: Objectivist and constructivist methods. In N. K. Denzin \& Y. S. Lincoln (Eds.), Handbook of qualitative research (2nd ed., pp. 509-536). Thousand Oaks, CA: Sage.

Cherryholmes, C. H. (1992, August-September). Notes on pragmatism and scientific realism. Educational Researcher, 14, 13-17.

Chickering, A. (1969). Education and identity. San Francisco: Jossey-Bass.

Chickering, A., \& Reisser, L. (1993). Education and identity (2nd ed.). San Francisco: Jossey-Bass.

Chodorow, N. (1978). The reproduction of mothering: Psychoanalysis and the sociology of gender. Berkely: University of California Press.

Clary, E.G. \& Snyder, M. (1999). The motivations to volunteer: Theoretical and practical considerations. Current Directions in Psychological Science, 8(5), 156159.

Cohen, J. (1988). Statistical power analysis for the behavioral sciences. Hillsdale, NJ: Lawrence Erlbaum.

Corporation for National \& Community Service, Office of Research and Policy Development. Volunteering in America: 2007 state trends and rankings in civic life. Washington, D.C. URL http://www.VolunteeringinAmerica.gov.

Corporation for National \& Community Service, Office or Research and Policy Development. Volunteering in America: 2008 state trends and rankings in civic life. Washington, D.C. URL http://www.VolunteeringinAmerica.gov.

Cross, K. (1971). Beyond the open door: New students to higher education. San Francisco: Jossey-Bass. 
Creswell, 1998. (1998). Qualitative inquiry and research design: Choosing among the five traditions. Thousand Oaks, CA: Sage.

Creswell, J. W. (1999). Mixed-methods research: Introduction and application. In G. J. Cizek (Ed.), Handbook of educational policy (pp. 455-472). San Diego, CA: Academic Press.

Creswell, J. W. (2007). Qualitative inquiry \& research design: Choosing among five approaches. Thousand Oaks, CA: Sage.

Creswell, J. W., Fetters, M. D., \& Ivankova, N. V. (2004). Designing a mixed methods study in primary care. Annals of Family Medicine, 2(1), 7-12.

Creswell, J. W., \& Plano Clark, V. L. (2007). Designing and conducting mixed methods research. Thousand Oaks, CA: Sage.

Creswell, J.W. \& Plano Clark, V.L. (2008). The Mixed Methods Reader. Thousand Oaks, CA: Sage.

Creswell, J. W., Plano Clark, V. L., Gutmann, M., \& Hanson, W. (2003). Advanced mixed methods research designs. In A Tashakkori \& C. Teddlie (Eds.), Handbook of mixed methods in social and behavioral research (pp. 209-240). Thousand Oaks, CA: Sage.

Crotty, M. (1998). The foundations of social research: Meaning and perspective in the research process. Thousand Oaks, CA: Sage.

Denzin, N. (1987). A phenomenology of the emotionally divided self. In K. Yardley \& T. Honess (Eds.), Self and identity: Perspectives across the lifespan (pp. 223240). New York: Routledge.

Denzin, N. (1989). The research act (3rd ed.). New York: Prentice-Hall. 
Dewey, J. (1916). Democracy and education. Carbondale, IL: Southern Illinois University.

Erikson, E. (1959). Identity and the life cycle. Psychological Issues Monograph 1(1), 1-171. New York: International Universities Press.

Erikson, E. (1963). Childhood and society (2nd ed.). New York: W.W. Norton.

Erikson, E. (1968). Identity: Youth and crisis. New York: W.W. Norton.

Eyler, J., \& Giles, D. E., Jr. (1999). Where’s the learning in service learning? San Francisco: Jossey-Bass.

Eyler, J., Giles, D., Lynch, C., \& Gray, C. (1997, March). Service learning and the development of reflective judgment. Paper presented at the meeting of the American Educational Research Association, Chicago.

Eyler, J., Giles, D., Root, S., \& Price, J. (1997, March). Service learning and the development of expert citizens. Paper presented at the American Educational Research Association, Chicago.

Fitch, R.T. (1987). Characteristics and motivations of college students volunteering for community service. Journal of College Student Personnel, 28, 424-431.

Gidron, B. (1983). Sources of job satisfaction among service volunteers. Journal of Voluntary Action Research, 12, 20-35.

Gilligan, C. (1977). In a different voice: Women’s conceptions of self and of morality. Harvard Educational Review, 47, 481-517.

Gilligan, C. (1982). In a different voice: Psychological theory and women's development. Cambridge, MA: Harvard University Press. 
Gravetter, F. J., \& Wallnau, L. B. (2005). Essentials of statistics for the behavioral sciences (5th ed.). Belmont, CA: Wadsworth.

Hatch, J. A. (2002). Doing qualitative research in education settings. Albany, NY: State University of New York.

Heath, D. (1968). Growing up in college. San Francisco: Jossey-Bass.

Heath, D. (1978). A model of becoming a liberally educated and mature student. In C. Parker (Ed.), Encouraging development in college students. Minneapolis: University of Minnesota Press.

Herzberg, F. (1966). Work and the nature of man. Cleveland, OH: World.

Holland, J. L. (1966). The psychology of vocational choice: A theory of personality types and model environments. Waltham, MA: Blaisdell.

Holland, J.L. (1985). Making vocational choices: A theory of vocational choices and work environments (2md ed.) Englewood Cliffs, NJ: Prentice Hall.

House, J. S. (1977). The three faces of social psychology. Sociometry, 40(2), 161-177.

Huebner, L. (1989). Interaction of student and campus. In U. Delworth, G. Hanson \& Associates (Eds.), Student services: A handbook for the profession. San Francisco: Jossey-Bass.

Jones, S. R., \& Abes, E. S. (2004). Enduring influences of service-learning on college students' identity development. Journal of College Student Development, 45(2), 149-166.

Jones, S. R., \& Hill, K. E. (2003). Patterns of commitment: student motivation for community service involvement. Journal of Higher Education, 74(5), 516-539. 
Josselson, R. (1987). Finding herself: Pathways to identity development in women. San Francisco: Jossey-Bass.

Jung, C. (1980). A way of being. Boston: Houghton Mifflin.

Kegan, R. (1982). The evolving self: Problem and process in human development. Cambridge, MA: Harvard University Press.

Kegan, R. (1994). In over our heads: The mental demands of modern life. Cambridge, MA: Harvard University Press.

Kendrick, J. (1996). Outcomes of service learning in an introduction to sociology course. Michigan Journal of Community Service Learning, 3 (1), 72-81.

King, P \& Kitchener, K. (1981). Reflective judgment: Concepts of justification and their relationship to age and education. Journal of Applied Developmental Psychology, 2, 89-116.

King, P. \& Kitchener, K. (1990). The reflective judgment model: Ten years of research. In M. Commons, C. Armon, L. Kohlberg, F. Richards, T. Grotzer, \& J. Sinnot (Eds.), Adult development: Models and methods in the study of adolescent and adult thought. New York: Praeger.

Kohlberg, L. (1972). The cognitive-developmental approach to moral education. Humanist, 32, 13-16.

Kohlberg, L. (1984). Essays on moral development (Vol. 2). The psychology of moral development. New York: Harper \& Row.

Komives, S.R., Woodward, D.B., \& Associates. (2003). Student services: A handbook for the profession. San Francisco: Jossey-Bass. 
Kuh, G. (1987). A brief for incorporating organizational theory in student affairs preparation and research. Paper presented at the meeting of the Association for the Study of Higher Education, Baltimore.

Lewin, K. (1951). Field theory in social science. New York: Harper \& Row.

Loevinger, J. (1976). Ego development: Conceptions and theories. San Francisco: JosseyBass.

Lorber, J. (1994). Paradoxes of gender. New Haven, CT: Yale University Press.

Marcia, J. (1965). Determination and construct validity of ego identity status. Dissertation Abstracts International, 25, 6763A.

Marcia, J. (1966). Development and validation of ego-identity status. Journal of Personality and Social Psychology, 3, 551-558.

Mead, G.H. (1934). Mind, self, and society. Chicago: University of Chicago Press.

Moos, R. (1976). The human context: Environmental determinants of behavior. New York: Wiley \& Sons.

Morgan, D. L. (1998). Practical strategies for combining qualitative and quantitative methods: Applications to health research. Qualitative Health Research, 8(3), 362-376.

Morse, J. M. (1991). Approaches to qualitative-quantitative methodological triangulation. Nursing Research, 40, 120-123.

Mounter, C.T. (1985). A study of the degree of success of a volunteer program based on the motivations of volunteer and perceptions of these by agents. Unpublished doctoral dissertation, University of Georgia, Athens. Dissertations Abstracts International, 45(1), A54. (University Microfilms No. AAC8606071). 
Moustakas, C. (1994). Phenomenological research methods. Thousand Oaks, CA: Sage. Murray, H. (1951). Toward a classification of interaction. In T. Parsons \& E. Shils (Eds.), Toward a general theory of action. Cambridge, MA: Harvard University Press. Myers, I. (1980). Introduction to type. Palo Alto, CA: Consulting Psychologists Press. Net Impact 2008 Membership Survey, June 23, 2008 at www.netimpact.org. Accessed July 15, 2008.

Noddings, N. (1984). Caring: A feminine approach to ethics and moral education. Berkely: University of California Press.

Noddings, N. (1992). The challenge to care in schools: An alternative approach to education. New York: Teachers College Press.

Pascarella, E. T., \& Terenzini, P. T. (1991). How college affects students. San Francisco: Jossey-Bass.

Pascarella, E. T., \& Terenzini, P. T. (2005). How college affects students: Volume 2: A third decade of research. San Francisco: Jossey-Bass.

Patton, M. Q. (1990). Qualitative education and research methods. Newbury Park, CA: Sage.

Perry, W. (1970). Forms of intellectual and ethical development in the college years: A scheme. New York: Holt, Rinehart \& Winston.

Perry, W. (1981). Cognitive and ethical growth. In A. Chickering \& Associates (Eds.), The modern American college: Responding to the new realities of diverse students and a changing society. San Francisco: Jossey-Bass.

Phillips, M. (1982). Motivation and expectation of successful volunteerism. Journal of Voluntary Action Research, 11, 118-125. 
Piaget, J. (1964). Judgment and reasoning in the child. Totowa, NJ: Littlefield, Adams. Polkinghorne, D. E. (1989). Phenomenological research methods. In R. S. Valle \& S. Halling (Eds.), Existential-phenomenological perspectives in psychology (pp. 41-60). New York: Plenum Press.

Rhoades, R. A. (1997). Community service and higher learning. Albany, NY: State University of New York.

Rodgers, R. (1989). Student development. In U. Delworth, G. Hanson, \& Associates (Eds.), Student services: A handbook for the profession (2nd ed.). San Francisco: Jossey-Bass.

Sandmann, L., Thornton, C. \& Jaeger, A., eds. (2009). Institutionalizing community engagement in higher education: The first wave of Carnegie classified institutions. San Francisco: Wiley.

Sax, L. (2008). The gender gap in college: Maximizing the developmental potential of women and men. San Francisco: Jossey-Bass.

Serow, R.C. (1991). Students and volunteerism: Looking into the motives of community service participants. American Educational Research Journal, 28, 543-556.

Smith, D.H. (1981). Altruism, volunteers, and volunteerism. Journal of Voluntary Action Research, 10, 21-38.

Strange, C., \& King, P. (1990). The professional practice of student development. In D. Creamer \& Associates (Eds.), College student development theory and practice for the 1990's. Alexandria, VA: American College Personnel Association. 
Strauss, A. \& Corbin, J. (1990). Basics of qualitative research: Grounded theory procedures and techniques. Newbury Park, CA: Sage.

Tashakkori, A., \& Teddlie, C. (1998). Mixed methodology: Combining qualitative and quantitative approaches. Thousand Oaks, CA: Sage.

Tashakkori, A., \& Teddlie, C. (2003). Handbook of mixed methods in social and behavioral research. Thousand Oaks, CA: Sage.

Thoits, P.A. \& Hewitt, L.N. (2001). Volunteer work and well-being. Journal of Health and Social Behavior, 42(2), pp. 115-131.

Whitehead, T. L., \& Reid, B. V. (1992). Gender constructs and social issues. Champaign, IL: University of Illinois Press.

Wilson, J. \& Musick, M. (1997). Who cares? Toward an integrated theory of volunteer work. American Sociological Review, 62, 694-713.

Wilson, J. (2000). Volunteering. Annual Review of Sociology, 26, 215-240.

Winniford, J.C., Carpenter, D.S., \& Grider, C. (1995). An analysis of the traits and motivations of college students involved in service organizations. Journal of College Student Development, 36, 27-38.

Winniford, J.C., Carpenter, D.S., \& Grider, C. (1997). Motivations of college student volunteers: A review. NASPA Journal, 34(2), 134-146. Washington, D.C.: NASPA.

Youniss, J. \& Yates, M. (1997). Community Service and social responsibility in youth. Chicago: The University of Chicago Press. 


\section{Appendix A}

Invitation to Participate and Informed Consent 


\section{Date \\ Name \\ Address \\ Dear (Name):}

You are invited to participate in a study to explore students' involvement in service at Hastings College. Specifically, the study, to be conducted by me with Colt Krauss as research assistant, will explore how men and women who have participated in service while in college chose their service commitments and how they describe their learning from service involvement. The study will take a special interest also in how participants describe any impact on their sense of meaning and purpose of their involvement in service.

Participation in this study is voluntary. You may withdraw from participation at any time and may determine that any information provided by you is not used in final publication of study results. You will be assured of anonymity in any publication of study findings and will be offered the opportunity to review any information provided by you prior to its use in determining and publishing findings of the study.

There is no extrinsic reward for participation in the study; however, participation in the study and review of its findings may be beneficial to you in your own process of reflection on service and its impacts on your life. Risks of participation are minimal or nonexistent.

Your participation will involve focus group interviews and possibly individual interviews with the Primary Investigator. These interviews will be taped - focus groups interviews will be both audio and video taped; individual interviews will be audio-taped only. You may review the contents of tapes of your interview(s) at any time. All information from interviews will be stored in a secure place and will be transcribed verbatim for the study.

If you are willing to participate in this study, please contact me at 402-461-7394 or by email at rchesbrough@hastings.edu. I will be happy to answer additional questions that you may have. If you elect to participate I will provide you with relevant information about the location and scheduling of interview session. Thank you for considering participation in this study.

Sincerely,

Ron Chesbrough

Principal Investigator 


\author{
INVITATION TO PARTICIPATE AND \\ RESEARCH PARTICIPANT CONSENT FORM \\ SERVICE LEARNING SURVEY \\ Understanding Service Learning in College \\ Ron Chesbrough, Principal Investigator \\ Hastings College, Student Life Division
}

Dear Student:

You are invited to complete the survey in the accompanying e-mail. The survey is being done for research purposes; results will be reported in a dissertation. Your responses will be anonymous and confidential. The survey is part of a dissertation study of how college students choose and describe their service involvements in college. Please read the information below and keep a copy for your records. Thank you for taking the time to complete the survey. Completion time should be about 10 minutes.

PURPOSE OF THIS STUDY

The purpose of this study is to explore how men and women choose their service commitments during college and how they describe their learning through service. The study will also explore how men and women in the study sample describe the impact, if any, of service on their sense of meaning and purpose in life.

PARTICIPANT SELECTION

You have been selected to participate in this study on the basis of your enrollment as a full-time undergraduate at Hastings College. You must be 19 years of age or older to complete this survey.

POTENTIAL RISKS

There are no known risks to participation in this study.

POTENTIAL BENEFITS

There is no direct benefit to you of participation in the study; however, with the completion of our study, you will receive a written summary of our findings, which may increase your awareness of this topic and may aid in your own self-awareness regarding the topic. There is no monetary or other type of compensation for participation.

GUARANTEE OF ANONYMTTY/CONFIDENTIALITY

Your responses will not be associated with your name in any written or oral form; therefore, your responses will be anonymous. All research materials and data will be stored in a locked filing cabinet in Ron Chesbrough's Hastings College office.

WITHDRAWAL FROM PARTICIPATION

Your participation in this research is voluntary. You are free to decide not to participate in this study. You may also withdraw at any time without harming your relationship with the researchers, the University of Nebraska-Lincoln, or Hastings College.

IF YOU HAVE QUESTIONS

You may ask any questions concerning this research and have those questions answered before agreeing to participate in or during the study. You may contact the principal investigator at (402) 461-7394 or rchesbrough@ hastings.edu. You may also contact the 
secondary investigator, Dr. James Griesen, at (402) 472-3725 or jgriesen@unlnotes.unl.edu. Please contact the investigators if you want to voice concerns or complaints about the research or in the event of a research-related injury.

Please contact the University of Nebraska-Lincoln Institutional Review Board (IRB) at (402) 472-6965 for the following reasons: you wish to talk to someone other than the research staff to obtain answers to questions about your rights as a research participant, to voice concerns or complaints about the research, to provide input concerning the research process, or in the event the study staff can not be reached. Please refer to

IRB\# 2009039814 when contact UNL's IRB. If you have additional concerns regarding your rights, you may also contact the chair of the Hastings College Committee for Human Subjects Research, Dr. John Perlich, at CHSRChair@hastings.edu.

Thank you once again for taking time to complete the survey. You may begin the survey by clicking on the link in the accompanying e-mail

Sincerely,

Ron Chesbrough

Principal Investigator

Click here to access and complete the survey:

http://qshare.qualtrics.com/SE?SID=SV elCOMTPH8E9iD6c\&\&VID=Prod 
Statement of Invitation to Participate in Individual Interviews

At the close of focus group interviews, the following invitation will be made to participate in individual interviews:

"Thank you for your participation in the focus group discussion. As part of this study, I am also interested in conducting individual interviews with up to four members of this group. These interviews will be approximately 75 minutes in length and will be scheduled to occur on the Hastings College campus at a time convenient to interviewees. There is no requirement of participation, nor any rewards or special qualifications for participating in these interviews. If you are interested in participating in an individual interview please e-mail me at rchesbrough@hastings.edu. If more than four expressions of interest are received I will select randomly from those received. Your selection or non-selection for individual interview will not be based on any particular characteristic or qualification, but rather a function of the limitations on individual interviews that $\mathrm{I}$ have placed on this study. Individual interview participants will be provided an additional informed consent letter regarding the individual interview process and uses of data." 


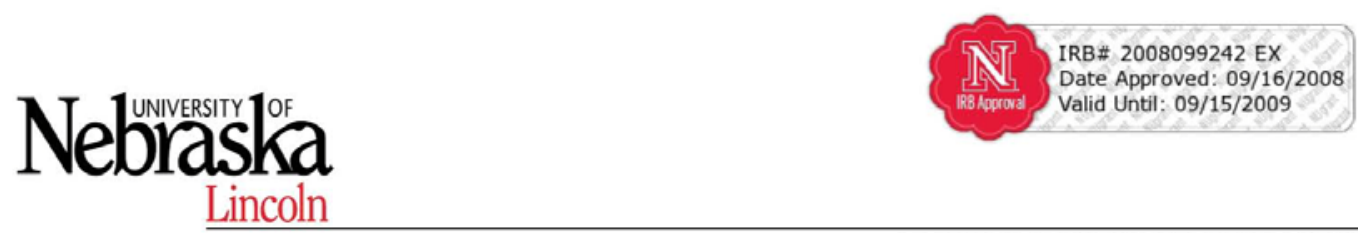

COLLEGE OF EDUCATION AND HUMAN SCIENCES Department of Educational Administration

\author{
RESEARCH PARTICIPANT CONSENT FORM \\ INDIVIDUAL INTERVIEWS \\ Meaning-Making in College: How Men and Women Talk About Service, Purpose \\ and Meaning at a Small Private Midwestern College \\ Ron Chesbrough, Principal Investigator \\ Hastings College, Student Life Division
}

PURPOSE OF THIS STUDY

The purpose of this study is to explore how men and women choose their service commitments during college and how they describe their learning through service. The study will also explore how men and women in the study sample describe the impact, if any, of service on their sense of meaning and purpose in life.

PARTICIPANT SELECTION

You have been selected to participate in this study on the basis of your involvement in service during your enrollment at Hastings College. Only students 19 years of age or older have been invited to participate.

PROCEDURES

You will be asked to participate in an individual interview lasting approximately 75 minutes. All interviews will occur on the Hastings College campus and at a time convenient to you. Interviews will be audio taped; tapes will be destroyed immediately following transcription. A transcription assistant will be utilized for this study; the assistant will sign a confidentiality statement indicating that the confidentiality rules of the study as described below will be followed.

POTENTIAL RISKS

There are no known risks to participation in this study.

\title{
POTENTIAL BENEFITS
}

There is no direct benefit to you of participation in the study; however, with the completion of our study, you will receive a written summary of our findings, which may increase your awareness of this topic and may aid in your own self-awareness regarding the topic. There is no monetary or other type of compensation for participation.

\section{GUARANTEE OF ANONYMITY/CONFIDENTIALITY}

Your responses will not be associated with your name in any written or oral form; therefore, your responses will be anonymous. All research materials and data will be stored in a locked filing cabinet in Ron Chesbrough's Hastings College office; all audio tapes of interviews will be destroyed immediately following transcription.

WITHDRAWAL FROM PARTICIPATION

Your participation in this research is voluntary. You are free to decide not to participate in this study. You may also withdraw at any time without harming your relationship with the researchers, the University of NebraskaLincoln, or Hastings College.

Page 1 of 2 
IF YOU HAVE QUESTIONS

If you have any questions about the procedures in which you will participate, please do not hesitate to ask the investigators. If you have questions later, please feel free to contact Ron Chesbrough at 402-461-7394. You may also contact Dr. James Griesen, Secondary Investigator and Professor of Educational Administration at the University of Nebraska-Lincoln, at 402-472-3725. If you have additional concerns regarding your rights, you may contact the chair of the Hastings College Committee for Human Subjects Research, Dr. John Perlich, at CHSRChair@hastings.edu, or the University of Nebraska-Lincoln's Institutional Review Board office at 402-4726965 .

I understand the purpose and conditions of this research as outlined above and that my participation is voluntary. I agree to be audio taped as part of my participation in this study (Yes I No

) .

Signature of Participant

Printed name of Participant

Participant's email
Date

Signature of Researcher

Date

My signature above indicates that I have read and reviewed the proposal and have checked its contents with CHSR guidelines. 


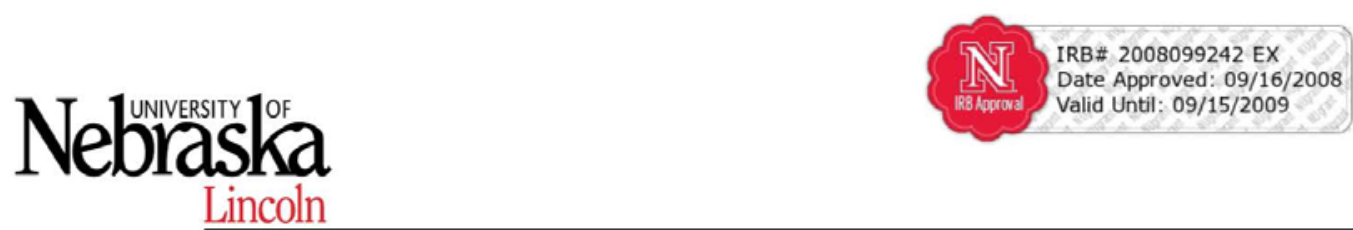

COLLEGE OF EDUCATION AND HUMAN SCIENCES Department of Educational Administration

\author{
RESEARCH PARTICIPANT CONSENT FORM \\ FOCUS GROUP INTERVIEWS \\ Meaning-Making in College: How Men and Women Talk About Service, Purpose \\ and Meaning at a Small Private Midwestern College \\ Ron Chesbrough, Principal Investigator \\ Hastings College, Student Life Division
}

PURPOSE OF THIS STUDY

The purpose of this study is to explore how men and women choose their service commitments during college and how they describe their learning through service. The study will also explore how men and women in the study sample describe the impact, if any, of service on their sense of meaning and purpose in life.

PARTICIPANT SELECTION

You have been selected to participate in this study on the basis of your involvement in service during your enrollment at Hastings College. Only students 19 years of age or older have been invited to participate.

\title{
PROCEDURES
}

You will be asked to participate in 2-3 focus group interviews lasting approximately 75 minutes. Up to four participants in the focus group interviews will be invited to participate in individual interviews; participants in individual interviews will complete an additional Informed Consent letter. All focus group interviews will occur on the Hastings College campus and at a time convenient to all participants. Focus group interviews will be audio/video taped; tapes will be destroyed immediately following transcription. A transcription assistant will be utilized for this study; the assistant will sign a confidentiality statement indicating that the confidentiality rules of the study as described below will be followed. As part of this study you will also be asked to share journal entries regarding your service involvements and to complete the Values in Action inventory and Meaning in Life questionnaire.

POTENTIAL RISKS

There are no known risks to participation in this study.

\section{POTENTIAL BENEFITS}

There is no direct benefit to you of participation in the study; however, with the completion of our study, you will receive a written summary of our findings, which may increase your awareness of this topic and may aid in your own self-awareness regarding the topic. There is no monetary or other type of compensation for participation.

\section{GUARANTEE OF ANONYMITYICONFIDENTIALITY}

Your responses will not be associated with your name in any written or oral form; therefore, your responses will be anonymous. Participants in focus group interviews will be asked not to share information about what is discussed or the names of fellow participants. All research materials and data will be stored in a locked filing cabinet in Ron Chesbrough's Hastings College office; all audio and video tapes of interviews will be destroyed immediately following transcription.

Page 1 of 2 
WITHDRAWAL FROM PARTICIPATION

Your participation in this research is voluntary. You are free to decide not to participate in this study. You may also withdraw at any time without harming your relationship with the researchers, the University of NebraskaLincoln, or Hastings College.

IF YOU HAVE QUESTIONS

If you have any questions about the procedures in which you will participate, please do not hesitate to ask the investigators. If you have questions later, please feel free to contact Ron Chesbrough at 402-461-7394. You

may also contact Dr. James Griesen, Secondary Investigator and Professor of Educational Administration at the University of Nebraska-Lincoln, at 402-472-3725. If you have additional concerns regarding your rights, you may contact the chair of the Hastings College Committee for Human Subjects Research, Dr. John Perlich, at

CHSRChair@hastings.edu, or the University of Nebraska-Lincoln's Institutional Review Board office at 402-4726965.

I understand the purpose and conditions of this research as outlined above and that my participation is voluntary. I agree to be audio and video taped as part of my participation in this study (Yes I No

Printed name of Participant

Participant's email

Signature of Researcher

Date

My signature above indicates that I have read and reviewed the proposal and have checked its contents with CHSR guidelines. 
Appendix B

IRB Approvals 
NUgrant Message

From:

Sent:

To:

Subject: nugrant-irb@unl.edu

Tuesday, September 16, 2008 10:52 PM

Chesbrough, Ron; jgriesen@unlnotes.unl.edu

NUgrant Message - Official Approval Letter for IRB project \#9242

September 16,2008

Ronald Chesbrough

Graduate Studies

James Griesen

Department of Educational Administration

125 TEAC UNL 68588-0360

IRB Number: 2008099242 EX

Project ID: 9242

Project Title: Meaning-Making in College: How Men \& Women Talk About Service, Meaning, and Purpose at a Small Midwestern College

Dear Ronald

This letter is to officially notify you of the approval of your project by the Institutional Review Board (IRB) for the Protection of Human Subjects. It is the Board's opinion that you have provided adequate safeguards for the rights and welfare of the participants in this study based on the information provided. Your proposal is in compliance with this institution's Federal Wide Assurance 00002258 and the DHHS Regulations for the Protection of Human Subjects (45 CFR 46) and has been classified as exempt

\section{Date of EX Review. 9/16/08}

You are authorized to implement this study as of the Date of Final Approval: 09/16/2008. This approval is Valid Until: 09/15/2009.

1. The approved informed consent forms have been uploaded to NUgrant (Informed Consent-Individual Interviews-Approved.pdf and Informed Consent-Focus Groups-Approved.pdf files). Please use these forms to distribute to participants. If you need to make changes to the informed consent forms, please submit the revised forms to the IRB for review and approval prior to using them.

We wish to remind you that the principal investigator is responsible for reporting to this Board any of the following events within 48 hours of the event

- Any serious event (including on-site and off-site adverse events, injuries, side effects, deaths, or other problems) which in the opinion of the local investigator was unanticipated, involved risk to subjects or others, and was possibly related to the research procedures;

- Any serious accidental or unintentional change to the IRB-approved protocol that involves risk or has the potential to recur;

- Any publication in the literature, safety monitoring report, interim result or other finding that indicates an unexpected change to the risk/benefit ratio of the research;

- Any breach in confidentiality or compromise in data privacy related to the subject or others; or

- Any complaint of a subject that indicates an unanticipated risk or that cannot be resolved by the research staff.

This project should be conducted in full accordance with all applicable sections of the IRB Guidelines and you should notify the IRB immediately of any proposed changes that may affect the exempt status of your research project. You should report any unanticipated problems involving risks to the participants or others to the Board. For projects which continue beyond one year from the starting date, the IRB will request continuing review and update of the research project. Your study will be due for continuing review as indicated above. The investigator must also advise the Board when this study is finished or discontinued by completing the enclosed Protocol Final Report form and returning it to the Institutional Review Board. 


\section{NUgrant Mesage}

If you have any questions, please contact the IRB office at 472-6965.

Sincerely,

Mario Scalora, Ph.D.

Chair for the IRB

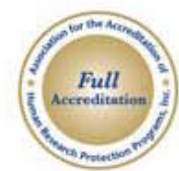

file:///C| ...ke1/CindyiOutside Files/C, D, \& E/C/Chesbrough, Ron/Original Files/Appendix files/Appendix B/NUgrant Message - Official.htm[8/10/2009 2:37:38 PM] 
NUgrant Message

From:

nugrant-irb@unl.edu

Sent:

Sunday, March 29, 2009 9:48 AM

To:

Chesbrough, Ron; jgriesen@unlnotes.unl.edu

Subject:

NUgrant Message - Official Approval Letter for IRB project \#9814

March 26, 2009

Ronald Chesbrough

Graduate Studies

James Griesen

Department of Educational Administration

125 TEAC UNL 68588-0360

IRB Number: 2009039814 EX

Project ID: 9814

Project Title: Understanding College Service Learning

Dear Ronald

This letter is to officially notify you of the approval of your project by the Institutional Review Board (IRB) for the Protection of Human Subjects. It is the Board's opinion that you have provided adequate safeguards for the rights and welfare of the participants in this study based on the information provided. Your proposal is in compliance with this institution's Federal Wide Assurance 00002258 and the DHHS Regulations for the Protection of Human Subjects (45 CFR 46) and has been classified as exempt

You are authorized to implement this study as of the Date of Final Approval: $03 / 26 / 2009$. This approval is Valid Until: 03/25/2010

1. Your IRB number has been added to the 'If you have questions' section of the invitation/consent form. Please make sure to use the text from the file 'Invitation_to_Particiapte_and_Informed_Consent-Approved.doc file.' If you need to make changes to the message please submit the revised message to the IRB for review and approval prior to using it.

We wish to remind you that the principal investigator is responsible for reporting to this Board any of the following events within 48 hours of the event:

- Any serious event (including on-site and off-site adverse events, injuries, side effects, deaths, or other problems) which in the opinion of the local investigator was unanticipated, involved risk to subjects or others, and was possibly related to the research procedures:

- Any serious accidental or unintentional change to the IRB-approved protocol that involves risk or has the potential to recur

- Any publication in the literature, safety monitoring report, interim result or other finding that indicates an unexpected change to the risk/benefit ratio of the research;

- Any breach in confidentiality or compromise in data privacy related to the subject or others; or

- Any complaint of a subject that indicates an unanticipated risk or that cannot be resolved by the research

This project should be conducted in full accordance with all applicable sections of the IRB Guidelines and you should notify the IRB immediately of any proposed changes that may affect the exempt status of your research project. You should report any unanticipated problems involving risks to the participants or others to the Board For projects which continue beyond one year from the starting date, the IRB will request continuing review and update of the research project. Your study will be due for continuing review as indicated above. The investigator must also advise the Board when this study is finished or discontinued by completing the enclosed Protocol Final Report form and returning it to the Institutional Review Board.

If you have any questions, please contact the IRB office at 472-6965. 
NUgrant Message

Sincerely,

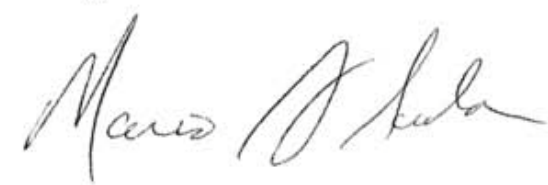

Mario Scalora, Ph.D.

Chair for the IRB

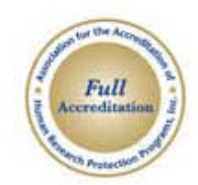

file ://C|/ ...e1/Cindy/Outside Files/C, D, \& E/C/Chesbrough, Ron/Onginal Files/Appendix files/Appendix B/NUgrant Message - Officiall htrm[8/10/2009 2:39:05 PM] 


\section{Nebraska \\ Lincoln}

July 22, 2009

Ronald Chesbrough

Graduate Studies

James Griesen

Department of Educational Administration

125 TEAC UNL 68588-0360

IRB Number: 2008099242 EX

Project ID: 9242

Project Title: Understanding College Service

Dear Ronald:

This is to officially notify you of the approval of your project's Continuing Review by the Institutional Review Board for the Protection of Human Subjects. It is the committee's opinion that you have provided adequate safeguards for the rights and welfare of the subjects in this study based on the information provided. Your proposal is in compliance with DHHS Regulations for the Protection of Human Subjects (45 CFR 46).

We wish to remind you that the principal investigator is responsible for reporting to this Board any of the following events within 48 hours of the event:

- Any serious event (including on-site and off-site adverse events, injuries, side effects, deaths, or other problems) which in the opinion of the local investigator was unanticipated, involved risk to subjects or others, and was possibly related to the research procedures;

- Any serious accidental or unintentional change to the IRB-approved protocol that involves risk or has the potential to recur;

- Any publication in the literature, safety monitoring report, interim result or other finding that indicates an unexpected change to the risk/benefit ratio of the research;

- Any breach in confidentiality or compromise in data privacy related to the subject or others; or

- Any complaint of a subject that indicates an unanticipated risk or that cannot be resolved by the research staff.

It is the responsibility of the principal investigator to provide the Board with a review and update of the research project each year the project is in effect. This approval is valid until 09/14/2010.

If you have any questions, please contact the IRB office at 472-6965.
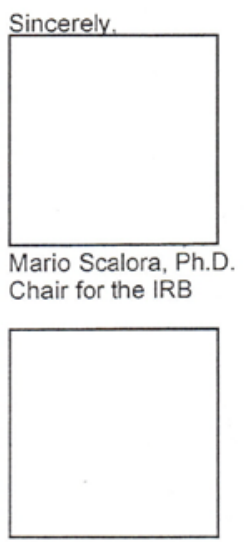


\section{Hastings College Committee for Human Subjects Research Signature Page}

1. Project title: Meaning-Making in College: How Men and Women Talk about Service, Purpose, and Meaning at a Small Private Midwestern College.

2. Name of Principal Investigator: Ron Chesbrough

3. Date: August 18, 2008

4. If student research, name of faculty supervisor: N/A
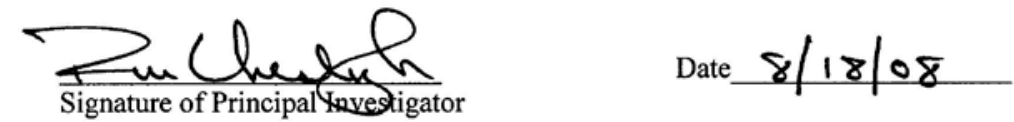

Signature of Principal knestigator

Date

$\overline{\text { Signature of Faculty Supervisor }}$

My signature above indicates that I have read and reviewed the proposal and have checked its contents with CHSR Guidelines.

\section{CHSR Response}

HC CHSR number 200814

X 1. This research project is approved as Exempt from Revigw. Date 8/25/08 CHSR Chair signature

2. This research project is forwarded for Expedited Roview and Approved

- Not approved. Revision and resubmission is required.

Date CHSR Chair signature

Expert Reviewer signature

\section{(}

3. This research project is forwarded for Full Committee Review and Approved

_ Not approved. Revision and resubmission is required.

Date CHSR member signatures 


\section{Nebrasha}

August 11, 2009

Ronald Chesbrough

Graduate Studies

James Griesen

Department of Educational Administration

125 TEAC UNL 68588-0360

IRB Number:

Project ID: 9814

Outcomes -- Part 2

Dear Ronald:

The Institutional Review Board for the Protection of Human Subjects has completed its review of the Request for Change in Protocol submitted to the IRB.

1. It has been approved to Change the title of the study to, "College Students and Service: A Mixed Methods Exploration of Motivations, Choices, and Learning Outcomes -- Part 2."

We wish to remind you that the principal investigator is responsible for reporting to this Board any of the following events within 48 hours of the event:

- Any serious event (including on-site and off-site adverse events, injuries, side effects, deaths, or other problems) which in the opinion of the local investigator was unanticipated, involved risk to subjects or others, and was possibly related to the research procedures;

- Any serious accidental or unintentional change to the IRB-approved protocol that involves risk or has the potential to recur;

- Any publication in the literature, safety monitoring report, interim result or other finding that indicates an unexpected change to the risk/benefit ratio of the research;

- Any breach in confidentiality or compromise in data privacy related to the subject or others; or

- Any complaint of a subject that indicates an unanticipated risk or that cannot be resolved by the research staff.

This letter constitutes official notification of the approval of the protocol change. You are therefore authorized to implement this change accordingly.

If you have any questions, please contact the IRB office at 472-6965.

Sincerely,

Mario Scalora, Ph.D.

Chair for the IRB 


\section{Nebraska \\ Lincoln}

August 11, 2009

Ronald Chesbrough

Graduate Studies

James Griesen

Department of Educational Administration

125 TEAC UNL 68588-0360

IRB Number: 2008099242 EX

Project ID: 9242

Project Title: College Students and Service: A Mixed Methods Exploration of Motivations, Choices, and Learning

Outcomes - Part 1

Dear Ronald:

The Institutional Review Board for the Protection of Human Subjects has completed its review of the Request for Change in Protocol submitted to the IRB.

1. It has been approved to change the title of the study to, "College Students and Service: A Mixed Methods Exploration of Motivations, Choices, and Learning Outcomes."

We wish to remind you that the principal investigator is responsible for reporting to this Board any of the following events within 48 hours of the event:

- Any serious event (including on-site and off-site adverse events, injuries, side effects, deaths, or other problems) which in the opinion of the local investigator was unanticipated, involved risk to subjects or others, and was possibly related to the research procedures;

- Any serious accidental or unintentional change to the IRB-approved protocol that involves risk or has the potential to recur;

- Any publication in the literature, safety monitoring report, interim result or other finding that indicates an unexpected change to the risk/benefit ratio of the research;

- Any breach in confidentiality or compromise in data privacy related to the subject or others; or

- Any complaint of a subject that indicates an unanticipated risk or that cannot be resolved by the research staff.

This letter constitutes official notification of the approval of the protocol change. You are therefore authorized to implement this change accordingly.

If you have any questions, please contact the IRB office at 472-6965.

Sincerely.

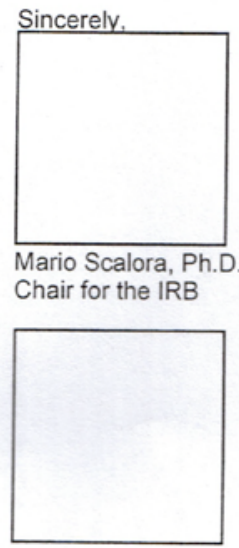




\section{Appendix C}

Interview Methodology and Scripts 


\title{
Individual Interview Methodology and Scripts
}

\begin{abstract}
Methodology
Interviews for this study were conducted with 4 male and 4 female students. Students were selected from the focus group cohorts based on their willingness and availability to participate in additional one-on-one interviews; all focus group participants were invited to participate in one-on-one interviews. Interviews were roughly one hour in duration and were conducted by the primary researcher in a neutral setting on campus. Interviews were tape recorded and transcribed verbatim following each interview. Participants were reminded at the outset of interviews of the nature and purpose of the study and of how the information they provided would be used in the study. All interview participants were afforded an opportunity to review information that they provided prior to its use in the study. Participants had been previously briefed on the study and had signed letters of informed consent encompassing their one-on-one interview participation.
\end{abstract}

\section{Script}

Interview scripts were identical in each case, with follow-up or probing questions added as appropriate.

Introduction

Thank you for agreeing to participate in individual follow-up interviews to our focus group interview. I am meeting with several students in one-on-one interviews in order to probe a little deeper into the subject of your involvement in service. Some of the questions will be similar to what I asked in the focus group interviews. We have talked about the purpose of the study that I am conducting and how the information that you provide will be used in the study. Do you have any questions before we begin?

Questions

1. First, let's talk again about how you decided to become involved in service while in college. What factors led you to become involved in service in college? Why did you decide to become involved?

2. Here's a slightly different question. How did you decide what service project or projects to become involved in? How did you choose among many opportunities to become involved?

3. Describe one project to me in depth; you can choose which project to talk about. Where were you, what did you do, how long were you involved, are there ongoing commitments from this project? 
4. What were the most challenging aspects of this experience?

5. What were the most rewarding aspects of this experience?

6. How would you describe the learning or impact of this or other service projects on you?

7. Let's talk about meaning and purpose in your life. Would you say that your service experience(s) have contributed in any way to your sense of meaning and purpose in life? If so, how? Be as specific as possible.

8. Conversely, would you say that your sense of meaning and purpose contributed in any way to your choosing to become involved in service and/or in the specific project(s) in which you have been involved?

9. Is there anything you would like to add? 


\section{Focus Group Methodology \& Scripts}

\section{Methodology}

For this study there were two single-gender focus group sessions per gender, each of 75 minute duration. Each focus group session contained 6-8 participants selected purposefully as described in the Methodology section of the study. One mixed-gender session of equal numbers men and women was held, with participants selected from those who had participated in one of the previous single-gender sessions. Participants had previously signed letters of informed consent describing all research activities of the study, the purpose of the study, and the intended use of data. Participants were afforded the opportunity to review all data and information gathered prior to its use in the study.

Focus group interviews were conducted by the primary researcher, with assistance from a research assistant (see Informed Consent and IRB approval). Video and audio taping occurred in all sessions. Results of interviews were transcribed verbatim subsequent to each session and video of each session was utilized as a secondary data gathering method with regard to non-verbal communications and actions. The primary researcher served as primary interviewer, with the assistant recording each session, observing participants, and providing some follow-up questioning in each session.

\section{Scripts}

While interviews were allowed to flow naturally to afford maximum interaction among participants on any given thread of dialogue, each began with an established script or set of questions or prompts. Single gender and mixed gender scripts were slightly different, as can be seen. All participants in each focus group were allowed to respond to all questions or threads of the dialogue.

Single gender focus group script

Introductory comments regarding the study (see above); instructions regarding open dialogue, confidentiality, voluntary participation, use of data, and consent to be audio/video taped.

Questions/Prompts:

1. Let's first talk about service in general - what the term means to you, how you define the term, whether there are various ways to 'define' service. Specifically, what comes to mind for you when I use the term "service?"

2. You have each been selected to participate in this study and this focus group interview on the basis of your prior participation in what I would describe as service during your time in college. Tell me how you decided to become 
involved in service? What motivated you to serve and how did you choose what project/issue to become involved with?

3. Have you felt that there have been either internal or external motivations to serve while in college, and what are these, if any? Similarly, have you felt there to be either internal or external inhibitors or obstacles to serve, and what are these, if any?

4. How would you describe your learning from the service experience(s) that you have been involved in? How have these experiences changed or impacted you in the short term or long-term, do you think, if at all?

5. Please talk about what you think were the most positive aspects of your involvement in service. What were the most challenging or negative aspects, if any?

6. Finally, what do you think are important considerations for people involved in creating and providing service opportunities to think about? How can your experience help peers, educators, administrators in leadership roles in service programs to understand the important elements of designing these experiences?

Mixed gender script

Same introductory comments.

1. Thank you for agreeing to participate in a second focus group interview. As you can see, this one is a bit different in that we have both men and women participating. I am interested in this session in exploring whether you think that choices about service and learning from service are the similar for men and women? To begin, do you think men and women define service similarly?

2. Do you think that men and women choose their service involvements for similar reasons, different reasons, or that there is no real basis in your experience for how men and women choose their service involvements?

3. Do you think that men and women take different types of learning from their service involvements or again, that there is no basis in your experience to know or see this as a relevant question?

4. Based on your experience(s) in service, is it sensible at all to ask about or be interested in men's experiences in service and that of women? If so, in what way does it make sense to ask about possible differences or similarities?

5. If you were able to create the perfect service opportunities for both men and women during college, what would some of the elements of those be? 


\section{Appendix D}

Survey 


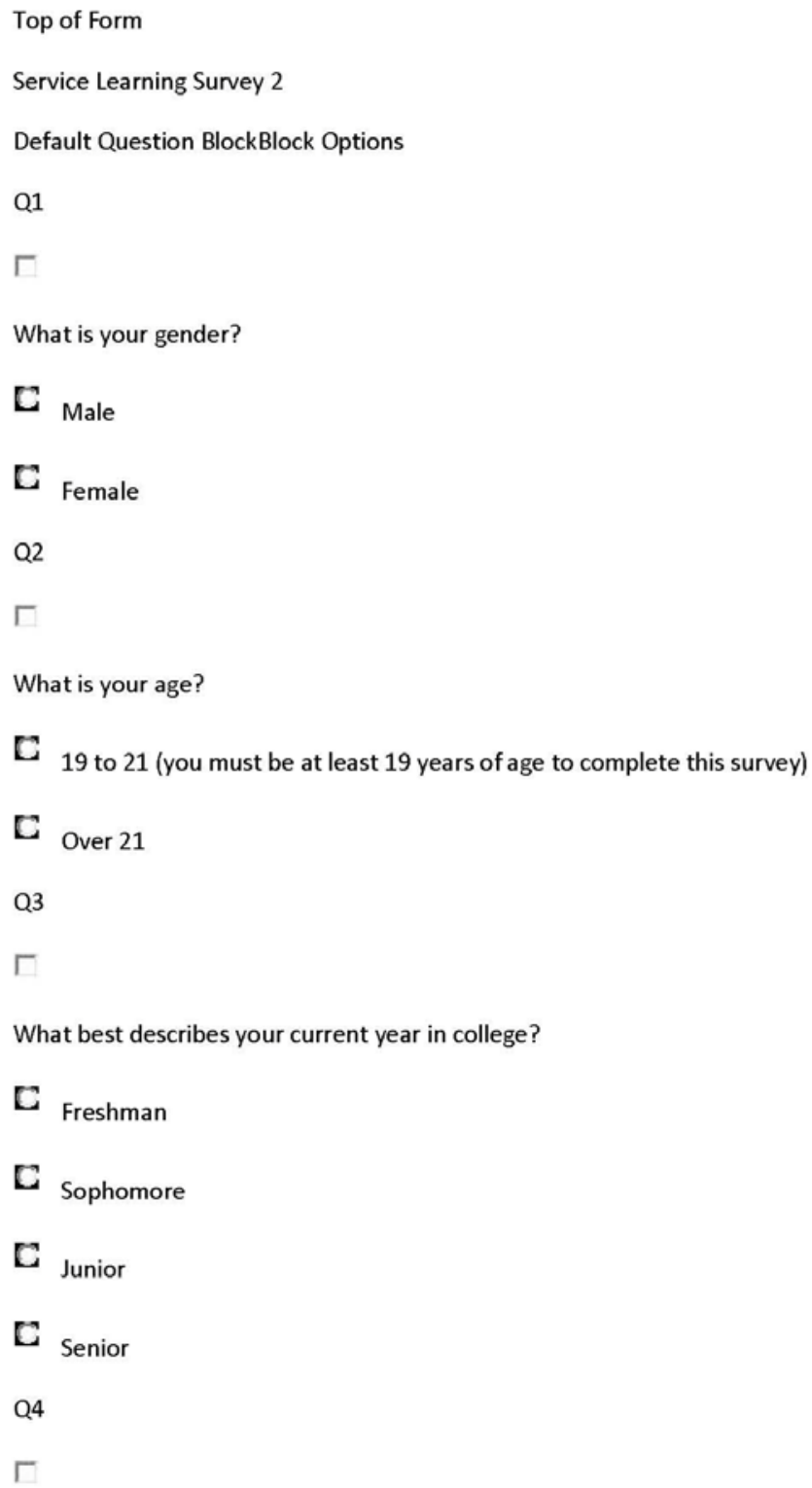




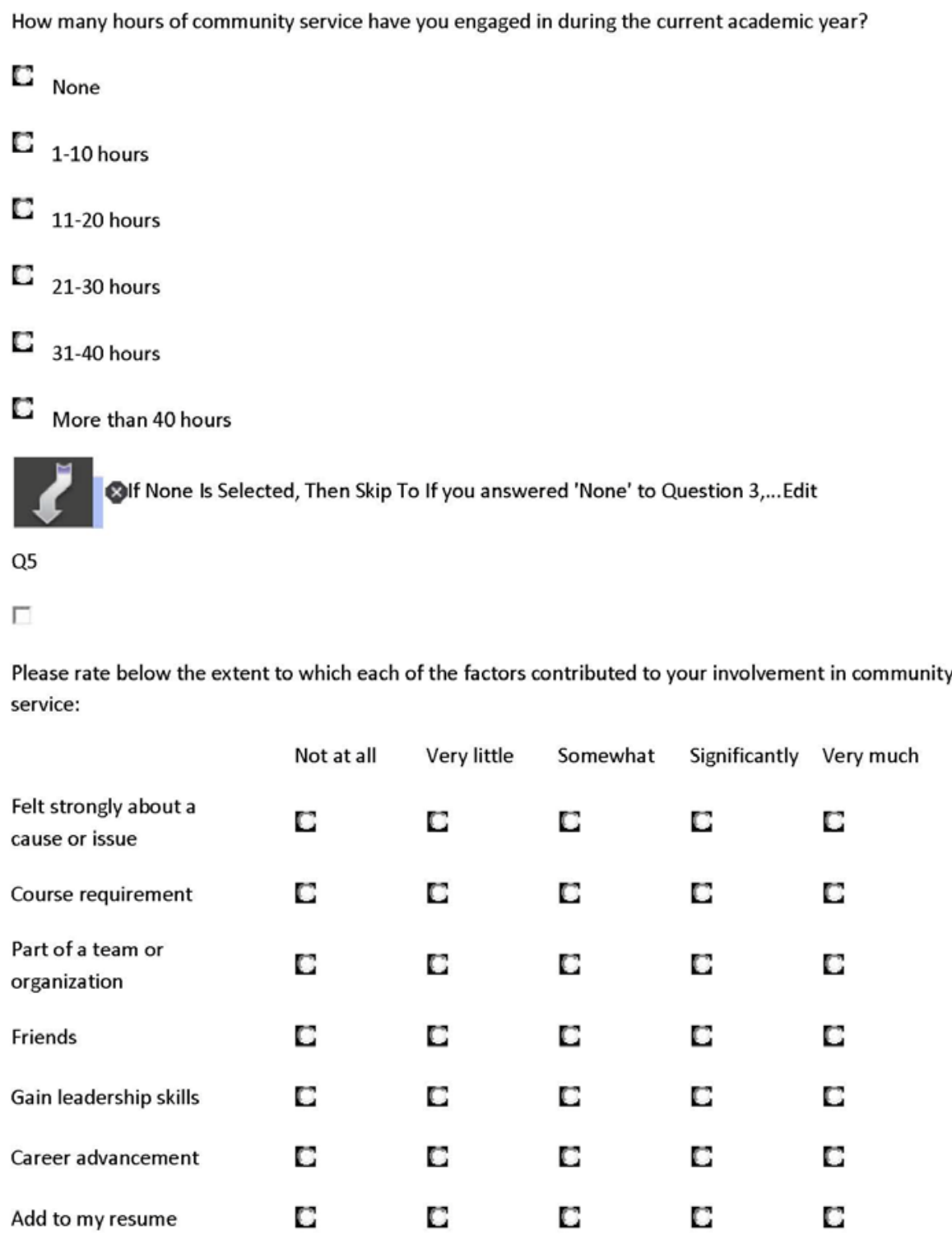




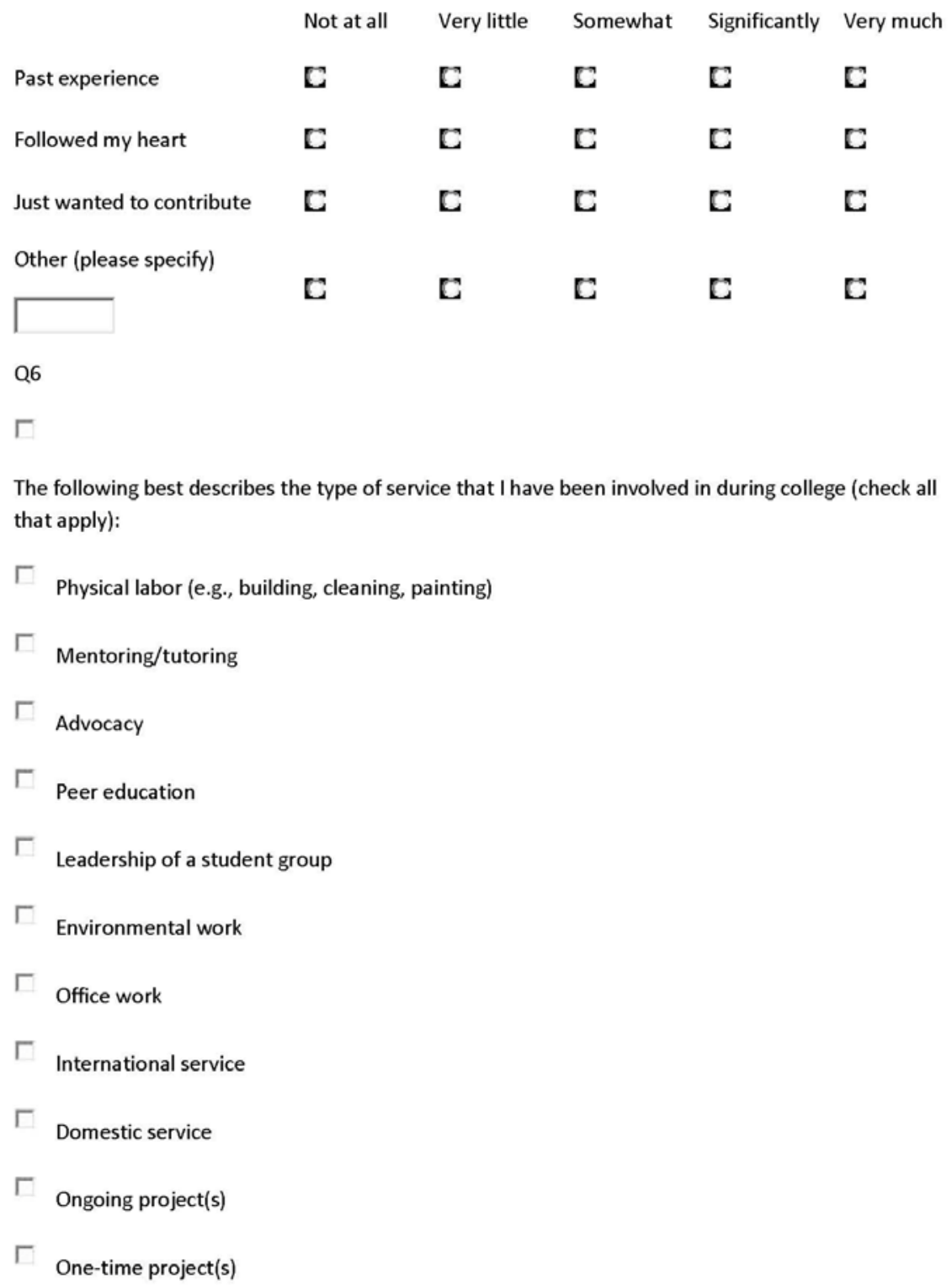




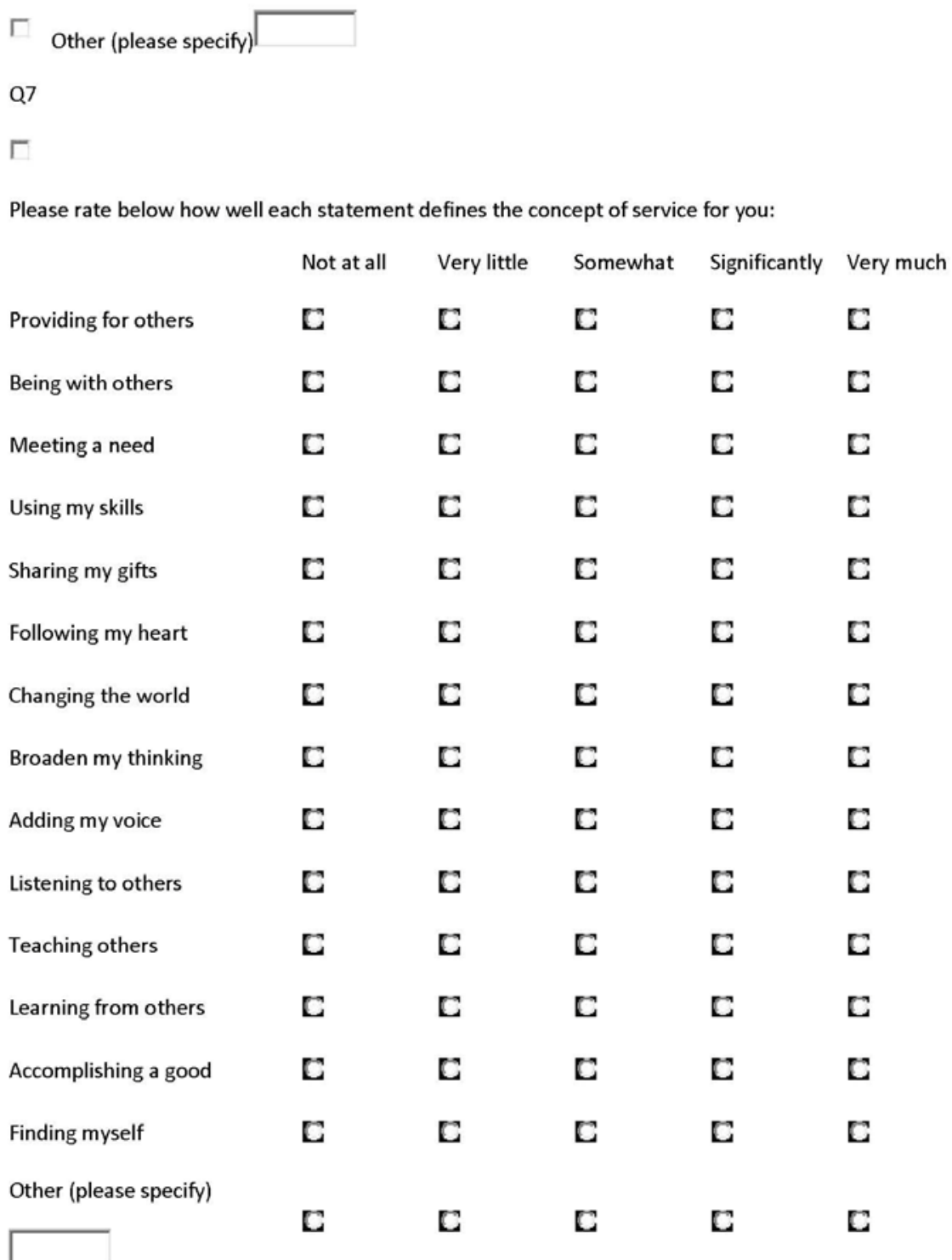




\begin{tabular}{|c|c|c|c|c|c|}
\hline \multicolumn{6}{|c|}{ Please rate below how influential each factor was in choosing the particular service project(s) that you } \\
\hline & Not at all & Very little & Somewhat & Significantly & Very much \\
\hline Right skills for the job & $\mathbf{C}$ & $\mathbf{E}$ & $\mathbf{C}$ & $\mathbf{E}$ & $\mathbf{E}$ \\
\hline Passion for the cause & $\mathbf{C}$ & $\mathbf{C}$ & $\mathbf{C}$ & $\mathbf{E}$ & $\mathbf{E}$ \\
\hline Potential for impact & $\mathbf{E}$ & $\mathbf{E}$ & $\mathbf{E}$ & $\mathbf{C}$ & $\mathbf{E}$ \\
\hline Importance of the need & $\mathbf{E}$ & $\mathbf{E}$ & $\mathbf{E}$ & $\mathbf{C}$ & $\mathbf{E}$ \\
\hline Breadth of impact & $\mathbf{E}$ & E & $\mathbf{E}$ & $\mathbf{E}$ & $\mathbf{E}$ \\
\hline Depth of involvement & $\mathbf{E}$ & $\mathbf{E}$ & $\mathbf{C}$ & $\mathbf{C}$ & $\mathbf{E}$ \\
\hline One-time project & $\mathbf{E}$ & $\mathbf{E}$ & $\mathbf{E}$ & $\mathbf{C}$ & $\mathbf{E}$ \\
\hline Ongoing commitment & $\mathbf{C}$ & $\mathbf{E}$ & $\mathbf{E}$ & $\mathbf{E}$ & $\mathbf{E}$ \\
\hline What I could offer & $\mathbf{C}$ & $\mathbf{C}$ & $\mathbf{C}$ & $\mathbf{C}$ & $\mathbf{C}$ \\
\hline What I could learn & $\mathbf{E}$ & $\mathbf{E}$ & $\mathbf{E}$ & $\mathbf{E}$ & $\mathbf{C}$ \\
\hline Physical nature of work & $\mathbf{E}$ & $\mathbf{E}$ & $\mathbf{E}$ & $\mathbf{C}$ & $\mathbf{C}$ \\
\hline Social nature of work & $\mathbf{C}$ & $\mathbf{C}$ & $\mathbf{E}$ & $\mathbf{C}$ & $\mathbf{C}$ \\
\hline Time available & $\mathbf{E}$ & $\mathbf{E}$ & $\mathbf{C}$ & $\mathbf{C}$ & $\mathbf{E}$ \\
\hline Career related & $\mathbf{E}$ & $\mathbf{E}$ & $\mathbf{E}$ & $\mathbf{E}$ & $\mathbf{E}$ \\
\hline Personal interest & $\mathbf{C}$ & $\mathbf{C}$ & $\mathbf{C}$ & $\mathbf{E}$ & $\mathbf{E}$ \\
\hline Other (please specify) & & & & & \\
\hline & $\mathbf{E}$ & $\mathbf{E}$ & $\mathbf{E}$ & $\mathbf{E}$ & $\mathbf{E}$ \\
\hline
\end{tabular}


Please rate below how well each phrase describes your learning from service:

\begin{tabular}{|c|c|c|c|c|c|}
\hline & Not at all & Very little & Somewhat & Significantly & Very much \\
\hline Learned about others & $\mathbf{C}$ & $\mathbf{C}$ & $\mathrm{C}$ & $\mathrm{C}$ & C \\
\hline Learned about myself & $\mathbf{C}$ & $\mathbf{C}$ & $\mathbf{C}$ & $\mathbf{C}$ & C \\
\hline Learned about leadership & $\mathbf{C}$ & $\mathbf{C}$ & $\mathbf{C}$ & $\mathrm{C}$ & $\mathrm{C}$ \\
\hline $\begin{array}{l}\text { Learned about } \\
\text { relationships }\end{array}$ & $\mathbf{C}$ & $\mathbf{C}$ & $\mathbf{C}$ & $\mathbf{C}$ & $\mathbf{E}$ \\
\hline $\begin{array}{l}\text { Learned about } \\
\text { organizations }\end{array}$ & $\mathbf{C}$ & $\mathbf{C}$ & $\mathbf{C}$ & C & $\mathbf{C}$ \\
\hline Learned about people & $\mathbf{C}$ & $\mathbf{C}$ & $\mathbf{C}$ & $\mathrm{C}$ & $\mathrm{C}$ \\
\hline Learned about justice & $\mathbf{C}$ & $\mathbf{C}$ & $\mathbf{C}$ & $\mathbf{C}$ & $\mathbf{E}$ \\
\hline Learned about caring & $\mathbf{C}$ & $\mathbf{C}$ & $\mathbf{C}$ & $\mathrm{C}$ & $\mathrm{C}$ \\
\hline $\begin{array}{l}\text { Learned about social } \\
\text { issues }\end{array}$ & $\mathbf{C}$ & C & $\mathbf{C}$ & $\mathbf{C}$ & C \\
\hline $\begin{array}{l}\text { Learned about } \\
\text { community }\end{array}$ & $\mathbf{C}$ & $\mathbf{C}$ & $\mathbf{C}$ & $\mathbf{C}$ & C \\
\hline Learned about duty & $\mathbf{C}$ & $\mathbf{C}$ & $\mathbf{C}$ & $\mathrm{C}$ & C \\
\hline Learned about love & $\mathbf{C}$ & $\mathbf{C}$ & $\mathbf{C}$ & $\mathbf{C}$ & $\mathrm{C}$ \\
\hline Other (please specify) & & & & & \\
\hline$\square$ & C & C & E & $\mathrm{E}$ & $\mathbf{E}$ \\
\hline \multicolumn{6}{|l|}{ Q10 } \\
\hline \multicolumn{6}{|l|}{$\Gamma$} \\
\hline \multicolumn{6}{|c|}{$\begin{array}{l}\text { In each pairing below, check the circle closest to the word or phrase that best describes how you think } \\
\text { about your service choices and experiences (e.g., think about how you would complete this sentence - } \\
\text { "When I think about service, I tend to think of it as a(n)___tivity."). }\end{array}$} \\
\hline Emotional & & & Rational/A & alytical & \\
\hline
\end{tabular}


C

Subjective

C

Justice-oriented

C

Personal

E

Global/societal duty

E

Individual

E

Q11

г

Please indicate below the extent to which each of these personal skills or characteristics was impacted positively by your service experience(s).

$\begin{array}{llllll}\begin{array}{l}\text { Sense of competence } \\ \begin{array}{l}\text { Ability to manage } \\ \text { emotions }\end{array}\end{array} & \text { Not at all } & \text { Very little } & \text { Somewhat } & \text { Significanlty } & \text { Very much } \\ \begin{array}{l}\text { Sense of autonomy in } \\ \text { decision-making }\end{array} & \text { C } & \text { C } & \text { C } & \text { C } & \text { C } \\ \begin{array}{l}\text { Ability to develop and } \\ \text { maintain relationships }\end{array} & \text { C } & \text { C } & \text { C } & \text { C } & \text { C } \\ \begin{array}{l}\text { Sense of my own identiy } \\ \text { Sense of meaning or }\end{array} & \text { C } & \text { C } & \text { C } & \text { C } & \text { C } \\ \end{array}$

$\mathbf{E}$

c

Caring-oriented

C

Impersonal

C

Peronal commitment

E

Relational

$\mathbf{E}$ 


purpose
Sense of my place in the
world
Sense of duty
Ability to nurture
Commitment to social
justice
Q12
In your experience, how likely are men and women to become involved in service during their college
years?
C Men are more likely than women to become involved.
C Women are more likely than men to become involved.
C Men and women are equally likely to become involved.

\&If Men and women are equally I... Is Selected, Then Skip To End of SurveyEdit

Q13

$\Gamma$

Based on your response above please check all of the factors below that you feel contribute to lower involvement for that of men or women:

$\Gamma$ Not enough time.

$\Gamma$ Service isn't cool.

$\Gamma$ Service is for women. 
Service is for men.

Not aware of service opportunities.

$\Gamma$ Social stigma of being a 'do-gooder.'

$\Gamma \quad$ No one asks.

$\Gamma$ Just not interested.

$\ulcorner$ Other (please specify):

Q14

$\Gamma$

If you answered 'None' to Question 3, please indicate below the factors that have contributed to your non-involvement in service during college (all others skip this question).

$\Gamma$ Not enough time.

$\Gamma$ Service isn't cool

$\Gamma$ Service is for women.

$\ulcorner$ Service is for men.

$\Gamma$ Not aware of service opportunities.

$\Gamma$ Social stigma of being a 'do-gooder.'

$\Gamma$ Someone else will take care of it.

$\Gamma$ No one asks.

$\Gamma$ Just not interested

$\ulcorner$ Other (please specify): 
Appendix E

External Audit 


\title{
External Audit Attestation
}

\author{
Dr. James Wiest \\ Director, Social Research Center \\ Hastings College
}

Ron Chesbrough requested that I complete an external audit of his dissertation study entitled "College Students and Service: A Mixed Methods Exploration of Motivations, Choices, and Learning Outcomes." The purpose of the audit was to determine the degree to which the study was conducted as described and the reported results are trustworthy. The audit was conducted in October 2009.

As outlined by Lincoln and Guba (1985), this audit examined both the process and the product of the research. Process review ensured that participants views were fairly represented in recorded accounts; product review ensured the accuracy of the findings of the study based on recorded data.

I completed the following steps during the audit:

1. Reviewed and compared recordings and transcriptions of participant focus group and individual interviews.

Findings: Transcription errors were negligible and confined to grammatical errors. No errors altered or affected the meaning of the data. Transcription was found to be substantively accurate and void of impactful errors.

2. Reviewed folders containing the following information:

- Dissertation Proposal

- Dissertation Draft

- Informed Consent and Invitation to Participate Letters

- IRB Approvals

- Interview Scripts and Methodology

- Interview Transcripts

- Response Coding Summary

- Member Check Notes

Findings: All folders contained the required information.

3. Reviewed signed Informed Consent/Participation forms for all interview participants.

Findings: All required forms were signed.

4. Reviewed coding summary and transcripts.

Findings: Transcribed data supported coded themes.

5. Read dissertation draft manuscript and appendices.

Findings: This was a mixed methods study. All qualitative and quantitative methodologies were designed and conducted properly. Reporting, analysis, and discussion of findings followed proper methodological protocols. Findings were supported by the data. 
Based on my review of the above items, the following conclusions were drawn:

The focus of the study was consistent with purpose as outlined in the study proposal and in IRB approval documents at both the research sponsor and host sites. Procedures for data collection and analysis and all verification strategies were adhered to. The following verification strategies were employed for the qualitative portion of the study: member checks, peer review, triangulation, and external audit. The survey instrument was tested for content validity by an external consultant. Findings of the study were supported by the data.

In summary, the research satisfies the criteria for dependability of findings and soundness of methodology.

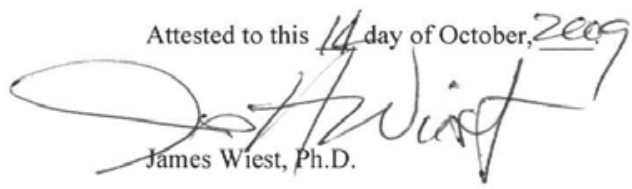


Appendix F

Response Coding Summary 


\section{Coding Summary for Single Gender Focus Groups}

The first number in parentheses represents the number of individual sources where a particular code was found. The second number represents the total number of references for the particular code.

\section{Coding Summary}

1. Let's first talk about service in general - what the term means to you, how you define the term, whether there are various ways to 'define' service. Specifically, what comes to mind for you when I use the term "service?"

- Contribute to others
- Change the world
- Meet a need
- Provide for others
- Accomplish a good

- Share skills/knowledge

$\begin{array}{ll}- \text { Share gifts } & (4,5) \\ \circ & (5,5) \\ \circ & \text { Teach others } \\ \circ \text { Provide for others } & (6,6) \\ \circ & (8,9)\end{array}$

- Improve self

$\begin{array}{ll}\circ \text { Follow one's heart } \\ \circ \text { Learn from others } \\ \circ \text { Listen to others } \\ \circ \text { Find one's self } & (3,3) \\ \circ & (4,5) \\ & (7,8)\end{array}$

2. You have each been selected to participate in this study and this focus group interview on the basis of your prior participation in what $I$ would describe as service during your time in college. Tell me how you decided to become involved in service. What motivated you to serve and how did you choose what project/issue to become involved with?

Motivation to serve

- Requirement
- Class requirement
- Team requirement
- Part of a student organization

- Develop skills/career

$\begin{array}{ll}\circ & \text { Gain leadership skills } \\ \circ & \text { Add to resume } \\ \circ & \text { Explore a career field }\end{array}$

- Intrinsic
- Gain a sense of meaning
- Desire to contribute
- Fulfill a responsibility 
- Extrinsic

$\begin{array}{lll}\circ & \text { Social justice or inequality } \\ \circ & (8,8) \\ \circ & (7,8) \\ \circ & \text { Friends' involvement } & (6,6) \\ \circ \text { Past experience } & (9,9)\end{array}$

Choice of service

- Match of skills

- Right skills for the job

- What I could offer

- Career related

- Type of project

$\begin{array}{ll}\circ & (4,4) \\ \circ & \text { Physical nature of work } \\ \circ \text { One-time project } & (3,3) \\ \circ \text { Ongoing commitment } & (8,8) \\ \circ & (6,7)\end{array}$

- Subjective interest

- Passion for the cause $\quad(9,9)$

- Importance of the need

- What I could learn $\quad(4,4)$

- Personal interest $\quad(10,10)$

- Friends were involved $\quad(3,4)$

- Outcomes driven

- Potential for impact $\quad(4,4)$

- Breadth of impact

3. Have you felt that there have been either internal or external motivations to serve while in college, and what are these, if any? Similarly, have you felt there to be either internal or external inhibitors or obstacles to serve, and what are these, if any?

Internal/External Motivations - coded in Question 2

Obstacles to service

- Internal
- Lack of time
$(3,3)$

- Apathy

- External/structural

- Lack of awareness of opportunities

- Not being invited to participate

4. How would you describe your learning from the service experience(s) that you have been involved in? How have these experiences changed or impacted you in the short term or long term, do you think, if at all? 
Learning from service

- Interpersonal learning

- Learned about others

- Learned about myself $\quad(9,9)$

- Learned about relationships

- Organizational learning

- Learned about leadership

- Learned about organizations

- Learned about community $\quad(8,9)$

- Social justice learning

- Learned about justice

- Learned about social issues

- Learned about duty $\quad(4,4)$

- Emotional learning

- Learned about caring $\quad(7,8)$

- Learned about love $\quad(6,7)$

Responses to questions 5 and 6 of the single gender focus groups were not coded or utilized in the generation of dimensions, properties, or categories. Responses to these questions were utilized in general discussion regarding participants' observations for involvement of peers in service. 


\section{Appendix G}

\section{Chi-square/Spearman Scores}


Chi-Square Summary by Gender

\begin{tabular}{|c|c|c|c|}
\hline Question & Chi-Square & Degrees of Freedom & Sig. level/Correction \\
\hline 5.1 Felt strongly & 16.471 & 3 & .001 \\
\hline 5.9 Followed my heart & 18.472 & 3 & .000 \\
\hline 5.10 Contribute & 9.736 & 3 & .021 \\
\hline 6.1 Physical labor & 7.848 & 1 & $.005 / .007$ \\
\hline 6.3 Advocacy & 6.233 & 1 & $.013 / .019$ \\
\hline 6.5 Leadership & 6.495 & 1 & $.011 / .015$ \\
\hline 6.9 Domestic service & 4.938 & 1 & $.026 / .041$ \\
\hline 6.10 Ongoing project & 13.058 & 1 & $.000 / .000$ \\
\hline 6.11 One-time project & 6.346 & 1 & $.012 / .016$ \\
\hline 6.12 Other & 5.029 & 1 & $.025 / .043$ \\
\hline 7.1 Provide for others & 27.303 & 3 & .000 \\
\hline $7.2 \mathrm{Be}$ with others & 8.932 & 3 & .030 \\
\hline 7.3 Meet a need & 14.950 & 3 & .002 \\
\hline 7.6 Followed my heart & 13.426 & 3 & .004 \\
\hline 7.7 Change the world & 32.048 & 3 & .000 \\
\hline 7.8 Broaden thinking & 14.552 & 3 & .002 \\
\hline 7.10 Adding my voice & 29.948 & 3 & .000 \\
\hline 7.12 Learn from others & 18.481 & 3 & .001 \\
\hline 7.13 Accomplish good & 17.410 & 3 & .001 \\
\hline 8.2 Passion for cause & 13.409 & 3 & .004 \\
\hline 8.7 One-time project & 10.615 & 3 & .014 \\
\hline 8.14 Career related & 7.931 & 3 & .047 \\
\hline 8.15 Personal interest & 11.174 & 3 & .011 \\
\hline 9.8 Caring & 13.750 & 3 & .003 \\
\hline 9.9 Social issues & 9.913 & 3 & .019 \\
\hline 9.10 Community & 9.328 & 3 & .025 \\
\hline 9.12 Love & 8.628 & 3 & .035 \\
\hline 10.1 Emot./Rat. & 20.442 & 1 & $.000 / .000$ \\
\hline 10.2 Subject./Object. & 4.823 & 1 & $.028 / .039$ \\
\hline 10.4 Pers./Impers. & 9.270 & 1 & $.002 / .004$ \\
\hline 10.5 Global/Personal & 6.413 & 1 & $.011 / .016$ \\
\hline 10.6 Indiv./Relat. & 6.378 & 1 & $.012 / .017$ \\
\hline 11.4 Relationships & 12.400 & 3 & .006 \\
\hline 11.7 Place in world & 12.596 & 3 & .006 \\
\hline 11.9 Nurture & 10.447 & 3 & .015 \\
\hline
\end{tabular}


Spearman Summary by Hours of Service

\begin{tabular}{|c|c|c|c|}
\hline Question & Spearman & Standard Error & Significance Level \\
\hline 5.1 Felt strongly & .462 & .041 & .000 \\
\hline 5.4 Friends & -.125 & .051 & .016 \\
\hline 5.5 Leadership skills & .241 & .050 & .000 \\
\hline 5.8 Past experience & .136 & .051 & .009 \\
\hline 5.9 Followed my heart & .270 & .048 & .000 \\
\hline 5.10 Contribute & .300 & .048 & .000 \\
\hline 5.11 Other & .289 & .048 & .000 \\
\hline 6.2 Mentoring/tutoring & .251 & .052 & .000 \\
\hline 6.3 Advocacy & .247 & .054 & .000 \\
\hline 6.4 Using my skills & .225 & .053 & .000 \\
\hline 6.5 Leadership & .253 & .051 & .000 \\
\hline 6.10 Ongoing project & .148 & .053 & .005 \\
\hline 7.1 Provide for others & 209 & .051 & .000 \\
\hline 7.2 Being with others & .138 & .054 & .010 \\
\hline 7.3 Meet a need & .246 & .050 & .000 \\
\hline 7.4 Use my skills & .218 & .051 & .000 \\
\hline 7.5 Share gifts & .207 & .053 & .000 \\
\hline 7.6 Follow my heart & .244 & .051 & .000 \\
\hline 7.7 Change the world & .149 & .054 & .005 \\
\hline 7.8 Broaden thinking & .179 & .051 & .001 \\
\hline 7.9 Add my voice & .126 & .053 & .018 \\
\hline 7.10 Listen to others & .250 & .050 & .000 \\
\hline 7.11 Teaching others & .234 & .052 & .000 \\
\hline 7.12 Learn from others & .299 & .048 & .000 \\
\hline 7.13 Accomplish a good & .228 & .052 & .000 \\
\hline 7.14 Find myself & .208 & .051 & .000 \\
\hline 8.1 Right skills for job & .133 & .053 & .018 \\
\hline 8.2 Passion for cause & .265 & .053 & .000 \\
\hline 8.3 Potential for impact & 191 & .054 & .001 \\
\hline 8.4 Importance of need & 262 & .053 & .000 \\
\hline 8.5 Breadth of impact & 153 & .055 & .006 \\
\hline 8.6 Depth of Involv. & .157 & .057 & .005 \\
\hline 8.7 One-time project & -.219 & .054 & .000 \\
\hline 8.8 Ongoing commit. & .175 & .057 & .002 \\
\hline 8.9 What I could offer & .185 & .056 & .001 \\
\hline 8.10 What I could learn & .267 & .054 & .000 \\
\hline 8.15 Personal interest & .241 & .053 & .000 \\
\hline 9.1 Others & .258 & .052 & .000 \\
\hline 9.2 Myself & .366 & .048 & .000 \\
\hline 9.3 Leadership & .325 & .050 & .000 \\
\hline 9.4 Relationships & .303 & .052 & .000 \\
\hline 9.5 Organizations & .322 & .052 & .000 \\
\hline 9.6 People & 296 & .051 & .000 \\
\hline
\end{tabular}




\begin{tabular}{|c|c|c|c|}
\hline 9.7 Justice & .338 & .052 & .000 \\
\hline 9.8 Caring & .231 & .053 & .000 \\
\hline 9.9 Social issues & .319 & .051 & .000 \\
\hline 9.10 Community & .238 & .054 & .000 \\
\hline 9.11 Duty & .263 & .053 & .000 \\
\hline 9.12 Love & .256 & .053 & .000 \\
\hline 11.1 Competence & .205 & .056 & .000 \\
\hline 11.2 Manage emotions & .257 & .055 & .000 \\
\hline 11.3 Autonomy & .252 & .054 & .000 \\
\hline 11.4 Relationships & .230 & .054 & .000 \\
\hline 11.5 Identity & .329 & .052 & .000 \\
\hline 11.6 Meaning & .314 & .052 & .000 \\
\hline 11.7 Place in world & .211 & .056 & .000 \\
\hline 11.8 Sense of duty & .165 & .057 & .004 \\
\hline 11.9 Nurture & .162 & .056 & .003 \\
\hline 11.10 Social Justice & .251 & .055 & .000 \\
\hline
\end{tabular}


Spearman Summary by Year in School

\begin{tabular}{lccc}
\hline Question & Spearman & Standard Error & Significance Level \\
\hline 5.1 Felt strongly & .187 & .050 & .000 \\
\hline 5.2 Course requirement & -.188 & .048 & .000 \\
\hline 5.3 Team or organiz. & -.131 & .050 & .012 \\
\hline 5.4 Friends & -.131 & .051 & .012 \\
\hline 5.7 Add to my resume & -.138 & .052 & .008 \\
6.2 Mentoring & .254 & .051 & .000 \\
6.3 Advocacy & .164 & .045 & .002 \\
6.5 Leadership & .299 & .050 & .000 \\
6.10 Ongoing project & .183 & .052 & .001 \\
7.2 Being with others & -.131 & .054 & .015 \\
7.11 Teaching others & .111 & .054 & .039 \\
7.15 Other & -.312 & .131 & .026 \\
8.2 Passion for cause & .124 & .056 & .027 \\
8.4 Importance of need & .111 & .057 & .049 \\
8.7 One-time project & .183 & .052 & .001 \\
\hline 9.2 Myself & .146 & .057 & .010 \\
\hline 9.3 Leadership & .172 & .056 & .004 \\
9.4 Relationships & .124 & .056 & .029 \\
9.5 Organizations & .213 & .054 & .000 \\
9.10 Community & .111 & .055 & .050 \\
\hline 11.6 Meaning & .195 & .058 & .001 \\
\hline
\end{tabular}




\section{Appendix H}

Raw Data Summary 


\section{What is your gender?}

\begin{tabular}{|c|l|l|c|c|}
\hline$\#$ & Answer & Response & $\%$ \\
\hline 1 & Male & 202 & $45 \%$ \\
2 & Female & 245 & $55 \%$ \\
\hline & Total & 447 & $100 \%$ \\
\hline
\end{tabular}

\begin{tabular}{|l|r|}
\hline Statistic & Value \\
\hline Mean & 1.55 \\
Variance & 0.25 \\
Standard Deviation & 0.50 \\
Total Responses & 447 \\
\hline
\end{tabular}

\section{What is your age?}

\begin{tabular}{|c|c|c|c|}
\hline$\#$ & Answer & Response & $\%$ \\
\hline 1 & $\begin{array}{l}19 \text { to } 21 \text { (you must be at least } 19 \text { years } \\
\text { of age to complete this survey) }\end{array}$ & 330 & $74 \%$ \\
\hline \multirow[t]{2}{*}{2} & Over 21 & 114 & $26 \%$ \\
\hline & Total & 444 & $100 \%$ \\
\hline
\end{tabular}

\begin{tabular}{|l|r|}
\hline Statistic & Value \\
\hline Mean & 1.26 \\
Variance & 0.19 \\
Standard Deviation & 0.44 \\
Total Responses & 444 \\
\hline
\end{tabular}

\section{What best describes your current year in college?}

\begin{tabular}{|c|l|l|c|c|}
\hline$\#$ & Answer & Response & $\%$ \\
\hline 1 & Freshman & & 127 & $29 \%$ \\
2 & Sophomore & 103 & $23 \%$ \\
\cline { 3 - 5 } 3 & Junior & & 95 & $21 \%$ \\
4 & Senior & 120 & $27 \%$ \\
\hline & Total & 445 & $100 \%$ \\
\hline
\end{tabular}




\begin{tabular}{|l|r|}
\hline Statistic & Value \\
\hline Mean & 2.47 \\
Variance & 1.36 \\
Standard Deviation & 1.17 \\
Total Responses & 445 \\
\hline
\end{tabular}

4. How many hours of community service have you engaged in during the current academic year?

\begin{tabular}{|c|l|l|c|c|}
\hline$\#$ & Answer & Response & $\%$ \\
\hline 1 & None & 52 & $12 \%$ \\
2 & 1 -10 hours & & 203 & $46 \%$ \\
3 & $11-20$ hours & 73 & $16 \%$ \\
4 & $21-30$ hours & & 48 & $11 \%$ \\
5 & $31-40$ hours & 20 & $4 \%$ \\
6 & More than 40 hours & & 50 & $11 \%$ \\
\hline & Total & & 446 & $100 \%$ \\
\hline
\end{tabular}

\begin{tabular}{|l|r|}
\hline Statistic & Value \\
\hline Mean & 2.85 \\
Variance & 2.20 \\
Standard Deviation & 1.48 \\
Total Responses & 446 \\
\hline
\end{tabular}

5. Please rate below the extent to which each of the factors contributed to your involvement in community service:

\begin{tabular}{|c|l|c|c|c|c|c|c|c|}
\hline \# & Question & $\begin{array}{c}\text { Not } \\
\text { at all }\end{array}$ & $\begin{array}{l}\text { Very } \\
\text { little }\end{array}$ & Somewhat & Significantly & $\begin{array}{c}\text { Very } \\
\text { much }\end{array}$ & Responses & Mean \\
\hline 1 & $\begin{array}{l}\text { Felt strongly about a } \\
\text { cause or issue }\end{array}$ & 17 & 24 & 120 & 125 & 82 & 368 & 3.63 \\
\hline 3 & $\begin{array}{l}\text { Course requirement } \\
\text { Part of a team or } \\
\text { organization }\end{array}$ & 80 & 52 & 84 & 97 & 57 & 370 & 3.00 \\
\hline
\end{tabular}




\begin{tabular}{|c|c|c|c|c|c|c|c|c|}
\hline 4 & Friends & 48 & 61 & 122 & 93 & 45 & 369 & 3.07 \\
\hline 5 & Gain leadership skills & 29 & 49 & 115 & 137 & 38 & 368 & 3.29 \\
\hline 6 & Career advancement & 45 & 86 & 100 & 86 & 48 & 365 & 3.02 \\
\hline 7 & Add to my resume & 44 & 74 & 99 & 91 & 58 & 366 & 3.12 \\
\hline 8 & Past experience & 33 & 53 & 135 & 100 & 46 & 367 & 3.20 \\
\hline 9 & Followed my heart & 27 & 54 & 106 & 110 & 70 & 367 & 3.39 \\
\hline 10 & $\begin{array}{l}\text { Just wanted to } \\
\text { contribute }\end{array}$ & 19 & 36 & 111 & 130 & 68 & 364 & 3.53 \\
\hline 11 & Other (please specify) & 39 & 2 & 12 & 7 & 6 & 66 & 2.08 \\
\hline
\end{tabular}

Other (please specify)
Fit well with my major
Enjoy working with kids
to aid a group with little participation
Enjoyment
church
Dorm requirement
wanted to give back as others have done for me
dorm activity

\begin{tabular}{|c|c|c|c|c|c|c|c|c|c|}
\hline Statistic & $\begin{array}{c}\text { Felt } \\
\text { strongly } \\
\text { about a } \\
\text { cause } \\
\text { or issue }\end{array}$ & $\begin{array}{l}\text { Course } \\
\text { requirement }\end{array}$ & $\begin{array}{c}\text { Part of a } \\
\text { team or } \\
\text { organization }\end{array}$ & Friends & $\begin{array}{l}\text { Gain } \\
\text { leadership } \\
\text { skills }\end{array}$ & $\begin{array}{c}\text { Career } \\
\text { advancement }\end{array}$ & $\begin{array}{l}\text { Add to } \\
\text { my } \\
\text { resume }\end{array}$ & $\begin{array}{c}\text { Past } \\
\text { experience }\end{array}$ & $\begin{array}{l}\text { Foll } \\
\text { my }\end{array}$ \\
\hline Mean & 3.63 & 3.00 & 3.56 & 3.07 & 3.29 & 3.02 & 3.12 & 3.20 & 3 \\
\hline Variance & 1.09 & 1.89 & 1.43 & 1.42 & 1.15 & 1.49 & 1.55 & 1.24 & 1 \\
\hline $\begin{array}{l}\text { Standard } \\
\text { Deviation }\end{array}$ & 1.04 & 1.37 & 1.20 & 1.19 & 1.07 & 1.22 & 1.25 & 1.11 & 1 \\
\hline $\begin{array}{l}\text { Total } \\
\text { Responses }\end{array}$ & 368 & 370 & 369 & 369 & 368 & 365 & 366 & 367 & 3 \\
\hline
\end{tabular}

\section{The following best describes the type of service that I have been involved in during college (check all that apply):}




\begin{tabular}{|c|c|c|c|c|}
\hline 1 & $\begin{array}{l}\text { Physical labor (e.g., building, cleaning, } \\
\text { painting) }\end{array}$ & 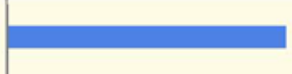 & 225 & $64 \%$ \\
\hline 2 & Mentoring/tutoring & $\square$ & 155 & $44 \%$ \\
\hline 3 & Advocacy & 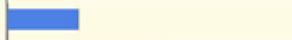 & 58 & $16 \%$ \\
\hline 4 & Peer education & & 120 & $34 \%$ \\
\hline 5 & Leadership of a student group & & 158 & $45 \%$ \\
\hline 6 & Environmental work & 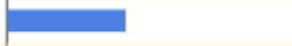 & 95 & $27 \%$ \\
\hline 7 & Office work & a & 58 & $16 \%$ \\
\hline 8 & International service & 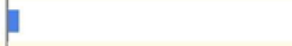 & 9 & $3 \%$ \\
\hline 9 & Domestic service & 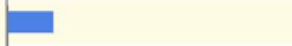 & 37 & $10 \%$ \\
\hline 10 & Ongoing project(s) & 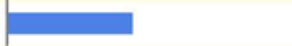 & 100 & $28 \%$ \\
\hline 11 & One-time project(s) & & 125 & $35 \%$ \\
\hline 12 & Other (please specify) & Q & 23 & $7 \%$ \\
\hline
\end{tabular}

\begin{tabular}{|l|}
\hline Other (please specify) \\
\hline volunteer at a funeral dinner \\
volunteer at a funeral dinner \\
Practicums \\
Full time employee of outside work. \\
Elder companionship \\
special olympics \\
Help at Church youth group \\
Girl Scouts \\
hospital pediatric patients \\
observed classes and helped teach kids \\
Hastings Literacy Program \\
Companionship for Elderly \\
nursing home service \\
Music \\
performing music \\
teaching english to a refugee family \\
Track \& Field \\
fundraising for causes \\
Adult ESL Education \\
Volunteering in coffee shop \\
Singing to the elderly \\
\hline
\end{tabular}


Volunteering at retirement community
Special Olympics

\begin{tabular}{|l|l|}
\hline Statistic & Value \\
\hline
\end{tabular}

\begin{tabular}{l|l} 
Total Responses $\quad 353$ \\
\hline
\end{tabular}

7. Please rate below how well each statement defines the concept of service for you:

\begin{tabular}{|c|c|c|c|c|c|c|c|c|}
\hline \# & Question & $\begin{array}{c}\text { Not at } \\
\text { all }\end{array}$ & $\begin{array}{l}\text { Very } \\
\text { little }\end{array}$ & Somewhat & Significantly & $\begin{array}{l}\text { Very } \\
\text { much }\end{array}$ & Responses & Mean \\
\hline 1 & $\begin{array}{l}\text { Providing for } \\
\text { others }\end{array}$ & 2 & 14 & 65 & 148 & 123 & 352 & 4.07 \\
\hline 2 & Being with others & 7 & 38 & 92 & 136 & 77 & 350 & 3.68 \\
\hline 3 & Meeting a need & 4 & 11 & 71 & 153 & 113 & 352 & 4.02 \\
\hline 4 & Using my skills & 4 & 26 & 107 & 126 & 88 & 351 & 3.76 \\
\hline 5 & Sharing my gifts & 6 & 21 & 98 & 130 & 95 & 350 & 3.82 \\
\hline 6 & $\begin{array}{l}\text { Following my } \\
\text { heart }\end{array}$ & 14 & 31 & 105 & 121 & 81 & 352 & 3.64 \\
\hline 7 & $\begin{array}{l}\text { Changing the } \\
\text { world }\end{array}$ & 19 & 51 & 107 & 106 & 68 & 351 & 3.44 \\
\hline 8 & $\begin{array}{l}\text { Broaden my } \\
\text { thinking }\end{array}$ & 9 & 37 & 118 & 118 & 69 & 351 & 3.57 \\
\hline 9 & Adding my voice & 17 & 61 & 126 & 99 & 48 & 351 & 3.28 \\
\hline 10 & Listening to others & 10 & 28 & 102 & 137 & 74 & 351 & 3.68 \\
\hline 11 & Teaching others & 4 & 23 & 84 & 146 & 93 & 350 & 3.86 \\
\hline 12 & $\begin{array}{l}\text { Learning from } \\
\text { others }\end{array}$ & 4 & 21 & 81 & 135 & 111 & 352 & 3.93 \\
\hline 13 & $\begin{array}{l}\text { Accomplishing a } \\
\text { good }\end{array}$ & 3 & 13 & 64 & 155 & 114 & 349 & 4.04 \\
\hline 14 & Finding myself & 27 & 60 & 120 & 85 & 60 & 352 & 3.26 \\
\hline 15 & $\begin{array}{l}\text { Other (please } \\
\text { specify) }\end{array}$ & 27 & 2 & 12 & 4 & 6 & 51 & 2.22 \\
\hline
\end{tabular}

Other (please specify)

Serving Christ 


\begin{tabular}{|l|c|c|c|c|c|c|c|c|c|c|}
\hline Statistic & $\begin{array}{c}\text { Providing } \\
\text { for } \\
\text { others }\end{array}$ & $\begin{array}{c}\text { Being } \\
\text { with } \\
\text { others }\end{array}$ & $\begin{array}{c}\text { Meeting } \\
\text { a need }\end{array}$ & $\begin{array}{c}\text { Using } \\
\text { my } \\
\text { skills }\end{array}$ & $\begin{array}{c}\text { Sharing } \\
\text { my } \\
\text { gifts }\end{array}$ & $\begin{array}{c}\text { Following } \\
\text { my heart }\end{array}$ & $\begin{array}{c}\text { Changing } \\
\text { the } \\
\text { world }\end{array}$ & $\begin{array}{c}\text { Broaden } \\
\text { my } \\
\text { thinking }\end{array}$ & $\begin{array}{c}\text { Adding } \\
\text { my } \\
\text { voice }\end{array}$ & $\begin{array}{c}\text { Listening } \\
\text { to } \\
\text { others }\end{array}$ \\
\hline Mean & 4.07 & 3.68 & 4.02 & 3.76 & 3.82 & 3.64 & 3.44 & 3.57 & 3.28 & 3.68 \\
Variance & 0.74 & 1.00 & 0.75 & 0.90 & 0.92 & 1.11 & 1.25 & 1.01 & 1.12 & 0.97 \\
$\begin{array}{l}\text { Standard } \\
\text { Deviation }\end{array}$ & 0.86 & 1.00 & 0.87 & 0.95 & 0.96 & 1.05 & 1.12 & 1.00 & 1.06 & 0.99 \\
$\begin{array}{l}\text { Total } \\
\text { Responses }\end{array}$ & 352 & 350 & 352 & 351 & 350 & 352 & 351 & 351 & 351 & 351 \\
\hline
\end{tabular}

8. Please rate below how influential each factor was in choosing the particular service project(s) that you have been involved in:

\begin{tabular}{|c|c|c|c|c|c|c|c|c|}
\hline \# & Question & $\begin{array}{l}\text { Not at } \\
\text { all }\end{array}$ & $\begin{array}{l}\text { Very } \\
\text { little }\end{array}$ & Somewhat & Significantly & $\begin{array}{l}\text { Very } \\
\text { much }\end{array}$ & Responses & Mean \\
\hline 1 & $\begin{array}{l}\text { Right skills for the } \\
\text { job }\end{array}$ & 18 & 37 & 129 & 82 & 51 & 317 & 3.35 \\
\hline 2 & $\begin{array}{l}\text { Passion for the } \\
\text { cause }\end{array}$ & 9 & 15 & 94 & 112 & 88 & 318 & 3.80 \\
\hline 3 & $\begin{array}{l}\text { Potential for } \\
\text { impact }\end{array}$ & 7 & 21 & 99 & 120 & 71 & 318 & 3.71 \\
\hline 4 & $\begin{array}{l}\text { Importance of the } \\
\text { need }\end{array}$ & 5 & 9 & 85 & 135 & 81 & 315 & 3.88 \\
\hline 5 & Breadth of impact & 7 & 44 & 137 & 94 & 33 & 315 & 3.32 \\
\hline 6 & $\begin{array}{l}\text { Depth of } \\
\text { involvement }\end{array}$ & 14 & 37 & 127 & 104 & 34 & 316 & 3.34 \\
\hline 7 & One-time project & 45 & 55 & 111 & 82 & 22 & 315 & 2.94 \\
\hline 8 & $\begin{array}{l}\text { Ongoing } \\
\text { commitment }\end{array}$ & 23 & 56 & 112 & 77 & 46 & 314 & 3.21 \\
\hline 9 & What I could offer & 7 & 23 & 106 & 119 & 60 & 315 & 3.64 \\
\hline 10 & What I could learn & 8 & 21 & 107 & 113 & 66 & 315 & 3.66 \\
\hline 11 & $\begin{array}{l}\text { Physical nature of } \\
\text { work }\end{array}$ & 41 & 44 & 123 & 74 & 34 & 316 & 3.05 \\
\hline 12 & $\begin{array}{l}\text { Social nature of } \\
\text { work }\end{array}$ & 15 & 30 & 113 & 108 & 47 & 313 & 3.45 \\
\hline 13 & Time available & 16 & 21 & 108 & 108 & 61 & 314 & 3.56 \\
\hline 14 & Career related & 34 & 59 & 90 & 86 & 46 & 315 & 3.16 \\
\hline 15 & Personal interest & 12 & 15 & 87 & 121 & 79 & 314 & 3.76 \\
\hline 16 & $\begin{array}{l}\text { Other (please } \\
\text { specify) }\end{array}$ & 22 & 1 & 11 & 9 & 5 & 48 & 2.46 \\
\hline
\end{tabular}


Other (please specify)

Availibility of food

\begin{tabular}{|c|c|c|c|c|c|c|c|c|c|c|}
\hline Statistic & $\begin{array}{l}\text { Right } \\
\text { skills } \\
\text { for } \\
\text { the } \\
\text { job }\end{array}$ & $\begin{array}{l}\text { Passion } \\
\text { for the } \\
\text { cause }\end{array}$ & $\begin{array}{c}\text { Potential } \\
\text { for } \\
\text { impact }\end{array}$ & $\begin{array}{l}\text { Importance } \\
\text { of the need }\end{array}$ & $\begin{array}{l}\text { Breadth } \\
\text { of } \\
\text { impact }\end{array}$ & $\begin{array}{l}\text { Depth of } \\
\text { involvement }\end{array}$ & $\begin{array}{l}\text { One- } \\
\text { time } \\
\text { project }\end{array}$ & $\begin{array}{c}\text { Ongoing } \\
\text { commitment }\end{array}$ & $\begin{array}{l}\text { What } \\
\text { I } \\
\text { could } \\
\text { offer }\end{array}$ & $\begin{array}{c}\text { Wha } \\
\text { I } \\
\text { could } \\
\text { learr }\end{array}$ \\
\hline Mean & 3.35 & 3.80 & 3.71 & 3.88 & 3.32 & 3.34 & 2.94 & 3.21 & 3.64 & 3.66 \\
\hline Variance & 1.13 & 0.98 & 0.92 & 0.77 & 0.84 & 0.94 & 1.29 & 1.26 & 0.89 & 0.93 \\
\hline $\begin{array}{l}\text { Standard } \\
\text { Deviation }\end{array}$ & 1.06 & 0.99 & 0.96 & 0.88 & 0.92 & 0.97 & 1.13 & 1.12 & 0.95 & 0.97 \\
\hline $\begin{array}{l}\text { Total } \\
\text { Responses }\end{array}$ & 317 & 318 & 318 & 315 & 315 & 316 & 315 & 314 & 315 & 315 \\
\hline
\end{tabular}

\section{Please rate below how well each phrase describes your learning}

\section{from service:}

\begin{tabular}{|c|c|c|c|c|c|c|c|c|}
\hline$\#$ & Question & $\begin{array}{l}\text { Not at } \\
\text { all }\end{array}$ & $\begin{array}{l}\text { Very } \\
\text { little }\end{array}$ & Somewhat & Significantly & $\begin{array}{l}\text { Very } \\
\text { much }\end{array}$ & Responses & Mean \\
\hline 1 & $\begin{array}{l}\text { Learned about } \\
\text { others }\end{array}$ & 5 & 14 & 81 & 126 & 88 & 314 & 3.89 \\
\hline 2 & $\begin{array}{l}\text { Learned about } \\
\text { myself }\end{array}$ & 10 & 26 & 90 & 105 & 83 & 314 & 3.72 \\
\hline 3 & $\begin{array}{l}\text { Learned about } \\
\text { leadership }\end{array}$ & 9 & 20 & 74 & 130 & 81 & 314 & 3.81 \\
\hline 4 & $\begin{array}{l}\text { Learned about } \\
\text { relationships }\end{array}$ & 9 & 24 & 86 & 119 & 76 & 314 & 3.73 \\
\hline 5 & $\begin{array}{l}\text { Learned about } \\
\text { organizations }\end{array}$ & 6 & 22 & 102 & 103 & 79 & 312 & 3.73 \\
\hline 6 & $\begin{array}{l}\text { Learned about } \\
\text { people }\end{array}$ & 5 & 5 & 74 & 138 & 92 & 314 & 3.98 \\
\hline 7 & $\begin{array}{l}\text { Learned about } \\
\text { justice }\end{array}$ & 24 & 61 & 103 & 74 & 52 & 314 & 3.22 \\
\hline 8 & $\begin{array}{l}\text { Learned about } \\
\text { caring }\end{array}$ & 6 & 17 & 80 & 122 & 89 & 314 & 3.86 \\
\hline 9 & Learned about social & 12 & 21 & 89 & 112 & 80 & 314 & 3.72 \\
\hline
\end{tabular}




\begin{tabular}{|c|c|c|c|c|c|c|c|c|}
\hline & issues & & & & & & & \\
\hline 10 & $\begin{array}{l}\text { Learned about } \\
\text { community }\end{array}$ & 9 & 18 & 84 & 114 & 89 & 314 & 3.82 \\
\hline 11 & Learned about duty & 14 & 34 & 109 & 102 & 54 & 313 & 3.47 \\
\hline 12 & Learned about love & 31 & 42 & 90 & 80 & 71 & 314 & 3.38 \\
\hline 13 & $\begin{array}{l}\text { Other (please } \\
\text { specify) }\end{array}$ & 22 & 1 & 9 & 8 & 6 & 46 & 2.46 \\
\hline
\end{tabular}

Other (please specify)

how $\mathrm{i}$ was raised

\begin{tabular}{|l|c|c|c|c|c|c|c|c|c|}
\hline Statistic & $\begin{array}{c}\text { Learned } \\
\text { about } \\
\text { others }\end{array}$ & $\begin{array}{c}\text { Learned } \\
\text { about } \\
\text { myself }\end{array}$ & $\begin{array}{c}\text { Learned } \\
\text { about } \\
\text { leadership }\end{array}$ & $\begin{array}{c}\text { Learned } \\
\text { about } \\
\text { relationships }\end{array}$ & $\begin{array}{c}\text { Learned } \\
\text { about } \\
\text { organizations }\end{array}$ & $\begin{array}{c}\text { Learned } \\
\text { about } \\
\text { people }\end{array}$ & $\begin{array}{c}\text { Learned } \\
\text { about } \\
\text { justice }\end{array}$ & $\begin{array}{c}\text { Learned } \\
\text { about } \\
\text { caring }\end{array}$ & $\begin{array}{c}\text { Learned } \\
\text { about } \\
\text { social } \\
\text { issues }\end{array}$ \\
\hline Mean & 3.89 & 3.72 & 3.81 & 3.73 & 3.73 & 3.98 & 3.22 & 3.86 & 3.72 \\
Variance & 0.85 & 1.09 & 0.97 & 1.01 & 0.96 & 0.74 & 1.35 & 0.91 & 1.08 \\
$\begin{array}{l}\text { Standard } \\
\text { Deviation }\end{array}$ & 0.92 & 1.04 & 0.99 & 1.00 & 0.98 & 0.86 & 1.16 & 0.95 & 1.04 \\
$\begin{array}{l}\text { Total } \\
\text { Responses }\end{array}$ & 314 & 314 & 314 & 314 & 312 & 314 & 314 & 314 & 314 \\
\hline
\end{tabular}

10. In each pairing below, check the circle closest to the word or phrase that best describes how you think about your service choices and experiences (e.g., think about how you would complete this sentence - "When I think about service, I tend to think of it as a(n) activity.").

\begin{tabular}{|l|l|c|c|c|c|}
\hline \# & Question & 1 & 2 & Responses & Mean \\
\hline 1 & Emotional:Rational/Analytical & 140 & 123 & 263 & 1.47 \\
2 & Subjective:Objective & 115 & 144 & 259 & 1.56 \\
3 & Justice-oriented:Caring-oriented & 52 & 222 & 274 & 1.81 \\
4 & Personal:Impersonal & 212 & 55 & 267 & 1.21 \\
5 & Global/societal duty:Peronal commitment & 91 & 180 & 271 & 1.66 \\
6 & Individual :Relational & 62 & 196 & 258 & 1.76 \\
\hline
\end{tabular}




\begin{tabular}{|c|c|c|c|c|c|}
\hline Statistic & Emotional:Rational/Analytical & Subjective:Objective & $\begin{array}{c}\text { Justice- } \\
\text { oriented:Caring- } \\
\text { oriented }\end{array}$ & Personal:Impersonal & $\begin{array}{l}\text { Global/so } \\
\text { duty:Perd } \\
\text { commitm }\end{array}$ \\
\hline Mean & 1.47 & 1.56 & 1.81 & 1.21 & 1.66 \\
\hline Variance & 0.25 & 0.25 & 0.15 & 0.16 & 0.22 \\
\hline $\begin{array}{l}\text { Standard } \\
\text { Deviation }\end{array}$ & 0.50 & 0.50 & 0.39 & 0.41 & 0.47 \\
\hline $\begin{array}{l}\text { Total } \\
\text { Responses }\end{array}$ & 263 & 259 & 274 & 267 & 271 \\
\hline
\end{tabular}

11. Please indicate below the extent to which each of these personal skills or characteristics was impacted positively by your service experience(s).

\begin{tabular}{|c|c|c|c|c|c|c|c|c|}
\hline$\#$ & Question & $\begin{array}{l}\text { Not } \\
\text { at all }\end{array}$ & $\begin{array}{l}\text { Very } \\
\text { little }\end{array}$ & Somewhat & Significanlty & $\begin{array}{l}\text { Very } \\
\text { much }\end{array}$ & Responses & Mean \\
\hline 1 & Sense of competence & 10 & 28 & 111 & 99 & 54 & 302 & 3.53 \\
\hline 2 & $\begin{array}{l}\text { Ability to manage } \\
\text { emotions }\end{array}$ & 18 & 38 & 126 & 80 & 40 & 302 & 3.28 \\
\hline 3 & $\begin{array}{l}\text { Sense of autonomy in } \\
\text { decision-making }\end{array}$ & 10 & 31 & 121 & 87 & 53 & 302 & 3.47 \\
\hline 4 & $\begin{array}{l}\text { Ability to develop and } \\
\text { maintain relationships }\end{array}$ & 11 & 29 & 108 & 93 & 61 & 302 & 3.54 \\
\hline 5 & $\begin{array}{l}\text { Sense of my own } \\
\text { identiy }\end{array}$ & 19 & 39 & 98 & 96 & 50 & 302 & 3.39 \\
\hline 6 & $\begin{array}{l}\text { Sense of meaning or } \\
\text { purpose }\end{array}$ & 10 & 25 & 93 & 107 & 67 & 302 & 3.65 \\
\hline 7 & $\begin{array}{l}\text { Sense of my place in } \\
\text { the world }\end{array}$ & 17 & 40 & 110 & 81 & 53 & 301 & 3.38 \\
\hline 8 & Sense of duty & 13 & 30 & 110 & 92 & 55 & 300 & 3.49 \\
\hline 9 & Ability to nurture & 12 & 39 & 108 & 93 & 48 & 300 & 3.42 \\
\hline 10 & $\begin{array}{l}\text { Commitment to social } \\
\text { justice }\end{array}$ & 33 & 48 & 108 & 62 & 47 & 298 & 3.14 \\
\hline
\end{tabular}

\begin{tabular}{|c|c|c|c|c|c|c|c|c|c|c|}
\hline Statistic & $\begin{array}{l}\text { Sense of } \\
\text { competence }\end{array}$ & $\begin{array}{l}\text { Ability to } \\
\text { manage } \\
\text { emotions }\end{array}$ & $\begin{array}{l}\text { Sense of } \\
\text { autonomy } \\
\text { in } \\
\text { decision- } \\
\text { making }\end{array}$ & $\begin{array}{l}\text { Ability to } \\
\text { develop and } \\
\text { maintain } \\
\text { relationships }\end{array}$ & $\begin{array}{c}\text { Sense } \\
\text { of my } \\
\text { own } \\
\text { identiy }\end{array}$ & $\begin{array}{l}\text { Sense of } \\
\text { meaning } \\
\text { or } \\
\text { purpose }\end{array}$ & $\begin{array}{l}\text { Sense } \\
\text { of my } \\
\text { place } \\
\text { in the } \\
\text { world }\end{array}$ & $\begin{array}{c}\text { Sense } \\
\text { of } \\
\text { duty }\end{array}$ & $\begin{array}{l}\text { Ability } \\
\text { to } \\
\text { nurture }\end{array}$ & $\begin{array}{r}\text { Com } \\
\text { to } \\
\text { jo }\end{array}$ \\
\hline
\end{tabular}




\begin{tabular}{|l|c|c|c|c|c|c|c|c|c|c|}
\hline Mean & 3.53 & 3.28 & 3.47 & 3.54 & 3.39 & 3.65 & 3.38 & 3.49 & 3.42 & 1.08 \\
Variance & 0.99 & 1.08 & 1.01 & 1.07 & 1.21 & 1.04 & 1.20 & 1.07 & 1.08 \\
$\begin{array}{l}\text { Standard } \\
\text { Deviation }\end{array}$ & 1.00 & 1.04 & 1.00 & 1.03 & 1.10 & 1.02 & 1.09 & 1.04 & 1.03 \\
$\begin{array}{l}\text { Total } \\
\text { Responses }\end{array}$ & 302 & 302 & 302 & 302 & 302 & 302 & 301 & 300 & 300 \\
\hline
\end{tabular}

12. In your experience, how likely are men and women to become involved in service during their college years?

\begin{tabular}{|c|c|c|c|}
\hline$\#$ & Answer & Response & $\%$ \\
\hline 1 & $\begin{array}{l}\text { Men are more likely than women to } \\
\text { become involved. }\end{array}$ & 2 & $1 \%$ \\
\hline 2 & $\begin{array}{l}\text { Women are more likely than men to } \\
\text { become involved. }\end{array}$ & 146 & $48 \%$ \\
\hline 3 & $\begin{array}{l}\text { Men and women are equally likely to } \\
\text { become involved. }\end{array}$ & 155 & $51 \%$ \\
\hline & Total & 303 & $100 \%$ \\
\hline
\end{tabular}

\begin{tabular}{|l|r|}
\hline Statistic & Value \\
\hline Mean & 2.50 \\
Variance & 0.26 \\
Standard Deviation & 0.51 \\
Total Responses & 303 \\
\hline
\end{tabular}

\section{Based on your response above please check all of the factors} below that you feel contribute to lower involvement for that of men or women:

\begin{tabular}{|c|l|c|c|c|}
\hline$\#$ & Answer & Response & $\%$ \\
\hline 1 & Not enough time. & 73 & $50 \%$ \\
2 & Service isn't cool. & 73 & $50 \%$ \\
3 & Service is for women. & 45 & $31 \%$ \\
9 & Service is for men. & 3 & $2 \%$ \\
4 & Not aware of service opportunities. & 83 & $57 \%$ \\
\hline
\end{tabular}




\begin{tabular}{|l|l|l|c|c|}
\hline 5 & Social stigma of being a 'do-gooder.' & 52 & $36 \%$ \\
6 & No one asks. & 64 & $44 \%$ \\
7 & Just not interested. & 108 & $74 \%$ \\
8 & Other (please specify): & & 5 & $3 \%$ \\
\hline
\end{tabular}

Other (please specify):
Think it is boring probably
not a priority
lazy
In the case of my service-learning program, the project was for young girls and therefore, only women
helped out with my project. Therefore, it is likely that more men are involved in service-learning than I
realize, I simply don't see it.
Don't have strong enough feeling for either side so they don't take a stand either way.

\begin{tabular}{|l|l|}
\hline Statistic & Value \\
\hline
\end{tabular}

\begin{tabular}{|l|r|}
\hline Total Responses & 146 \\
\hline
\end{tabular}

\section{If you answered 'None' to Question 3, please indicate below the factors that have contributed to your non-involvement in service during college (all others skip this question).}

\begin{tabular}{|c|l|c|c|c|}
\hline$\#$ & Answer & Response & $\%$ \\
\hline 1 & Not enough time. & 52 & $75 \%$ \\
2 & Service isn't cool & 3 & $4 \%$ \\
3 & Service is for women. & 3 & $4 \%$ \\
4 & Service is for men. & 4 & $6 \%$ \\
5 & Not aware of service opportunities. & 30 & $43 \%$ \\
6 & Social stigma of being a 'do-gooder.' & 2 & $3 \%$ \\
7 & Someone else will take care of it. & 8 & $12 \%$ \\
8 & No one asks. & 23 & $33 \%$ \\
9 & Just not interested. & 14 & $20 \%$ \\
10 & Other (please specify): & 4 & $6 \%$ \\
\hline
\end{tabular}


dont wanna put in time for no money

dont wanna put in time for no money

Jesus Christ I'm going to school to get a degree what more do you want from me!?

school, sports

\begin{tabular}{l|l} 
Statistic & Value \\
\hline
\end{tabular}

Total Responses 